\title{
A Review on the Electrodeposition of Aluminum and Aluminum Alloys in Ionic Liquids
}

\author{
Kranthi Kumar Maniam ${ }^{1}$ (D) and Shiladitya Paul ${ }^{1,2, *(\mathbb{D})}$ \\ 1 Materials Innovation Centre, School of Engineering, University of Leicester, Leicester LE1 7RH, UK; \\ km508@leicester.ac.uk \\ 2 Materials and Structural and Integrity Technology Group, TWI, Cambridge CB21 6AL, UK \\ * Correspondence: shiladitya.paul@twi.co.uk
}

Citation: Maniam, K.K.; Paul, S. A Review on the Electrodeposition of Aluminum and Aluminum Alloys in Ionic Liquids. Coatings 2021, 11, 80. https://doi.org/10.3390/coatings 11010080

Received: 7 December 2020 Accepted: 4 January 2021

Published: 12 January 2021

Publisher's Note: MDPI stays neutral with regard to jurisdictional clai$\mathrm{ms}$ in published maps and institutional affiliations.

Copyright: $(\odot 2021$ by the authors. Licensee MDPI, Basel, Switzerland. This article is an open access article distributed under the terms and conditions of the Creative Commons Attribution (CC BY) license (https:// creativecommons.org/licenses/by/ $4.0 /$ )

\begin{abstract}
Aluminum plays an essential role as an excellent coating material in diversified applications due to its better corrosion resistance and physicochemical properties. Employing such a material as a coating on different metallic substrates such as carbon steel would benefit many industries such as the automotive, aviation, shipbuilding, construction, electronics etc. Amongst the various available coating techniques, electrodeposition of aluminum ( $\mathrm{Al}) \mathrm{Al}$ alloys have gained significant attention in the last 10 years as a metallic protection coating for various commercial substrates and has become the industry's choice owing to being lightweight, corrosion-resistant, and cost-effective. This paper shall provide a detailed review covering electrochemical deposition of $\mathrm{Al}$ and $\mathrm{Al}$ alloys using ionic liquids with various cations, anions, and additives, and reports on progress in development thus far. It shall also cover the challenges in the electrodepositing aluminum, its alloys on light weight metal substrates viz., magnesium (Mg), commercial substrates such as low carbon steel, spring steel, and their pretreatments. The factors that play an important role in electroplating on an industrial scale, along with future challenges, are discussed.
\end{abstract}

Keywords: aluminum; electrodeposition; ionic liquids; aerospace; corrosion; electroplating

\section{Introduction}

Aluminum (Al) and Aluminum alloys are excellent materials with good potential capability for various applications because of their excellent thermal properties, electric conductivity, light weight, and corrosion resistance [1]. Amongst them, $\mathrm{Al}, \mathrm{Al}$ alloys are regarded as the preferred choice of coating material, as they tend to develop a natural passive oxide layer on their surface during their contact with air, which makes them corrosion-resistant in different environments [2,3]. Globally renowned companies such as Applied Materials, Raytheon employ electroplated aluminum to protect components in corrosive environments [4]. Electroplating of $\mathrm{Al}$ offers certain advantages such as high purity deposits ( $\geq 99.99 \% \mathrm{Al})$, higher deposition rate compared to other vacuum deposition methods (ion vapor, chemical vapor, physical vapor), and allows for deposition of thick layers (up to $1000 \mu \mathrm{m}$ ) [5]. Also, electrodeposition is a 'non-line-of-sight' process and provides excellent coverage for small or complex geometries. Electroplating of $\mathrm{Al}$ finds application in aerospace, electrorefining etc. In addition, $\mathrm{Al}$ deposits provide very high reflectivity of light and heat and show promising potential in the renewable energy sector such as solar energy (e.g., solar panels) [6]. The versatility of electrodeposition lies in controlling the grain size and structure of the deposits with simple variation of the process parameters such as voltage, current density, and bath composition, which makes the electrodeposition method versatile relative to other coating methods where the substrate can be kept at a low temperature such as thermal spray coatings, physical, chemical vapor deposition, and roll binding [7]. Table 1 lists the application areas of $\mathrm{Al}$ coatings along with the real-time test parts, which are considered to be of strategic importance for modern society. 
Table 1. Table showing the industrial applications of aluminum coatings.

\begin{tabular}{|c|c|}
\hline Application Segment & Parts \\
\hline Aerospace & $\begin{array}{c}\text { Landing gears, wheel fuse plugs, eye bolts, grounding straps, fuel } \\
\text { mesh screens, flap actuator systems, engine drive coupling, radar } \\
\text { array components, electronic components, targeting mirrors, } \\
\text { structural high strength steel plates, structural welded steel } \\
\text { assemblies }\end{array}$ \\
\hline Electrical & connectors \\
\hline Electronics & circuit boards, micro electro mechanical systems \\
\hline Automotive & $\begin{array}{l}\text { Fasteners, nuts, bolts, spring steel, high tensile strength steel bolts, } \\
\text { car body parts, and rail road vehicles }\end{array}$ \\
\hline Industrial Fittings & forged fittings, brazed fittings, bars, tube fittings \\
\hline Solar & Display panels, photovoltaics \\
\hline Others & $\begin{array}{l}\text { Mirrors, medical/dental devices, semiconductors, microsystem } \\
\text { applications } \\
\text { (wafer-level bonding sealing frame, thermal actuators) }\end{array}$ \\
\hline
\end{tabular}

Since $\mathrm{Al}$ has high negative reduction potential ( $-1.67 \mathrm{~V}$ vs. SHE), it cannot be electrodeposited from aqueous electrolyte media due to the occurrence of hydrogen evolution reaction prior to the $\mathrm{Al}$ metal or $\mathrm{Al}$ alloy reduction [8]. Therefore, electrodeposition of $\mathrm{Al}$, $\mathrm{Al}$ alloys needs to be performed in non-aqueous electrolytes. Most of the electrodeposition studies on Al performed so far utilized three types of non-aqueous baths: (i) inorganic molten salts, (ii) organic solvents, and (iii) ionic liquids (ILs). Considering the first two kinds, although $\mathrm{Al}$ can be electrodeposited, the processes pose certain complications. For instance, $\mathrm{Al}$ deposition from inorganic molten salts requires very high temperatures, high energy consumption, and volatilization of corrosive compounds such as $\mathrm{AlCl}_{3}$ gas [9-11]. Similarly, the utilization of organic solvents for the deposition of $\mathrm{Al}$ is poorly suited for practical applications owing to the highly volatile nature, flammability, and toxicity of the employed organic media. These factors hinder the commercialization of the corresponding electroplating processes. Hence, deposition of $\mathrm{Al}, \mathrm{Al}$ alloys from ILs is considered to be a potential alternative, as ILs feature certain advantages such as low melting points, excellent chemical and thermal stabilities, high intrinsic electrical conductivity, and low vapor pressure $[12,13]$. The non-flammable and less volatile nature of ionic liquids at room temperature demonstrate their superiority as safe and promising alternative electrolytes for the deposition of $\mathrm{Al}$ to non-aqueous aprotic solvents and high-temperature molten salts [14]. The number of SCI papers published on the deposition of $\mathrm{Al}$ and $\mathrm{Al}$ alloys in ILs has increased significantly in the last 10 years, indicating that much of the research work is being focused on studying this interesting field, with the deliverables being plentiful. This has attracted certain major industry segments such as automotive, aerospace, and electronics to develop significant interest in this technology [15]. The formation of an adherent aluminum oxide film on steel surface during its exposure to air makes aluminum as a promising candidate for corrosion mitigation of steel and a potential alternative to replacement of cadmium coatings [16]. Also, ILs have increasingly attracted interest because they play a promising role in electrochemical applications, catalysis, separation, carbonization, and so on. ILs are formed from an organic cation and discrete anion (inorganic /organic) and are generally asymmetric in nature. One of the benefits with ILs is their flexibility to tailor/tune the chemical, physical properties, which can be achieved via different cation-anion arrangements. Deposition of $\mathrm{Al}$ and its alloys is also performed in deep eutectic solvents (DESs), which are considered as a class of ILs that exhibit the same physical properties but different chemical properties. DESs are low melting point eutectic mixtures that are prepared by simple mixing of salts, hydrogen bond donors (amides, carboxylic acids), usually composed of a combination of one or more anionic, cationic species, whereas ILs consist majorly of one type of discrete ions (cation, anion) [17]. By employing 
DESs as an electrolyte media, electrodepositing $\mathrm{Al}$ and $\mathrm{Al}$ alloys (generally binary) with varying compositions that follow normal deposition behavior can be achieved, allowing either primary metal or alloying metal rich in overall composition, which is dependent on the primary $\mathrm{Al}$ metal ion, binary metal ion (alloying metal ion) concentration and the deposition potential that is to be applied [18-20]. The highly asymmetric nature of ILs makes the stacking of the large size cations and relatively small size anions difficult, thereby controlling IL's crystallization and reducing its melting point. By utilizing the IL's ability to tune the redox potentials of the metals during metal alloy deposition via metal speciation, it is possible to perform co-deposition of metals that has significantly larger redox potential difference and are difficult to deposit in aqueous systems [21]. With ILs, it is also possible to avoid the hydrogen embrittlement of ferrous steel substrates and the hydrogen evolution reaction, which are commonly observed during deposition in aqueous electrolytes. The combination of these features, along with their high ionic conductivity and good metal solubility, makes them exceptional over other non-aqueous media for depositing metals and alloys by electrodeposition [22]. Developing a cost effective, novel ionic liquid-based technology for the $\mathrm{Al}$ and $\mathrm{Al}$ alloy electrodeposition on different commercial substrates would promote the practical application in automotive, aerospace, and so on. Employing ILs for the $\mathrm{Al}$ and $\mathrm{Al}$ alloy deposition is expected to enhance the corrosion protection against the marine and other corrosive environments such as oil and gas, materials, and agricultural industries $[23,24]$.

There are a significant number of published reviews that discussed on the metal, metal alloy electrodeposition in non-aqueous electrolyte media viz., ionic liquids, including the $\mathrm{Al}$, $\mathrm{Al}$ alloys electrodeposition [21,22,25-28]. Since then, there were significant developments in the studies related to Al deposition in ionic liquids. For instance, Al deposition from second-generation ILs with different alkyl cation chain lengths, which are air, waterstable, on different substrates and their pretreatments was not reviewed. New additives that were introduced for the deposition of Al were also not covered. Kujime et al. [29] reviewed the progress on $\mathrm{Al}$ deposition covering the aprotic solvents, ILs, and DESs. However, these do not cover the latest developments associated with the Al and Al alloys' deposition in ionic liquids especially the additive, cationic effects associated with secondgeneration air, water-stable ILs and Al deposition from bi-phasic mixtures, the importance of surface pretreatment, anodic effects, cost and scalability issues, and the industrial challenges. The primary objective of the review article is to provide an insight on the IL-based electrodeposition of aluminum, Al alloys covering the Al, Al alloy deposition from first-generation chloroaluminate ILs to third-generation DESs and its progress in developments so far. It shall also cover the electroplating, scalability aspects, and cost considerations, along with future challenges. Table 2 lists the ionic liquids that have been considered in this review.

Table 2. Table showing the list of ionic liquids studied in this review.

\begin{tabular}{|c|c|c|c|c|c|}
\hline Ionic Liquid & Chemical Formula & Cation & Anion & Abbreviation & Ref. \\
\hline $\begin{array}{l}\text { 1-ethyl-3- } \\
\text { methylimidazolium } \\
\text { chloride }\end{array}$ & {$\left[\left(\mathrm{C}_{6} \mathrm{H}_{11} \mathrm{~N}_{2} \mathrm{Cl}\right)\right]$} & {$\left[\left(\mathrm{C}_{2} \mathrm{H}_{5}\right)\left(\mathrm{CH}_{3}\right)\left(\mathrm{C}_{3} \mathrm{H}_{3} \mathrm{~N}_{2}\right)\right]^{+}$} & {$[\mathrm{Cl}]^{-}$} & [EMIm] $][\mathrm{Cl}]$ & [30] \\
\hline $\begin{array}{l}\text { 1-ethyl-3- } \\
\text { methylimidazolium } \\
\text { bromide }\end{array}$ & {$\left[\left(\mathrm{C}_{6} \mathrm{H}_{11} \mathrm{~N}_{2} \mathrm{Br}\right)\right]$} & {$\left[\left(\mathrm{C}_{2} \mathrm{H}_{5}\right)\left(\mathrm{CH}_{3}\right)\left(\mathrm{C}_{3} \mathrm{H}_{3} \mathrm{~N}_{2}\right)\right]^{+}$} & {$[\mathrm{Br}]^{-}$} & [EMIm] $[\mathrm{Br}]$ & [31] \\
\hline $\begin{array}{l}\text { 1-ethyl-3- } \\
\text { methylimidazolium } \\
\text { fluoride }\end{array}$ & {$\left[\left(\mathrm{C}_{6} \mathrm{H}_{11} \mathrm{~N}_{2} \mathrm{~F}\right)\right]$} & {$\left[\left(\mathrm{C}_{2} \mathrm{H}_{5}\right)\left(\mathrm{CH}_{3}\right)\left(\mathrm{C}_{3} \mathrm{H}_{3} \mathrm{~N}_{2}\right)\right]^{+}$} & {$[\mathrm{F}]^{-}$} & [EMIm][F] & [32] \\
\hline $\begin{array}{c}\text { 1-butyl-3- } \\
\text { methylimidazolium } \\
\text { chloride }\end{array}$ & {$\left[\left(\mathrm{C}_{8} \mathrm{H}_{15} \mathrm{~N}_{2} \mathrm{Cl}\right)\right]$} & {$\left[\left(\mathrm{C}_{4} \mathrm{H}_{9}\right)\left(\mathrm{CH}_{3}\right)\left(\mathrm{C}_{3} \mathrm{H}_{3} \mathrm{~N}_{2}\right)\right]^{+}$} & {$[\mathrm{Cl}]^{-}$} & [BMIm] $][\mathrm{Cl}]$ & [30] \\
\hline
\end{tabular}


Table 2. Cont.

\begin{tabular}{|c|c|c|c|c|c|}
\hline Ionic Liquid & Chemical Formula & Cation & Anion & Abbreviation & Ref. \\
\hline $\begin{array}{l}\text { 1-butyl-3-methyl } \\
\text { pyridinium chloride }\end{array}$ & {$\left[\left(\mathrm{C}_{10} \mathrm{H}_{16} \mathrm{NCl}\right)\right]$} & {$\left[\left(\mathrm{C}_{4} \mathrm{H}_{9}\right)\left(\mathrm{CH}_{3}\right)\left(\mathrm{C}_{5} \mathrm{H}_{5} \mathrm{~N}\right)\right]^{+}$} & {$[\mathrm{Cl}]^{-}$} & [BMPyri][Cl] & [30] \\
\hline $\begin{array}{l}\text { 1-butyl-1-methyl } \\
\text { pyrrolidinium chloride }\end{array}$ & {$\left[\left(\mathrm{C}_{9} \mathrm{H}_{20} \mathrm{NCl}\right)\right]$} & {$\left[\left(\mathrm{C}_{4} \mathrm{H}_{9}\right)\left(\mathrm{CH}_{3}\right)\left(\mathrm{C}_{4} \mathrm{H}_{10} \mathrm{~N}\right)\right]^{+}$} & {$[\mathrm{Cl}]^{-}$} & [BMPyl][Cl] & [33] \\
\hline $\begin{array}{l}\text { 1-benzyl-3- } \\
\text { methylimidazolium } \\
\text { chloride }\end{array}$ & {$\left[\left(\mathrm{C}_{11} \mathrm{H}_{13} \mathrm{~N}_{2} \mathrm{Cl}\right)\right]$} & $\begin{array}{c}{\left[\left(\mathrm{C}_{6} \mathrm{H}_{5} \mathrm{CH}_{2}\right)\left(\mathrm{CH}_{3}\right)\right.} \\
\left.\quad\left(\mathrm{C}_{3} \mathrm{H}_{3} \mathrm{~N}_{2}\right)\right]^{+}\end{array}$ & {$[\mathrm{Cl}]^{-}$} & [BeMImCl][Cl] & [34] \\
\hline $\begin{array}{l}\text { 1,3-dibenzyl-imidazolium } \\
\text { chloride }\end{array}$ & {$\left[\left(\mathrm{C}_{17} \mathrm{H}_{17} \mathrm{~N}_{2} \mathrm{Cl}\right)\right]$} & $\begin{array}{c}{\left[\left(\mathrm{C}_{6} \mathrm{H}_{5} \mathrm{CH}_{2}\right)\left(\mathrm{C}_{6} \mathrm{H}_{5} \mathrm{CH}_{2}\right)\right.} \\
\left.\left(\mathrm{C}_{3} \mathrm{H}_{3} \mathrm{~N}_{2}\right)\right]^{+}\end{array}$ & {$[\mathrm{Cl}]^{-}$} & {$\left[\mathrm{Be}_{1,3} \operatorname{ImC}\right][\mathrm{Cl}]$} & [34] \\
\hline $\begin{array}{l}\text { Trimethyl phenyl } \\
\text { ammonium chloride }\end{array}$ & $\left.\left[\left(\mathrm{CH}_{3}\right)_{3} \mathrm{~N}(\mathrm{Cl}) \mathrm{C}_{6} \mathrm{H}_{5}\right)\right]$ & {$\left[\left(\mathrm{CH}_{3}\right)_{3} \mathrm{C}_{6} \mathrm{H}_{5} \mathrm{NH}\right]^{+}$} & {$[\mathrm{Cl}]^{-}$} & [TMPA] [Cl] & [35] \\
\hline $\begin{array}{l}\text { 1-methyl-3- } \\
\text { butylimidazolium } \\
\text { chloride }\end{array}$ & {$\left[\left(\mathrm{C}_{8} \mathrm{H}_{16} \mathrm{~N}_{2} \mathrm{Cl}\right]\right.$} & {$\left[\left(\mathrm{CH}_{3}\right)\left(\mathrm{C}_{4} \mathrm{H}_{9}\right)\left(\mathrm{C}_{3} \mathrm{~N}_{2} \mathrm{H}_{4} \mathrm{H}\right)\right]^{+}$} & {$[\mathrm{Cl}]^{-}$} & [MBIm] $[\mathrm{Cl}]$ & [36] \\
\hline $\begin{array}{l}\text { 1-ethyl-3-methyl } \\
\text { imidazolium bis(trifluoro } \\
\text { methyl sulfonyl) imide }\end{array}$ & {$\left[\left(\mathrm{C}_{8} \mathrm{H}_{11} \mathrm{~F}_{6} \mathrm{~N}_{3} \mathrm{O}_{4} \mathrm{~S}_{2}\right)\right]$} & $\begin{array}{l}{\left[\left(\mathrm{C}_{2} \mathrm{H}_{5}\right)\left(\mathrm{CH}_{3}\right)\right.} \\
\left.\left(\mathrm{C}_{3} \mathrm{~N}_{2} \mathrm{H}_{4} \mathrm{H}\right)\right]^{+}\end{array}$ & {$\left[\mathrm{CF}_{3} \mathrm{SO}_{2} \mathrm{CF}_{3} \mathrm{SO}_{2} \mathrm{~N}\right]^{-}$} & {$[\mathrm{EMIm}]\left[\mathrm{Tf}_{2} \mathrm{~N}\right]$} & [37] \\
\hline $\begin{array}{l}\text { 1-butyl-3-methyl } \\
\text { imidazolium bis(trifluoro } \\
\text { methyl sulfonyl) imide }\end{array}$ & {$\left[\left(\mathrm{C}_{10} \mathrm{H}_{15} \mathrm{~F}_{6} \mathrm{~N}_{3} \mathrm{O}_{4} \mathrm{~S}_{2}\right)\right]$} & $\begin{array}{l}{\left[\left(\mathrm{C}_{4} \mathrm{H}_{9}\right)\left(\mathrm{CH}_{3}\right)\right.} \\
\left.\left(\mathrm{C}_{3} \mathrm{~N}_{2} \mathrm{H}_{4} \mathrm{H}\right)\right]^{+}\end{array}$ & {$\left[\mathrm{CF}_{3} \mathrm{SO}_{2} \mathrm{CF}_{3} \mathrm{SO}_{2} \mathrm{~N}\right]^{-}$} & {$[\mathrm{BMIm}]\left[\mathrm{Tf}_{2} \mathrm{~N}\right]$} & [38] \\
\hline $\begin{array}{l}\text { 1-propyl-1-methyl } \\
\text { pyrrolidinium bis(trifluoro } \\
\text { methyl sulfonyl) imide }\end{array}$ & {$\left[\mathrm{C}_{10} \mathrm{H}_{18} \mathrm{~F}_{6} \mathrm{~N}_{2} \mathrm{O}_{4} \mathrm{~S}_{2}\right]$} & {$\left[\left(\mathrm{C}_{3} \mathrm{H}_{7}\right)\left(\mathrm{CH}_{3}\right)\left(\mathrm{C}_{4} \mathrm{H}_{9} \mathrm{NH}\right)\right]^{+}$} & {$\left[\mathrm{CF}_{3} \mathrm{SO}_{2} \mathrm{CF}_{3} \mathrm{SO}_{2} \mathrm{~N}\right]^{-}$} & {$[\mathrm{PMPyl}]\left[\mathrm{Tf}_{2} \mathrm{~N}\right]$} & [37] \\
\hline $\begin{array}{l}\text { 1-butyl-3-methyl } \\
\text { pyridinium bis(trifluoro } \\
\text { methyl sulfonyl) imide }\end{array}$ & {$\left[\left(\mathrm{C}_{12} \mathrm{H}_{16} \mathrm{~F}_{6} \mathrm{~N}_{2} \mathrm{O}_{4} \mathrm{~S}_{2}\right)\right]$} & {$\left[\left(\mathrm{C}_{4} \mathrm{H}_{9}\right)\left(\mathrm{CH}_{3}\right)\left(\mathrm{C}_{5} \mathrm{H}_{6} \mathrm{~N}\right)\right]^{+}$} & {$\left[\mathrm{CF}_{3} \mathrm{SO}_{2} \mathrm{CF}_{3} \mathrm{SO}_{2} \mathrm{~N}\right]^{-}$} & {$[\mathrm{BMPyri}]\left[\mathrm{Tf}_{2} \mathrm{~N}\right]$} & [39] \\
\hline $\begin{array}{l}\text { 1-butyl-1-methyl } \\
\text { pyrrolidine bis(trifluoro } \\
\text { methyl sulfonyl) imide }\end{array}$ & {$\left[\left(\mathrm{C}_{11} \mathrm{H}_{20} \mathrm{~F}_{6} \mathrm{~N}_{2} \mathrm{O}_{4} \mathrm{~S}_{2}\right)\right]$} & $\left.\left[\left(\mathrm{C}_{4} \mathrm{H}_{9}\right)\left(\mathrm{CH}_{3}\right) \mathrm{C}_{4} \mathrm{H}_{9} \mathrm{NH}\right)\right]^{+}$ & {$\left[\mathrm{CF}_{3} \mathrm{SO}_{2} \mathrm{CF}_{3} \mathrm{SO}_{2} \mathrm{~N}\right]^{-}$} & {$[\mathrm{BPyl}]\left[\mathrm{Tf}_{2} \mathrm{~N}\right]$} & [39] \\
\hline $\begin{array}{l}\text { 1-hexyl-3-methyl } \\
\text { imidazolium bis(trifluoro } \\
\text { methyl sulfonyl) imide }\end{array}$ & {$\left[\left(\mathrm{C}_{12} \mathrm{H}_{19} \mathrm{~F}_{6} \mathrm{~N}_{3} \mathrm{O}_{4} \mathrm{~S}_{2}\right)\right]$} & $\begin{array}{l}{\left[\left(\mathrm{C}_{6} \mathrm{H}_{13}\right)\left(\mathrm{CH}_{3}\right)\right.} \\
\left.\left(\mathrm{C}_{3} \mathrm{~N}_{2} \mathrm{H}_{4} \mathrm{H}\right)\right]^{+}\end{array}$ & {$\left[\mathrm{CF}_{3} \mathrm{SO}_{2} \mathrm{CF}_{3} \mathrm{SO}_{2} \mathrm{~N}\right]^{-}$} & {$[\mathrm{HMIm}]\left[\mathrm{Tf}_{2} \mathrm{~N}\right]$} & [37] \\
\hline $\begin{array}{l}\text { 1-hexyl 2,3-dimethyl } \\
\text { imidazolium bis(trifluoro } \\
\text { methyl sulfonyl) imide }\end{array}$ & {$\left[\left(\mathrm{C}_{13} \mathrm{H}_{21} \mathrm{~F}_{6} \mathrm{~N}_{2} \mathrm{O}_{4} \mathrm{~S}_{2}\right)\right.$} & $\begin{array}{l}{\left[\left(\mathrm{C}_{6} \mathrm{H}_{13}\right)\left(\mathrm{CH}_{3} \mathrm{CH}_{3}\right)\right.} \\
\left.\quad\left(\mathrm{C}_{3} \mathrm{~N}_{2} \mathrm{H}_{4} \mathrm{H}\right)\right]^{+}\end{array}$ & {$\left[\mathrm{CF}_{3} \mathrm{SO}_{2} \mathrm{CF}_{3} \mathrm{SO}_{2} \mathrm{~N}\right]^{-}$} & $\begin{array}{l}{\left[\mathrm{HM}^{\prime} \mathrm{Im}\right]} \\
{\left[\mathrm{Tf}_{2} \mathrm{~N}\right]}\end{array}$ & [40] \\
\hline $\begin{array}{l}\text { 1-hexyl pyridinium } \\
\text { bis(trifluoro methyl } \\
\text { sulfonyl)imide }\end{array}$ & {$\left[\left(\mathrm{C}_{13} \mathrm{H}_{18} \mathrm{~F}_{6} \mathrm{~N}_{2} \mathrm{O}_{4} \mathrm{~S}_{2}\right)\right]$} & {$\left[\left(\mathrm{C}_{6} \mathrm{H}_{13}\right)\left(\mathrm{C}_{5} \mathrm{H}_{5} \mathrm{NH}\right)\right]^{+}$} & {$\left[\mathrm{CF}_{3} \mathrm{SO}_{2} \mathrm{CF}_{3} \mathrm{SO}_{2} \mathrm{~N}\right]^{-}$} & {$[\mathrm{HPyr}]\left[\mathrm{Tf}_{2} \mathrm{~N}\right]$} & [40] \\
\hline $\begin{array}{l}\text { 1-hexyl-3-methyl } \\
\text { pyridinium bis(trifluoro } \\
\text { methyl sulfonyl)imide }\end{array}$ & {$\left[\left(\mathrm{C}_{14} \mathrm{H}_{20} \mathrm{~F}_{6} \mathrm{~N}_{2} \mathrm{O}_{4} \mathrm{~S}_{2}\right)\right]$} & $\begin{array}{c}{\left[\left(\mathrm{C}_{6} \mathrm{H}_{13}\right)\right.} \\
\left.\left(\mathrm{CH}_{3}\right)\left(\mathrm{C}_{5} \mathrm{H}_{5} \mathrm{NH}\right)\right]^{+}\end{array}$ & {$\left[\mathrm{CF}_{3} \mathrm{SO}_{2} \mathrm{CF}_{3} \mathrm{SO}_{2} \mathrm{~N}\right]^{-}$} & {$\left[\mathrm{HM}^{\prime} \mathrm{Pyr}\right]\left[\mathrm{Tf}_{2} \mathrm{~N}\right]$} & [40] \\
\hline $\begin{array}{l}\text { 1-hexyl-3,5 dimethyl } \\
\text { pyridinium bis(trifluoro } \\
\text { methyl sulfonyl) imide }\end{array}$ & {$\left[\left(\mathrm{C}_{15} \mathrm{H}_{22} \mathrm{~F}_{6} \mathrm{~N}_{2} \mathrm{O}_{4} \mathrm{~S}_{2}\right)\right]$} & $\begin{array}{c}{\left[\left(\mathrm{C}_{6} \mathrm{H}_{13}\left(\mathrm{CH}_{3} \mathrm{CH}_{3}\right) \mathrm{HH}\right.\right.} \\
\left.\left(\mathrm{C}_{5} \mathrm{H}_{5} \mathrm{NH}\right)\right]^{+}\end{array}$ & {$\left[\mathrm{CF}_{3} \mathrm{SO}_{2} \mathrm{CF}_{3} \mathrm{SO}_{2} \mathrm{~N}\right]^{-}$} & {$\left[\mathrm{HM}^{\prime \prime} \mathrm{Pyr}\right]\left[\mathrm{Tf}_{2} \mathrm{~N}\right]$} & [40] \\
\hline $\begin{array}{l}\text { 1-hexyl-1-methyl } \\
\text { pyrrolidinium bis(trifluoro } \\
\text { methyl sulfonyl) imide }\end{array}$ & {$\left[\left(\mathrm{C}_{13} \mathrm{H}_{22} \mathrm{~F}_{6} \mathrm{~N}_{2} \mathrm{O}_{4} \mathrm{~S}_{2}\right)\right]$} & $\begin{array}{c}{\left[\left(\mathrm{C}_{6} \mathrm{H}_{13}\right)\left(\mathrm{CH}_{3}\right)\right.} \\
\left.\left(\mathrm{C}_{4} \mathrm{H}_{9} \mathrm{NH}\right)\right]^{+}\end{array}$ & {$\left[\mathrm{CF}_{3} \mathrm{SO}_{2} \mathrm{CF}_{3} \mathrm{SO}_{2} \mathrm{~N}\right]^{-}$} & {$[\mathrm{HMPyl}]\left[\mathrm{Tf}_{2} \mathrm{~N}\right]$} & [37] \\
\hline $\begin{array}{l}\text { 1-octyl-1-methyl } \\
\text { pyrrolidinium bis(trifluoro } \\
\text { methyl sulfonyl) imide }\end{array}$ & {$\left[\left(\mathrm{C}_{15} \mathrm{H}_{28} \mathrm{~F}_{6} \mathrm{~N}_{2} \mathrm{O}_{4} \mathrm{~S}_{2}\right)\right]$} & $\begin{array}{c}{\left[\left(\mathrm{C}_{8} \mathrm{H}_{17}\right)\left(\mathrm{CH}_{3}\right)\right.} \\
\left.\left(\mathrm{C}_{4} \mathrm{H}_{9} \mathrm{NH}\right)\right]^{+}\end{array}$ & {$\left[\mathrm{CF}_{3} \mathrm{SO}_{2} \mathrm{CF}_{3} \mathrm{SO}_{2} \mathrm{~N}\right]^{-}$} & {$[\mathrm{OMPyl}]\left[\mathrm{Tf}_{2} \mathrm{~N}\right]$} & [37] \\
\hline
\end{tabular}


Table 2. Cont.

\begin{tabular}{|c|c|c|c|c|c|}
\hline Ionic Liquid & Chemical Formula & Cation & Anion & Abbreviation & Ref. \\
\hline $\begin{array}{c}\text { 1-octyl-3- } \\
\text { methylimidazolium } \\
\text { bis(trifluoro methyl } \\
\text { sulfonyl) imide }\end{array}$ & {$\left[\left(\mathrm{C}_{14} \mathrm{H}_{23} \mathrm{~F}_{6} \mathrm{~N}_{3} \mathrm{O}_{4} \mathrm{~S}_{2}\right)\right]$} & $\begin{array}{l}{\left[\left(\mathrm{C}_{8} \mathrm{H}_{17}\right)\left(\mathrm{CH}_{3}\right)\right.} \\
\left.\left(\mathrm{C}_{3} \mathrm{~N}_{2} \mathrm{H}_{4} \mathrm{H}\right)\right]^{+}\end{array}$ & {$\left[\mathrm{CF}_{3} \mathrm{SO}_{2} \mathrm{CF}_{3} \mathrm{SO}_{2} \mathrm{~N}\right]^{-}$} & {$[\mathrm{OMIm}]\left[\mathrm{Tf}_{2} \mathrm{~N}\right]$} & [41] \\
\hline $\begin{array}{l}\text { trihexyl-tetradecyl } \\
\text { phosphonium } \\
\text { bis(trifluoromethyl } \\
\text { sulfonyl)imide }\end{array}$ & {$\left[\mathrm{C}_{34} \mathrm{H}_{68} \mathrm{~F}_{6} \mathrm{NO}_{4} \mathrm{PS}_{2}\right]$} & {$\left[\left(\mathrm{C}_{6} \mathrm{H}_{13}\right)_{3}\left(\mathrm{C}_{14} \mathrm{H}_{30} \mathrm{PH}\right]^{+}\right.$} & {$\left[\mathrm{CF}_{3} \mathrm{SO}_{2} \mathrm{CF}_{3} \mathrm{SO}_{2} \mathrm{~N}\right]^{-}$} & {$\left[\mathrm{P}_{14,6,6,6}\right]\left[\mathrm{Tf}_{2} \mathrm{~N}\right]$} & [37] \\
\hline $\begin{array}{l}\text { 1-ethyl-3-methyl } \\
\text { imidazolium hexa } \\
\text { fluorophosphate }\end{array}$ & {$\left[\left(\mathrm{C}_{6} \mathrm{H}_{11} \mathrm{~F}_{6} \mathrm{~N}_{2} \mathrm{P}\right)\right]$} & {$\left[\left(\mathrm{C}_{2} \mathrm{H}_{5}\right)\left(\mathrm{CH}_{3}\right)\left(\mathrm{C}_{3} \mathrm{~N}_{2} \mathrm{H}_{4} \mathrm{H}\right)\right]^{+}$} & {$\left[\mathrm{PF}_{6}\right]^{-}$} & {$[\mathrm{EMIm}]\left[\mathrm{PF}_{6}\right]$} & [41] \\
\hline $\begin{array}{l}\text { 1-butyl-3-methyl } \\
\text { imidazolium hexa } \\
\text { fluorophosphate }\end{array}$ & {$\left[\left(\mathrm{C}_{8} \mathrm{H}_{15} \mathrm{~F}_{6} \mathrm{~N}_{2} \mathrm{P}\right)\right]$} & {$\left[\left(\mathrm{C}_{4} \mathrm{H}_{9}\right)\left(\mathrm{CH}_{3}\right)\left(\mathrm{C}_{3} \mathrm{~N}_{2} \mathrm{H}_{4} \mathrm{H}\right)\right]^{+}$} & {$\left[\mathrm{PF}_{6}\right]^{-}$} & {$[\mathrm{BMIm}]\left[\mathrm{PF}_{6}\right]$} & [41] \\
\hline $\begin{array}{l}\text { 1-hexyl-3-methyl } \\
\text { imidazolium hexa } \\
\text { fluorophosphate }\end{array}$ & {$\left[\left(\mathrm{C}_{10} \mathrm{H}_{19} \mathrm{~F}_{6} \mathrm{~N}_{2} \mathrm{P}\right)\right]$} & {$\left[\left(\mathrm{C}_{6} \mathrm{H}_{13}\right)\left(\mathrm{CH}_{3}\right)\left(\mathrm{C}_{3} \mathrm{~N}_{2} \mathrm{H}_{4} \mathrm{H}\right)\right]^{+}$} & {$\left[\mathrm{PF}_{6}\right]^{-}$} & {$[\mathrm{HMIm}]\left[\mathrm{PF}_{6}\right]$} & [41] \\
\hline $\begin{array}{l}\text { 1-octyl-3-methyl } \\
\text { imidazolium hexa } \\
\text { fluorophosphate }\end{array}$ & {$\left[\left(\mathrm{C}_{12} \mathrm{H}_{23} \mathrm{~F}_{6} \mathrm{~N}_{2} \mathrm{P}\right)\right]$} & {$\left[\left(\mathrm{C}_{8} \mathrm{H}_{17}\right)\left(\mathrm{CH}_{3}\right)\left(\mathrm{C}_{3} \mathrm{~N}_{2} \mathrm{H}_{4} \mathrm{H}\right)\right]^{+}$} & {$\left[\mathrm{PF}_{6}\right]^{-}$} & {$[\mathrm{OMIm}]\left[\mathrm{PF}_{6}\right]$} & [41] \\
\hline $\begin{array}{l}\text { 1-ethyl-3-methyl } \\
\text { imidazolium } \\
\text { tetrafluoroborate }\end{array}$ & {$\left[\left(\mathrm{C}_{6} \mathrm{H}_{11} \mathrm{~F}_{4} \mathrm{~N}_{2} \mathrm{~B}\right)\right]$} & {$\left[\left(\mathrm{C}_{2} \mathrm{H}_{5}\right)\left(\mathrm{CH}_{3}\right)\left(\mathrm{C}_{3} \mathrm{~N}_{2} \mathrm{H}_{4} \mathrm{H}\right)\right]^{+}$} & {$\left[\mathrm{BF}_{4}\right]^{-}$} & {$[\mathrm{EMIm}]\left[\mathrm{BF}_{4}\right]$} & [41] \\
\hline $\begin{array}{l}\text { 1-butyl-3-methyl } \\
\text { imidazolium } \\
\text { tetrafluoroborate }\end{array}$ & {$\left[\left(\mathrm{C}_{8} \mathrm{H}_{15} \mathrm{~F}_{4} \mathrm{~N}_{2} \mathrm{~B}\right)\right]$} & {$\left[\left(\mathrm{C}_{4} \mathrm{H}_{9}\right)\left(\mathrm{CH}_{3}\right)\left(\mathrm{C}_{3} \mathrm{~N}_{2} \mathrm{H}_{4} \mathrm{H}\right)\right]^{+}$} & {$\left[\mathrm{BF}_{4}\right]^{-}$} & {$[\mathrm{BMIm}]\left[\mathrm{BF}_{4}\right]$} & [41] \\
\hline $\begin{array}{l}\text { 1-hexyl-3-methyl } \\
\text { imidazolium } \\
\text { tetrafluoroborate }\end{array}$ & {$\left[\left(\mathrm{C}_{10} \mathrm{H}_{19} \mathrm{~F}_{4} \mathrm{~N}_{2} \mathrm{~B}\right)\right]$} & {$\left[\left(\mathrm{C}_{6} \mathrm{H}_{13}\right)\left(\mathrm{CH}_{3}\right)\left(\mathrm{C}_{3} \mathrm{~N}_{2} \mathrm{H}_{4} \mathrm{H}\right)\right]^{+}$} & {$\left[\mathrm{BF}_{4}\right]^{-}$} & {$[\mathrm{HMIm}]\left[\mathrm{BF}_{4}\right]$} & [41] \\
\hline $\begin{array}{l}\text { 1-octyl-3-methyl } \\
\text { imidazolium } \\
\text { tetrafluoroborate }\end{array}$ & {$\left[\left(\mathrm{C}_{12} \mathrm{H}_{23} \mathrm{~F}_{4} \mathrm{~N}_{2} \mathrm{~B}\right)\right]$} & {$\left[\left(\mathrm{C}_{8} \mathrm{H}_{17}\right)\left(\mathrm{CH}_{3}\right)\left(\mathrm{C}_{3} \mathrm{~N}_{2} \mathrm{H}_{4} \mathrm{H}\right)\right]^{+}$} & {$\left[\mathrm{BF}_{4}\right]^{-}$} & {$[\mathrm{OMIm}]\left[\mathrm{BF}_{4}\right]$} & [41] \\
\hline $\begin{array}{l}\text { 1-ethyl-3-methyl } \\
\text { imidazolium trifluoro } \\
\text { methane sulfonate }\end{array}$ & {$\left[\left(\mathrm{C}_{7} \mathrm{H}_{11} \mathrm{~F}_{3} \mathrm{~N}_{2} \mathrm{O}_{3} \mathrm{~S}\right)\right]$} & {$\left[\left(\mathrm{C}_{2} \mathrm{H}_{5}\right)\left(\mathrm{CH}_{3}\right)\left(\mathrm{C}_{3} \mathrm{~N}_{2} \mathrm{H}_{4} \mathrm{H}\right)\right]^{+}$} & {$\left[\mathrm{CF}_{3} \mathrm{SO}_{3}\right]^{-}$} & $\begin{array}{c}{[\mathrm{EMIm}]} \\
{\left[\mathrm{CF}_{3} \mathrm{SO}_{3}\right]}\end{array}$ & [41] \\
\hline $\begin{array}{l}\text { 1-butyl-3-methyl } \\
\text { imidazolium trifluoro } \\
\text { methane sulfonate }\end{array}$ & {$\left[\left(\mathrm{C}_{9} \mathrm{H}_{15} \mathrm{~F}_{3} \mathrm{~N}_{2} \mathrm{O}_{3} \mathrm{~S}\right)\right]$} & {$\left[\left(\mathrm{C}_{4} \mathrm{H}_{9}\right)\left(\mathrm{CH}_{3}\right)\left(\mathrm{C}_{3} \mathrm{~N}_{2} \mathrm{H}_{4} \mathrm{H}\right)\right]^{+}$} & {$\left[\mathrm{CF}_{3} \mathrm{SO}_{3}\right]^{-}$} & $\begin{array}{c}{[\mathrm{BMIm}]} \\
{\left[\mathrm{CF}_{3} \mathrm{SO}_{3}\right]}\end{array}$ & [41] \\
\hline $\begin{array}{l}\text { 1-hexyl-3-methyl } \\
\text { imidazolium trifluoro } \\
\text { methane sulfonate }\end{array}$ & {$\left[\left(\mathrm{C}_{11} \mathrm{H}_{19} \mathrm{~F}_{3} \mathrm{~N}_{2} \mathrm{O}_{3} \mathrm{~S}\right)\right]$} & {$\left[\left(\mathrm{C}_{6} \mathrm{H}_{13}\right)\left(\mathrm{CH}_{3}\right)\left(\mathrm{C}_{3} \mathrm{~N}_{2} \mathrm{H}_{4} \mathrm{H}\right)\right]^{+}$} & {$\left[\mathrm{CF}_{3} \mathrm{SO}_{3}\right]^{-}$} & $\begin{array}{l}{[\mathrm{HMIm}]} \\
{\left[\mathrm{CF}_{3} \mathrm{SO}_{3}\right]}\end{array}$ & [41] \\
\hline $\begin{array}{l}\text { 1-octyl-3-methyl } \\
\text { imidazolium trifluoro } \\
\text { methane sulfonate }\end{array}$ & {$\left[\left(\mathrm{C}_{11} \mathrm{H}_{23} \mathrm{~F}_{3} \mathrm{~N}_{2} \mathrm{O}_{3} \mathrm{~S}\right)\right]$} & {$\left[\left(\mathrm{C}_{8} \mathrm{H}_{17}\right)\left(\mathrm{CH}_{3}\right)\left(\mathrm{C}_{3} \mathrm{~N}_{2} \mathrm{H}_{4} \mathrm{H}\right)\right]^{+}$} & {$\left[\mathrm{CF}_{3} \mathrm{SO}_{3}\right]^{-}$} & $\begin{array}{c}{[\mathrm{OMIm}]} \\
{\left[\mathrm{CF}_{3} \mathrm{SO}_{3}\right]}\end{array}$ & [41] \\
\hline $\begin{array}{l}\text { Choline chloride: Urea } \\
(1: 1)\end{array}$ & $\begin{array}{c}{\left[\left(\mathrm{C}_{5} \mathrm{H}_{14} \mathrm{ClNO}\right)\right.} \\
\left.\left(\mathrm{CH}_{4} \mathrm{~N}_{2} \mathrm{O}\right)\right]\end{array}$ & {$\left[\left(\mathrm{C}_{5} \mathrm{H}_{14} \mathrm{NOH}\right)\right]^{+}$} & {$\left[\left(\mathrm{CH}_{4} \mathrm{~N}_{2} \mathrm{O}\right) \mathrm{Cl}\right]^{-}$} & $\begin{array}{c}\text { [ChCl:Urea] } \\
(1: 1)\end{array}$ & [42] \\
\hline $\begin{array}{l}\text { Choline chloride: Urea } \\
\qquad(1: 2)\end{array}$ & $\begin{array}{c}{\left[\left(\mathrm{C}_{5} \mathrm{H}_{14} \mathrm{ClNO}\right)\right.} \\
\left.\left(\mathrm{CH}_{4} \mathrm{~N}_{2} \mathrm{O}\right)\right]\end{array}$ & {$\left[\left(\mathrm{C}_{5} \mathrm{H}_{14} \mathrm{NOH}\right)\right]^{+}$} & {$\left[\left(\mathrm{CH}_{4} \mathrm{~N}_{2} \mathrm{O}\right) \mathrm{Cl}\right]^{-}$} & $\begin{array}{c}\text { [ChCl:Urea] } \\
(1: 2)\end{array}$ & [43] \\
\hline $\begin{array}{l}\text { Choline Chloride: } \\
\text { Ethylene glycol }\end{array}$ & $\begin{array}{l}{\left[\left(\mathrm{C}_{5} \mathrm{H}_{14} \mathrm{ClNO}\right)\right.} \\
\left.\left(\mathrm{C}_{2} \mathrm{H}_{6} \mathrm{O}_{2}\right)\right]\end{array}$ & {$\left[\left(\mathrm{C}_{5} \mathrm{H}_{14} \mathrm{NOH}\right)\right]^{+}$} & {$\left[\left(\mathrm{C}_{2} \mathrm{H}_{6} \mathrm{O}\right) \mathrm{Cl}\right]^{-}$} & $\begin{array}{c}{[\mathrm{ChCl:EG]}} \\
(1: 2)\end{array}$ & [44] \\
\hline
\end{tabular}




\section{Aluminum Deposition in Ionic Liquids}

\subsection{Introduction}

Ionic liquids for $\mathrm{Al}$ deposition can be categorized into first-generation and secondgeneration, depending on their nature. First-generation ILs are also known as chloroaluminate ILs and generally halide-based, while second-generation ILs are generally stable against moisture and air. First-generation ILs are generally produced by mixing $\mathrm{AlCl}_{3}$ (anhydrous) and an IL containing halides such as $\mathrm{Cl}^{-}, \mathrm{F}^{-}, \mathrm{Br}^{-}, \mathrm{I}^{-}$[27]. Chloroaluminate ILs are the simplest ones composed of mostly inorganic halide anions and organic cations, and display high conductivity, wide electrochemical potential window and considered to be the potential system that can be used as an electrolyte media for electrodepositing $\mathrm{Al}, \mathrm{Al}$ alloys. By changing the molar ratio of IL to $\mathrm{AlCl}_{3}$, it is possible to tune the Lewis acidity and can be classified into acidic, neutral, and basic [45]. Neutral mixtures are usually obtained when the molar ratio is $1: 1$ and contains $\mathrm{Al}(\mathrm{III})$ species in the form of $\left[\left(\mathrm{AlCl}_{4}\right)\right]^{-}$, whereas acidic mixtures obtained by changing the molar ratio to $1: 2$ contains $\mathrm{Al}(\mathrm{III})$ species in the form of $\left[\left(\mathrm{Al}_{2} \mathrm{Cl}_{7}\right)\right]^{-}$. The basic mixture with molar ratio between 1:1 and 1:2 contains both $\left[\left(\mathrm{Al}_{2} \mathrm{Cl}_{7}\right)\right]^{-}$and $\left[\left(\mathrm{AlCl}_{4}\right)\right]^{-}$. Based on the literature, it is reported that chloroaluminate ILs are widely used for $\mathrm{Al}$ deposition since they have rich $\mathrm{Al}(\mathrm{III})$ reducible species; $\left[\mathrm{Al}_{2} \mathrm{Cl}_{7}\right]^{-}$, which is considered to be the electro-active species and will be reduced as per the following Equation

$$
4\left[\mathrm{Al}_{2} \mathrm{Cl}_{7}\right]^{-}+3 \mathrm{e}^{-} \rightarrow \mathrm{Al}+7\left[\mathrm{AlCl}_{4}\right]^{-}
$$

Since acidic mixtures with molar ratio of $1: 2$ contain predominantly high number of $\left[\left(\mathrm{Al}_{2} \mathrm{Cl}_{7}\right)\right]^{-}$species, it becomes obvious that they contain a relatively high amount of $\mathrm{Al}(\mathrm{III})$ reducible species. So, deposition in acidic mixtures would be the preferred choice for $\mathrm{Al}$ deposition in chloroaluminate ILs to neutral, basic mixtures. Another distinct feature of $\mathrm{Al}$ deposition from chloroaluminate ionic liquids is the type of deposit in terms of size, structure, and shape. Deposition of $\mathrm{Al}$ and $\mathrm{Al}$-based alloys from first-generation chloroaluminate ILs such as [EMIm][Cl]- $\mathrm{AlCl}_{3}$ and other imidazolium chloride-based ILs with different substituents are very attractive owing to their low (i) melting point, (ii) viscosity, (iii) vapor pressure over a broad range of compositions, with sufficiently wide electrochemical window, good intrinsic electrical conductivity, and a low vapor pressure [46]. Jiang et al. [47,48] studied the nucleation mechanism during Al electrodeposition, in relation to surface morphological features of $\mathrm{Al}$ on tungsten, aluminum electrodes employing [EMIm] $[\mathrm{Cl}]-\mathrm{AlCl}_{3}$ as the IL. The $\mathrm{Al}$ electrodeposits obtained on the substrates were not only dense but also adherent with complete coverage. It was concluded that the electrodeposition of $\mathrm{Al}$ from [EMIm] $[\mathrm{Cl}]-\mathrm{AlCl}_{3}$-based IL is a three electron reduction process [49] with the following chemical reactions

$$
\begin{aligned}
& \mathrm{AlCl}_{3}+[\mathrm{EMIm}] \mathrm{Cl} \rightarrow[\mathrm{EMIm}] \mathrm{AlCl}_{4} \\
& {[\mathrm{EMIm}] \mathrm{AlCl}_{4}+\mathrm{AlCl}_{3} \rightarrow[\mathrm{EMIm}] \mathrm{Al}_{2} \mathrm{Cl}_{7}} \\
& 2[\mathrm{EMIm}] \mathrm{Al}_{2} \mathrm{Cl}_{7} \rightarrow 2 \mathrm{Al}+2[\mathrm{EMIm}] \mathrm{AlCl}_{4}+3 \mathrm{Cl}_{2}
\end{aligned}
$$

Besides the deposition mechanism, the dissolution was also studied, and the results demonstrated that the $\mathrm{Al}$ deposits underwent a corrosion process gradually indicative of unstable nature of the deposit, and complicated kinetics signifying the effect of impurities. So far, most of the deposition of $\mathrm{Al}$ was carried out mainly employing the simplest chloroaluminate IL systems listed in Table 3 and resulted in a good deposition. Though there were many reports published on successfully electrodepositing aluminum using ILs, most of them have focused on chloroaluminate-based ILs. One of the distinctive features of the chloroaluminate-based IL systems is that electrochemical reduction of $\mathrm{Al}$ on the substrate occurs via Equation (1) at 100\% coulombic efficiency. Also, deposition of Al under galvanostatic conditions influences the morphological features of Al deposit significantly and is represented by the general schematic, as shown in Figure 1. When current densities $\leq 40 \mathrm{~mA} \mathrm{~cm}^{-2}$ are applied while employing the chloroaluminate-based IL systems during 
the deposition of $\mathrm{Al}$, dense, and crystalline deposits are formed [25]. On increasing the current density beyond $40 \mathrm{~mA} \mathrm{~cm}{ }^{-2}$, dendritic $\mathrm{Al}$ deposits are observed on the cathode surface. Change in the Lewis acidity due to the depletion of reducible $\left[\left(\mathrm{Al}_{2} \mathrm{Cl}_{7}\right)\right]^{-}$species at the surface of the cathode during the deposition at high current densities, was shown to the responsible factor related to the morphological changes of the $\mathrm{Al}$ deposit.

Table 3. Table listing the classification of chloroaluminate-based ionic liquids (ILs) employed for Al electrodeposition.

\begin{tabular}{cccc}
\hline Type \# & Cation & Example & Ref. \\
\hline Type 1 & N-alkylpyridinium & {$[\mathrm{BPyri}][\mathrm{Cl}]-\mathrm{AlCl}_{3}$} & {$[50]$} \\
\hline \multirow{3}{*}{ Type 2 } & & {$[\mathrm{BMIm}][\mathrm{Cl}]-\mathrm{AlCl}_{3}$} & {$[51]$} \\
\cline { 3 - 3 } & $\mathrm{N}, \mathrm{N}^{\prime}$-dialkylimidazolium & {$\left[\mathrm{BeMImC]}[\mathrm{Cl}]-\mathrm{AlCl}_{3}\right.$} & \multirow{2}{*}[34]{} \\
\cline { 3 - 3 } & & {$\left[\mathrm{Be}_{1,3} \mathrm{ImC}\right][\mathrm{Cl}]-\mathrm{AlCl}_{3}$} & \\
\hline Type 3 & N-alkylpyrrolidinium & {$[\mathrm{BMPyl}][\mathrm{Cl}]-\mathrm{AlCl}_{3}$} & {$[33]$} \\
\hline Type 4 & Trialkyl-arylammonium & {$[\mathrm{TMPA}][\mathrm{Cl}]-\mathrm{AlCl}_{3}$} & {$[35]$} \\
\hline
\end{tabular}

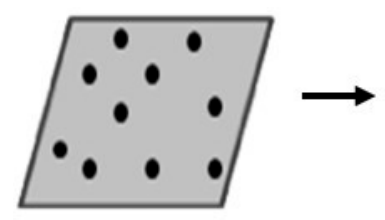

(a)

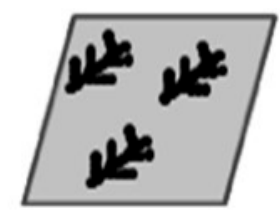

(b)

Figure 1. General schematic showing the change in the morphological features of Al deposited via galvanostatic deposition from chloroaluminate-based ILs at (a) $\leq 40 \mathrm{~mA} \mathrm{~cm}^{-2} ;(\mathbf{b}) \geq 40 \mathrm{~mA} \mathrm{~cm}^{-2}$.

However, chloroaluminate ILs suffer from high hygroscopicity and needs to be handled in an inert gas environment. For instance, a closed system filled with an inert gas such as a glove box is required for carrying out the electrodeposition of $\mathrm{Al}$ on a larger scale. Deploying such a system complicates the process, increase additional costs, and hinders its extensive applications in industry sectors such as automotive, aerospace. Bakkar et al. [52] presented a new methodology of electrodepositing aluminum in an open-air environment on low carbon steel substrate by covering the previously prepared [EMIm] $[\mathrm{Cl}]-\mathrm{AlCl}_{3}$-based IL mixture with a non-water-absorbable layer of an organic compound: decane, formed above the surface of the IL as a protective insulating layer against air and moisture. Decane was identified to be stable and unreactive with the IL mixture. Also, an insulated layer is reported to be formed above the surface of the IL mixture. Comparison of the voltammograms of the low carbon steel substrate in [EMIm][Cl]- $\mathrm{AlCl}_{3}$ showed the same characteristics when conducted inside and outside glove box, indicating the stability of the bath against air and moisture. Also, properties of the Al deposit such as adhesion, resistance against mechanical scratch, and bending were shown to be significantly improved when the deposition was performed in room atmosphere with the addition of decane. Such systems lack industrial attention owing to their disadvantage associated with the preparation of IL system in an inert atmosphere, for instance, argon-filled glove box. Zhang et al. [53] developed a simple and practical method to electrodeposit $\mathrm{Al}$ coatings on $\mathrm{Mg}$ alloys such as AZ91D in air from a first-generation IL [BMIm] [Cl]- $\mathrm{AlCl}_{3}(1: 2)$ by adding an adsorbent material to the IL system. $\mathrm{Al}$ is the preferred choice of metal coating for protecting $\mathrm{Mg}$ alloys as it has certain advantages such as (i) no significant change in the overall density due to their light weight, (ii) good corrosion resistance as they form an intermetallic compound $\mathrm{Mg}_{x} \mathrm{Al}_{y}$ during its deposition on $\mathrm{Mg}$ alloy surfaces, which are considered to be a beneficial feature in the aerospace industry [54]. AZ91 alloy is regarded as the preferrable magnesium alloys as they are castable easily, possess relatively good strength, and corrosion resistance. These alloys are generally formed by die-casting and designated by short codes as per 
ASTM B 275 standards [55], which denote the elements present and approximate chemical compositions by weight. AZ91 alloy contains 9\% Al, 1\% Zn and the rest is magnesium. The advantage with these series of alloys is the presence of $\mathrm{Al}$ as the primary alloy element, which contributes to maintaining the recycling of materials effectively. The AZ91D version is superior grade amongst the other alloys in terms of purity containing 9\% $\mathrm{Al}, 1 \% \mathrm{Zn}$ with very low impurities of nickel, iron, and copper impurity levels. These alloys also exhibit good physical and mechanical properties, better corrosion resistance than the other series of Mg alloys (AZ91A, AZ91B) [55,56]. These alloys find application in automotive and a few of the examples include clutch pedal, drive bracket, steering column brackets, oil pan, brake pedal, crankcase, and other automobile parts. Undecane, a water-adsorbent solid material, was added to the $[\mathrm{EMIm}][\mathrm{Cl}]-\mathrm{AlCl}_{3}$ mixture, which formed an organic protective layer on the liquid and prevent the IL mixture from moisture and air. The deposition was performed using potentiostatic and galvanostatic methods at $-0.67 \mathrm{~V}$ (vs. Al wire) and $-30.08 \mathrm{~mA} \mathrm{~cm}^{-2}$ for $7500 \mathrm{~s}$. Al deposits by galvanostatic approach displayed a continuous and compact structure while the Al deposition using potentiostatic method resulted in the formation of loose and cracked structure. Corrosion test results showed a better protective behavior of $\mathrm{Al}$ deposits from the galvanostatic method than with the deposits obtained from potentiostatic mode [53]. Furthermore, the Al coating obtained by the addition of undecane demonstrated its feasibility at an industrial scale and helped to understand the potential of the proposed method.

\subsection{Influence of Cation}

ILs formed from an organic cation and an inorganic anion are often complex in nature, whose complexity varies depending on the various combinations formed by different cations, anions, and therefore, the properties (physical, chemical) of such IL systems are dependent on the ions' structure and composition. By choosing cations and anions appropriately, ILs with desired characteristics can be obtained [21,27-29]. In such context, the role of cation becomes vital during the $\mathrm{Al}, \mathrm{Al}$ alloys electrodeposition. Although Moustafa [57] has demonstrated that cations influenced the morphological features of the Al deposited from a variety of triflimide-based ILs, certain understanding on the cations' role in tailoring the structure properties, the influence of Helmholtz double layer thickness on the final deposit remains unexplored. Large size cations shall lead to an increased asymmetric substitution with their anions and results in a melting point reduction. Since melting points are often characterized by the cation's size and symmetry and as a result, the role of cation becomes important. Similarly, majority of ILs with low vapor pressure shall facilitate the easy water removal from the liquid to $<1 \mathrm{ppm}$ by simple heating under a vacuum. Cations can significantly influence the morphologies of Al deposits when performed in chloroaluminate-based ILs. For instance, Endres et al. [58] reported the formation of microcrystalline $\mathrm{Al}$ deposits from [EMIm] $[\mathrm{Cl}]-\mathrm{AlCl}_{3}$ and nanocrystalline $\mathrm{Al}$ deposit from [BMPyl][Cl]- $\mathrm{AlCl}_{3}$-based ILs. Most of the ILs that behave like a fluid at normal room temperatures with low melting points when formed using organic cations, as it is difficult to produce low melting point mixtures using inorganic cations because they possess high charge density. The deposition of $\mathrm{Al}$ from chroloraluminate-based ILs depends on the composition of the chloroaluminate and the molar ratio of $\mathrm{AlCl}_{3}$. Deposition of $\mathrm{Al}$ from chloraluminate ILs with different cations is expected to happen with $\mathrm{AlCl}_{3}$ mole fraction $>0.5$. Electrodeposition of $\mathrm{Al}$ with varying $\mathrm{AlCl}_{3}$ mole fractions shall lead to crystalline deposits with different grain sizes in the final deposit. One interesting fact when employing such ILs is that, above a certain concentration of $\mathrm{AlCl}_{3}$, an aluminum-containing IL complex with reducible Al-cationic species is generated in the solution, within the electrochemical potential window of ILs. In such cases, these ILs exhibited different phase behavior with varying molar ratios of $\mathrm{AlCl}_{3}$ and the IL. For instance, Pulletikurthi et al. [59] conducted a $\mathrm{Al}$ electrodeposition feasibility by adding 1-butylpyrrolidine [BPyl][Cl] to $\mathrm{AlCl}_{3}$ varying the molar ratio from 1.3:1 to 1:1.3, observed a bi-phasic mixture when the [BPyl][Cl]: $\mathrm{AlCl}_{3}$ molar ratio is 1:1.3. The lower phase was observed to be a solid thin layer 
at the bottom and composed mostly of anionic-aluminum species and neutral in nature. The upper clear yellow phase had the organic cation [BMPyl] ${ }^{+}$and the presence of reducible species $\left[\left(\mathrm{AlCl}_{4}\right)\right]^{-}$. Since the electro-active aluminum-containing species $\left[\left(\mathrm{AlCl}_{4}\right)\right]^{-}$that can be reduced to $\mathrm{Al}$, existed only in the upper phase of the [BMPyl][Cl]- $\mathrm{AlCl}_{3}$ mixture, $\mathrm{Al}$ was deposited from the upper phase on copper-based substrates and a uniform thick layer of $\mathrm{Al}$ was obtained.

Wang et al. [39] performed $\mathrm{Al}$ deposition employing four types of chloroaluminatebased ILs, which are categorized based on the nature of cation, with copper as the cathodic substrate and are listed in Table 4 along with their physical property and the current density results. The tabulated results showed that viscosity of [BMIm] $[\mathrm{Cl}]-\mathrm{AlCl}_{3}$-based ILs had the lowest value, while the conductivity was highest amongst the four systems studied, followed the order for the viscosity: [BMIm][Cl]- $\mathrm{AlCl}_{3}<[\mathrm{BMPyri}][\mathrm{Cl}]-\mathrm{AlCl}_{3}$ $<[\mathrm{BMPyl}][\mathrm{Cl}]-\mathrm{AlCl}_{3}<[\mathrm{TMPA}][\mathrm{Cl}]-\mathrm{AlCl}_{3}$. Comparison of electrical conductivities at two different temperatures: $30{ }^{\circ} \mathrm{C}, 60{ }^{\circ} \mathrm{C}$ reveal that the values followed the order of sequence: $[\mathrm{BMIm}][\mathrm{Cl}]-\mathrm{AlCl}_{3}>[\mathrm{BMPyri}][\mathrm{Cl}]-\mathrm{AlCl}_{3}>[\mathrm{BMPyl}][\mathrm{Cl}]-\mathrm{AlCl}_{3}>[\mathrm{TMPA}][\mathrm{Cl}]-$ $\mathrm{AlCl}_{3}$. While Raman results showed that $\left[\left(\mathrm{Al}_{2} \mathrm{Cl}_{7}\right)\right]^{-}$were the main anionic species for all the systems studied, reduction current was found to be highest for the $\mathrm{Al}$ deposition from [BMIm] $[\mathrm{Cl}]-\mathrm{AlCl}_{3}$ amongst them, when studied using cyclic voltammogram results. Also, by comparison of current density range values at different temperatures: $30^{\circ} \mathrm{C}$, $60{ }^{\circ} \mathrm{C}$, it can be observed that $[\mathrm{BMIm}][\mathrm{Cl}]-\mathrm{AlCl}_{3}$ exhibited the widest working current density range [3-15 $\mathrm{mA} \mathrm{cm}^{-2}$ ] that can be employed to obtain a uniform and smooth $\mathrm{Al}$ deposits amongst the four IL systems studied by Wang et al. [39]. On the contrary, $\mathrm{Al}$ deposition was reported to be observed from [BMPyl]Cl-AlCl 3 , [TMPA]Cl- $\mathrm{AlCl}_{3}$ at a lower temperature $\left(30^{\circ} \mathrm{C}\right)$ due to their lower conductivity, combined with their high viscosity, which reduced ion mobility of the electroactive reducible species towards the cathode. Also, it is interesting to note from Table 4 that ILs with higher viscosity exhibited lower conductivity at $30{ }^{\circ} \mathrm{C}$. Increasing the temperature to $60^{\circ} \mathrm{C}$ lowered the viscosity and increased the conductivity, which significantly enhanced the ion mobility, favoring good Al deposition. Physical characterization results demonstrated that the morphological differences of the deposited $\mathrm{Al}$ under galvanostatic conditions are consistent in all the IL systems at different temperatures. Al deposition from [BMIm] $[\mathrm{Cl}]-\mathrm{AlCl}_{3}$ resulted in a compact and smooth coating when deposited at constant current density. Also, Karthika et al. [30] conducted a systematic investigation of the electrodeposition behaviors of $\mathrm{Al}$ from $[\mathrm{EMIm}][\mathrm{Cl}]-\mathrm{AlCl}_{3},[\mathrm{BMIm}][\mathrm{Cl}]-\mathrm{AlCl}_{3}$-based ILs on copper substrates and compared the deposition characteristics, tabulated in Table 5.

Table 4. Table comparing the viscosity and electrical conductivity of the IL systems reported by Wang et al. [39].

\begin{tabular}{|c|c|c|c|c|c|c|}
\hline \multirow[t]{2}{*}{ System } & \multirow{2}{*}{ Cation } & \multirow{2}{*}{ Viscosity ${ }^{1}$, mPas } & \multicolumn{2}{|c|}{$\begin{array}{c}\text { Electrical Conductivity }{ }^{2} \\
\mathrm{mS} \mathrm{cm}^{-1}\end{array}$} & \multicolumn{2}{|c|}{ Current Density, $\mathrm{mA} \mathrm{cm}^{-2}$} \\
\hline & & & $30^{\circ} \mathrm{C}$ & $60{ }^{\circ} \mathrm{C}$ & $30^{\circ} \mathrm{C}$ & $60{ }^{\circ} \mathrm{C}$ \\
\hline$[\mathrm{BMIm}][\mathrm{Cl}]-\mathrm{AlCl}_{3}$ & BMMIm] $^{+}$ & 18.1262 & 10 & 32.5 & $3-15$ & $3-15$ \\
\hline$[\mathrm{BMPyri}] \mathrm{Cl}-\mathrm{AlCl}_{3}$ & [BMPyri $^{+}$ & 26.8728 & 7.5 & 22.5 & $3-10$ & $3-15$ \\
\hline$[\mathrm{BMPyl}] \mathrm{Cl}-\mathrm{AlCl}_{3}$ & {$\left[_{\mathrm{BMPyl}}\right]^{+}$} & 37.6965 & 5 & 17.5 & - & $3-15$ \\
\hline$[\mathrm{TMPA}] \mathrm{Cl}-\mathrm{AlCl}_{3}$ & [TMPA] $^{+}$ & 37.7386 & 2.5 & 12.5 & - & $3-10$ \\
\hline
\end{tabular}

${ }^{1}$ Viscosity values were reported to be measured at $30{ }^{\circ} \mathrm{C} .{ }^{2}$ Electrical conductivity values were taken from the plots reported in [39]. 
Table 5. Table comparing the deposit characteristics of Al deposits in [EMIm] and [BMIm]-based ILs.

\begin{tabular}{|c|c|c|c|c|}
\hline System & $\begin{array}{l}\text { Current Density, } \\
\qquad \mathrm{mA} \mathrm{cm}^{-2}\end{array}$ & $\begin{array}{c}\text { Deposition Efficiency, } \\
\eta^{1} \%\end{array}$ & Deposit Morphology & $\begin{array}{c}\text { Deposit Thickness, } \\
\mu \mathrm{m}\end{array}$ \\
\hline \multirow{6}{*}[\mathrm{EMIm}]{$\mathrm{Cl}-\mathrm{AlCl}_{3}(1: 2)$} & -5 & 53 & Flaky & 2.9 \\
\hline & -7 & $\sim 65$ & Compact with some cracks & $\sim 5$ \\
\hline & -10 & 75 & Granular with small voids & 10 \\
\hline & -12 & 87.5 & $\begin{array}{l}\text { Compact with reduced } \\
\text { particle size }\end{array}$ & 12.9 \\
\hline & -15 & $\sim 90$ & $\begin{array}{l}\text { smooth surface with bigger } \\
\text { particle sizes and very clear } \\
\text { particles shapes }\end{array}$ & $\sim 17.5$ \\
\hline & -20 & 97 & $\begin{array}{l}\text { refined crystalline particles } \\
\text { with tightly packed more } \\
\text { compact surface }\end{array}$ & 24 \\
\hline \multirow{4}{*}[\mathrm{BMIm}]{$\mathrm{Cl}-\mathrm{AlCl}_{3}(1: 2)$} & -5 & 91 & Flaky & 5.6 \\
\hline & -7 & $\sim 93$ & Thick flaky & $\sim 7.5$ \\
\hline & -10 & 97 & Granular with small voids & 10 \\
\hline & -12 & 97 & Granular agglomerates & 14.4 \\
\hline
\end{tabular}

${ }^{1}$ Deposition efficiency values were approximated to the nearest value from the plots reported in reference [30].

On one hand, $\mathrm{Al}$ deposition from [EMIm] $[\mathrm{Cl}]-\mathrm{AlCl}_{3} \mathrm{IL}$ followed a two-step reduction mechanisms favoring the uniform coating on the surface, while on the other hand, $\mathrm{Al}$ deposition from [BMIm] $\mathrm{Cl}-\mathrm{AlCl}_{3} \mathrm{IL}$ followed a single-step reduction mechanism and formed more agglomerates than the uniform coating. Also, [EMIm] $[\mathrm{Cl}]-\mathrm{AlCl}_{3}$-based IL exhibited a wider operating current density window than the [BMIm] $[\mathrm{Cl}]-\mathrm{AlCl}_{3} \mathrm{IL}$. On comparing the cathodic current efficiency and deposit thickness, it was reported that $\mathrm{Al}$ deposit from [EMIm][Cl]- $\mathrm{AlCl}_{3}$-based IL had a higher thickness in contrast to the [BMIm] $[\mathrm{Cl}]-\mathrm{AlCl}_{3}$-based IL when compared at their highest cathodic current efficiencies $(97 \%)$. At lower current densities, the cathodic current efficiency in the case of [EMIm] [Cl]$\mathrm{AlCl}_{3}$ was lower and increased on increasing the current density, achieving a maximum of $97 \%$ when deposited at $20 \mathrm{~mA} \mathrm{~cm}{ }^{-2}$. This was explained from the comparison of voltammograms, which displayed two reduction processes during $\mathrm{Al}$ deposition at low current densities: (i) underpotential and (ii) overpotential for the deposition of $\mathrm{Al}$ in [EMIm] $[\mathrm{Cl}]-\mathrm{AlCl}_{3}$. Varying the current density resulted in an effective utilization of current for overpotential, an increased thickness of the deposit. The results confirmed that the $[\mathrm{EMIm}][\mathrm{Cl}]-\mathrm{AlCl}_{3}$-based IL can be employed for the production of aluminum deposit with a high deposition rate. This study has given an understanding that cation not only affect the quality of the deposit but also significantly influences the deposition conditions. Vivegnis et al. [35] studied the electrodeposition of [TMPA] $[\mathrm{Cl}]-\mathrm{AlCl}_{3}$ on carbon steel substrates (DC01 Grade) and investigated the influence of nucleation and growth of $\mathrm{Al}$ at different temperatures: in the range $25-75^{\circ} \mathrm{C}$ under galvanostatic, potentiostatic deposition conditions. The results showed that $\mathrm{Al}$ deposition at higher temperatures favored the growth of nuclei irrespective of the deposition method, demonstrating the influence of temperature on deposit growth rather than the evolution of nuclei. Besides, the study also provided an insight on understanding the relation between the viscosity of the ILs and their influence on the mass transport. Al deposited at $25^{\circ} \mathrm{C}$ under galvanostatic conditions displayed a good metallic crystalline coating with complete coverage. Though there are significant reports on the deposition of $\mathrm{Al}$ from first-generation chloroaluminate ILs, their hygroscopic nature requiring handling under inert gas environment hinders their commercialization. To overcome the challenges, air and water-stable-based ionic liquids also known as second-generation ILs, were introduced as an electrolyte media for the deposition of $\mathrm{Al}$ on different industrially used substrates. The advantages of these ILs over 
chloroaluminates include being less reactive with water, only require simple purification without requiring expensive equipment, and have high ease in drying the mixtures with low water content $[26,27]$, demonstrating their feasibility in the field of electroplating for aerospace, automotive applications.

The viscosity and conductivity are influenced by the cations' (i) size (or) chain length, (ii) structure as these properties regulate the mass transportation of metal ionic species to the cathode surface. Figure 2 shows the influence of viscosity of commonly used water and air-stable ILs, plotted with different cationic chain lengths based on the literature data obtained from [40] with $\left[\mathrm{Tf}_{2} \mathrm{~N}\right]^{-}$as the common anion. As can be seen from the figure, these ILs differ in their cationic chain length and viscosity at different temperatures (data provide for the temperature range $283-343 \mathrm{~K}$ or $\left(10-70^{\circ} \mathrm{C}\right)$. The viscosity values displayed an increasing trend with increasing cationic chain length and a decreasing order with an increase in temperature. When deposition of $\mathrm{Al}$ is performed using different alkyl cationic chain lengths, cations that are adsorbed at the cathode surface shall influence the double layer structure at the deposition potential, control the quality of the $\mathrm{Al}$ deposit. Viscosity plays an important role in controlling the mass transport of the metal ion species. A decrease in viscosity can enhance the mass transportation of the reducible species to the electrode surface and also favor the conductivity, thereby improving the deposit quality. Also, employing different cations for the electrodeposition of Al shall not only alter the morphological features but also result in different grain sizes in the deposit. The length of the alkyl cations in ionic liquid shall influence the crystallinity (micro/nano) of the $\mathrm{Al}$ deposits, while the cationic decomposition of such ionic liquids can also alter the grain size of the deposit and morphology. To get more insight into the processes, it is important to study the influence of cationic species of the IL on the electrodeposition behavior of $\mathrm{Al}$ deposit. Few researchers $[37,57,58]$ studied the role of cation on the overall nature of the Al deposit and the cations employed with the same anion are tabulated in Table 6 along with their physical properties and the concentration ranges used for the deposition of Al. Abedin et al. [60] demonstrated that $\mathrm{Al}$ with different crystalline (micro/nano) nature can be electrodeposited from second-generation air and water-stable ionic liquids with different cations: $[\mathrm{BMPyl}]^{+},[\mathrm{EMIm}]^{+}$, and $\left[\mathrm{P}_{14,6,6,6}\right]^{+}$and $\left[\mathrm{Tf}_{2} \mathrm{~N}\right]^{-}$was chosen as the common anion. $\mathrm{Al}$ deposited from [BMPyl][ $\left.\mathrm{Tf}_{2} \mathrm{~N}\right]-\mathrm{AlCl}_{3}$ displayed a fine adherent deposit with nanocrystalline nature while $\mathrm{Al}$ from [EMIm] $\left[\mathrm{Tf}_{2} \mathrm{~N}\right]-\mathrm{AlCl}_{3}$ showed a coarse, micro-crystalline $\mathrm{Al}$ deposit with cubic-shape. Fomin et al. [37] performed the $\mathrm{Al}$ deposition from four different air and water-stable ILs with four different cations: $[\mathrm{HMIm}]^{+} ;[\mathrm{HMPyl}]^{+},[\mathrm{OMPyl}]^{+}$and $[\mathrm{PMPyl}]^{+}$, which had the same anion, $\left[\mathrm{Tf}_{2} \mathrm{~N}\right]^{-}$. The study focused on the influence of ILs' cationic chain length on the electrochemical and phase behavior on the nature of $\mathrm{Al}$ deposit. These ILs were different in terms of their physical, chemical properties, molecular structure, and the anions' interaction with their cations in respective ILs. Comparison of the surface morphology of $\mathrm{Al}$ coatings deposited under galvanostatic conditions at a given temperature in terms of grain size showed that it followed a decreasing trend in the grain size with the increase of current density, but an increased trend with an increasing temperature. Since the only difference amongst the ILs employed are the cations, it can be interpreted that cations play a critical role not only in controlling the properties of the ILs but also in producing different quality when deposited under similar conditions. Density functional theory (DFT) calculations reported by [39,51,61], demonstrated that ILs prepared with different cations and same anion were different in their properties, which could be ascribed to their different molecular structure and anions' interaction with their cations in the ILs. While imidazolium-based cations exhibited superior fluidity and conductivity, pyrrolidinium cations showed a good interaction strength to the substrate. As can be seen from Table 6, the ILs represent different cations with the same anion $\left[\mathrm{Tf}_{2} \mathrm{~N}\right]^{-}$and different physical properties and are reported to be some of the most commonly used air and stable ILs employed for the deposition of Al. One interesting feature with these ILs is that they exhibited a biphasic behavior when mixed with $\mathrm{AlCl}_{3}$ in their respective concentration ranges, as mentioned in Table 6, except $\left[\mathrm{P}_{14,6,6,6}\right]^{+}$. Also, [BMPyl][Tf $\left.{ }_{2} \mathrm{~N}\right]$ and 
[EMIm] $\left[\mathrm{Tf}_{2} \mathrm{~N}\right]$-based ILs became monophasic at $\geq 80{ }^{\circ} \mathrm{C}$. When $\mathrm{Al}$ deposition was performed from $\left[\mathrm{P}_{14,6,6,6}\right]\left[\mathrm{Tf}_{2} \mathrm{~N}\right]-\mathrm{AlCl}_{3}$ at room temperature, nanocrystalline $\mathrm{Al}$ with a particle size of $\sim 20 \mathrm{~nm}$ and mirror like appearance were obtained. Higher temperatures of $150{ }^{\circ} \mathrm{C}$ resulted in a higher grain size up to $35 \mathrm{~nm}$, demonstrating that crystal size is influenced by the deposition temperature, which increased with an increase in temperature. Similarly, deposition from the upper phase of the $[\mathrm{BMPyl}]\left[\mathrm{Tf}_{2} \mathrm{~N}\right] /[\mathrm{EMIm}]\left[\mathrm{Tf}_{2} \mathrm{~N}\right]-\mathrm{AlCl}_{3}$, biphasic IL mixture, resulted in the formation of nanocrystalline and microcrystalline Al. Welladhering thick $\mathrm{Al}$ deposits were reported to be obtained when deposition is performed from the upper phase of [PMPyl][Tf $\left.f_{2} \mathrm{~N}\right]-\mathrm{AlCl}_{3}$ and $[\mathrm{HMPyl}]\left[\mathrm{Tf}_{2} \mathrm{~N}\right]-\mathrm{AlCl}_{3}$ biphasic IL mixtures at temperatures higher than $100{ }^{\circ} \mathrm{C}$. The biphasic behavior of IL mixtures: [BMPyl][Tf $f_{2} \mathrm{~N}$ ] and [EMIm] $\left[\mathrm{Tf}_{2} \mathrm{~N}\right.$ ] with $\mathrm{AlCl}_{3}$ has been studied by Eiden et al. [62]. These ILs were demonstrated to be formed from two phases when higher concentrations of $\mathrm{AlCl}_{3}$ are added to them. Initial addition of $\mathrm{AlCl}_{3}$ to these ILs lead to the formation of complexes with $\left[\mathrm{Tf}_{2} \mathrm{~N}^{-}\right.$, $\left[\mathrm{AlCl}_{x}\left(\mathrm{Tf}_{2} \mathrm{~N}\right)_{y}\right]^{-}$, which subsequently resulted in the formation of $\mathrm{Al}\left(\mathrm{Tf}_{2} \mathrm{~N}\right)_{3}$ and $\left[\left(\mathrm{AlCl}_{4}\right)\right]^{-}$ via the complex disproportionation mechanism. While $[\mathrm{BMPyl}]\left[\mathrm{Tf}_{2} \mathrm{~N}\right]-\mathrm{AlCl}_{3}$ exhibited a biphasic behavior at a concentration of $1.6 \mathrm{~mol} \mathrm{~L}^{-1}$, it was $2.5 \mathrm{~mol} \mathrm{~L}^{-1}$ for the EMIm] $\left[\mathrm{Tf}_{2} \mathrm{~N}\right]$ $-\mathrm{AlCl}_{3}$ system. The species $\mathrm{Al}\left(\mathrm{Tf}_{2} \mathrm{~N}\right)_{3}$ was reported to be present in the lower phase while the upper phase consisted of $\left[\left(\mathrm{AlCl}_{4}\right)\right]^{-}$ions as the major species. In addition, a mixed species $\left(\mathrm{AlCl}_{x}\left[\mathrm{Tf}_{2} \mathrm{~N}\right]_{y}\right)^{-}$formed at the boundary between $\left(\mathrm{Al}\left[\mathrm{Tf}_{2} \mathrm{~N}\right]_{3}\right)$ and $\left[\mathrm{AlCl}_{4}\right]^{-}$was demonstrated to be a critical interface at which $\mathrm{Al}$ deposition occurred. Liu et al. [63] demonstrated the possibility of electrodepositing nanocrystalline $\mathrm{Al}$ at room temperature without any additives from second-generation $[\mathrm{EMIm}]\left[\mathrm{Tf}_{2} \mathrm{~N}\right]-\mathrm{AlCl}_{3}$ and first-generation $[\mathrm{EMIm}][\mathrm{Cl}]-\mathrm{AlCl}_{3}$ while employing different anions.

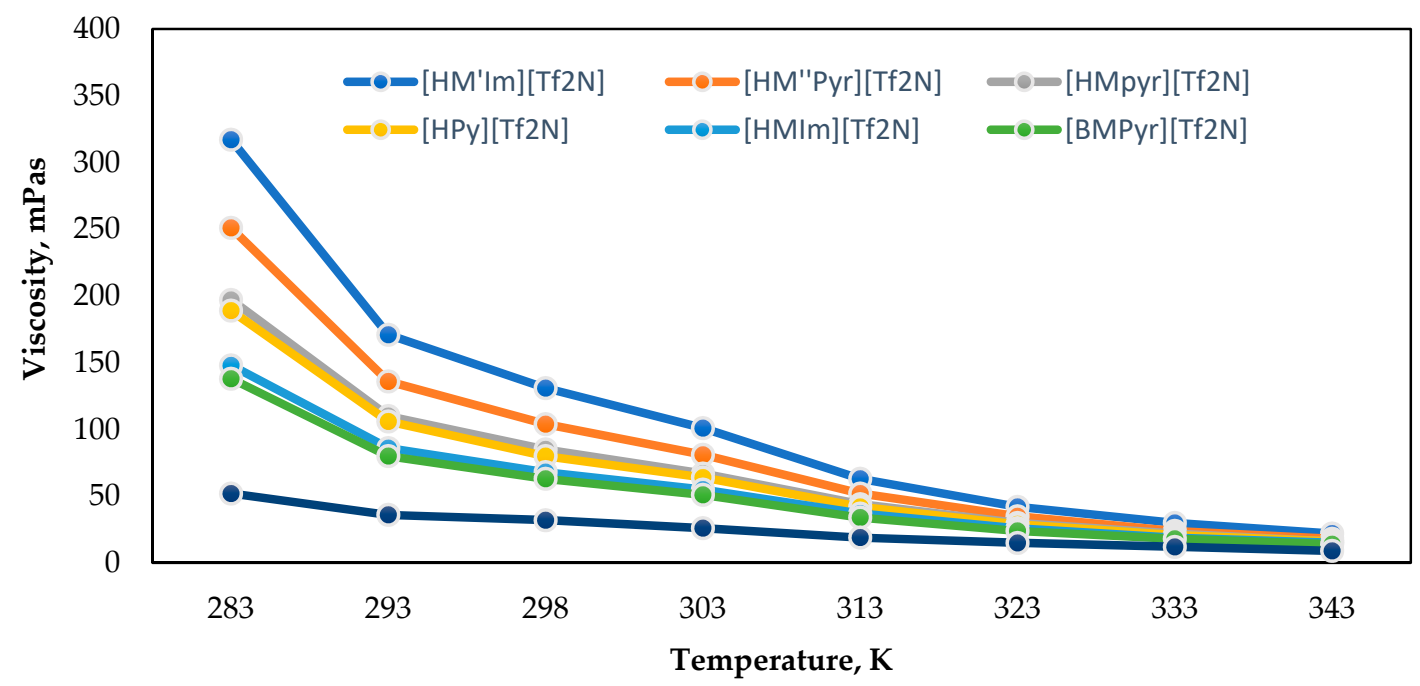

Figure 2. Figure showing the comparison of viscosity of air and water-stable ILs with cationic chain lengths at different temperatures: 283:343 K. Cations: $\left[\mathrm{HM}^{\prime} \mathrm{Im}\right]^{+}$; $\left[\mathrm{HM}^{\prime} \mathrm{Pyr}\right]^{+}$; $\left[\mathrm{HM}^{\prime \prime} \mathrm{pyr}\right]^{+}$; $[\mathrm{Hpyr}]^{+}$; $[\mathrm{HMIm}]^{+}$; $[\mathrm{BMpyr}]^{+} ;[\mathrm{EMIm}]^{+}$. Anion: $\left[\mathrm{Tf}_{2} \mathrm{~N}\right]^{-}$. Plotted based on the data from [40]. 
Table 6. Table showing the properties of air and water-stable ILs with different cations and same anion $\left[\mathrm{Tf}_{2} \mathrm{~N}\right]$ at $25^{\circ} \mathrm{C}$.

\begin{tabular}{|c|c|c|c|c|c|c|c|c|}
\hline Cation & $\begin{array}{c}\text { Mol. wt } \\
\left(\mathrm{g} \mathrm{mol}^{-1}\right)\end{array}$ & $\begin{array}{c}\rho \\
\left(\mathrm{g} \mathrm{cm}^{-3}\right)\end{array}$ & $\begin{array}{c}\eta \\
(\mathrm{mPa} s)\end{array}$ & $\begin{array}{c}\sigma \\
\left(\mathrm{mScm}^{-1}\right)\end{array}$ & $\begin{array}{l}\text { EW } \\
(\mathrm{V})\end{array}$ & $\begin{array}{l}\mathrm{AlCl}_{3} \text { Conc. } \\
(\mathrm{mol} / \mathrm{L})\end{array}$ & Nature of Mixture & Ref. \\
\hline$[\mathrm{BMPyl}]^{+}$ & 422.41 & 1.4 & 85 & 2.2 & 5.5 & $1.6-2.5$ & biphasic & {$[37,62,64]$} \\
\hline [EMIm] $^{+}$ & 391.31 & 1.53 & 32 & 8.8 & 4.1 & $2.5-5.0$ & biphasic & {$[37,62]$} \\
\hline$\left[_{\mathrm{HMIm}}\right]^{+}$ & 447.42 & 1.37 & 68 & 2.2 & 4 & $4.5-6.5$ & biphasic & [37] \\
\hline [HMPyl] $^{+}$ & 450.47 & 1.34 & 87.6 & 1.18 & 5.67 & $1.3-1.8$ & biphasic & [37] \\
\hline [OMPyl] $^{+}$ & 478.53 & 1.29 & 136.6 & 0.78 & 4.8 & $2.0-3.0$ & biphasic & [37] \\
\hline [PMPyl] $^{+}$ & 408.38 & 1.43 & 90 & 1.6 & 4 & $1.6-2.0$ & biphasic & [37] \\
\hline$\left[\mathrm{P}_{14,6,6,6}\right]^{+}$ & 764 & 1.07 & 401 & - & 5.2 & $1.5-4.0$ & single phase & [37] \\
\hline
\end{tabular}

[EMIm] $\left[\mathrm{Tf}_{2} \mathrm{~N}\right]$ exhibited a biphasic behavior, while [EMIm][Cl]- $\mathrm{AlCl}_{3}$ exhibited monophasic behavior. It was demonstrated that the morphology of the Al deposited from these ILs can be transformed from micro-crystalline to nanocrystalline through ionic liquid decomposition followed by deposition. ILs were subjected to a controlled cationic decomposition by performing the Al deposition at different current density ranges and these ILs with a certain percentage of decomposition are then employed for potentiostatic deposition at -0.4 to $-0.45 \mathrm{~V}$ (vs. $\mathrm{Al} / \mathrm{Al}(\mathrm{III})$ ). Electrochemical results demonstrated that the upper phase of the bi-phasic ILs [EMIm] $\left.\mathrm{Tf}_{2} \mathrm{~N}\right]-\mathrm{AlCl}_{3}$; and monophasic [EMIm] $[\mathrm{Cl}]-\mathrm{AlCl}_{3}$ underwent IL decomposition at higher current densities: $10 \mathrm{~mA} \mathrm{~cm}{ }^{-2}$ for the [EMIm] $\left[\mathrm{Tf}_{2} \mathrm{~N}\right]-\mathrm{AlCl}_{3}$; $50 \mathrm{~mA} \mathrm{~cm}^{-2}$ for $[\mathrm{EMIm}][\mathrm{Cl}]-\mathrm{AlCl}_{3}$. The significant color change was observed evidencing the IL decomposition and $\mathrm{Al}$ deposited using constant potential $(-0.4$ to $-0.45 \mathrm{~V})$ employing the ILs containing the decomposition products resulted in the formation of nanocrystalline morphology for both the cases. The studies also suggested that the cathodic decomposition of the imidazolium cations to a certain extent shall contribute to crystal refinement and favored the formation of nanocrystalline $\mathrm{Al}$ deposit. It was shown that the decomposition products beyond a threshold value of $0.2 \%$ in $[E M I m]\left[\mathrm{Tf}_{2} \mathrm{~N}\right]-\mathrm{AlCl}_{3}$ and $1.3 \%$ in [EMIm] $[\mathrm{Cl}]-\mathrm{AlCl}_{3}$ could act like a crystal size refiner. These results confirmed that decomposition products of imidazolium ion altered the crystallinity of the deposit but the anions were not shown to be having any significant impact on the physical characteristics of the $\mathrm{Al}$ deposit. These deposits contained only fine nanocrystallites. Figure 3 shows the schematic of the cationic structures and $\left[\mathrm{Tf}_{2} \mathrm{~N}\right]^{-}$anion that are used to prepare the commonly used air and water ILs and are employed for the deposition of Al. One problem associated with the biphasic mixtures is the viscosity of the upper phase, which is used for the deposition of Al. For instance, the viscosity values measured from upper phase of the [PMPyl][Tf $2 \mathrm{~N}]-\mathrm{AlCl}_{3}$ is reported to be $9000 \mathrm{mPas}$, which is at least 100 times than the original solution [37]. Deposition in such an electrolyte is expected to slow down the mass transportation rate of the reducible species to the cathode surface drastically and may result in either a poor deposition or no deposition at all. Therefore, the cation should be carefully chosen while considering the deposition of $\mathrm{Al}$ in air and water-stable ILs as they affect the overall deposit behavior. 


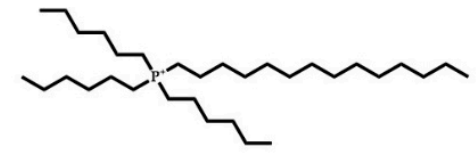

Trihexyl(tetradecyl)phosphonium

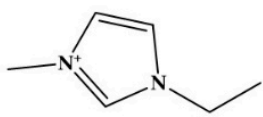

1-ethyl-3-methyl imidazolium

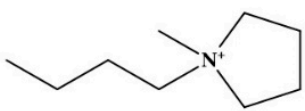

1-butyl-3-methyl pyrrolidinium

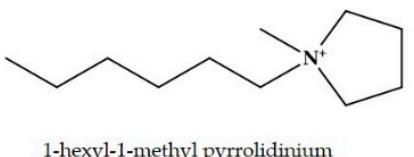

Cations

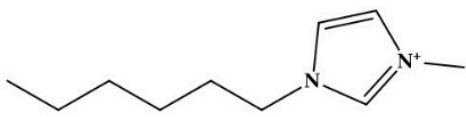

1-hexyl-3-methylimidazolium

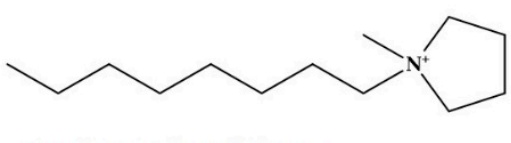

1-octyl-1-methyl pyrrolidinium

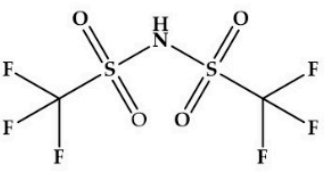

bis(trifluoromethylsulfonyl)imide

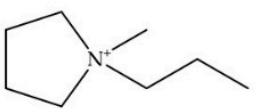

1-propyl-1-methyl pyrrolidinium

Anion

Figure 3. Schematic showing the structure of commonly used cations and a common anion $\left[\mathrm{Tf}_{2} \mathrm{~N}\right]^{-}$for preparing the air and water-stable ILs.

\subsection{Influence of Anion}

Anions in ILs play a vital role in tailoring certain physicochemical properties such as viscosity, conductivity when paired with different cations. While cations control melting points, lattice energies of the ILs, anions influence the coordination geometry, cathodic deposition current and nucleation characteristics of the $\mathrm{Al}$ deposit, and the reduction potential of either the $\mathrm{Al}$ or $\mathrm{Al}$ alloy metals to be deposited. Considering the number of ILs that has been introduced with variety of cation-anion arrangements and combinations, it is possible to design the ILs with desired physical, chemical, and electrochemical properties for various applications, including electroplating and cater different industry segments. Reviews by El Abedin and Endres [64], presented a detailed understanding of this topic. The cation-anion interaction combined with their ability to form an IL shall not only influence the solution properties, transport properties, but also the deposition conditions, electrochemical behavior, deposit properties. Anions can be inorganic (chloride, bromide, fluoride, tetrafluoroborate) or organic $\left(\left[\mathrm{CF}_{3} \mathrm{SO}_{3}\right]^{-},\left[\mathrm{Tf}_{2} \mathrm{~N}\right]^{-}\right)$; discrete or complexed. Figure 4 shows the viscosities of various IL systems with different anions commonly used in the deposition of $\mathrm{Al}$ at $298 \mathrm{~K}\left(25^{\circ} \mathrm{C}\right)$, which were plotted based on the data from [41,65] and Figure 5 show the schematic of the anion structures that are commonly used for preparing ILs. Among them, $\left[\mathrm{Tf}_{2} \mathrm{~N}\right]^{-},[\mathrm{BF} 4]^{-},\left[\mathrm{PF}_{6}\right]^{-},\left[\mathrm{CF}_{3} \mathrm{SO}_{3}\right]^{-}$are the most commonly employed anions used in the preparation of ILs that are used for the deposition of Al. As can be seen from Figure 4, the viscosities of ILs follow the order: $\left[\mathrm{PF}_{6}\right]^{-}>\left[\mathrm{BF}_{4}\right]^{-}>\left[\mathrm{CF}_{3} \mathrm{SO}_{3}\right]^{-}>\left[\mathrm{Tf}_{2} \mathrm{~N}\right]^{-}$ with $\left[\mathrm{Tf}_{2} \mathrm{~N}\right]^{-}$being the lowest. This suggests that the presence of $\left[\mathrm{Tf}_{2} \mathrm{~N}\right]^{-}$ions shall ease the movement of ions within ILs owing to their excellent charge delocalization behavior when relative to the other anions and facilitate good transport of $\mathrm{Al}$ metal ion species to the cathode surface, favor a good deposition. 


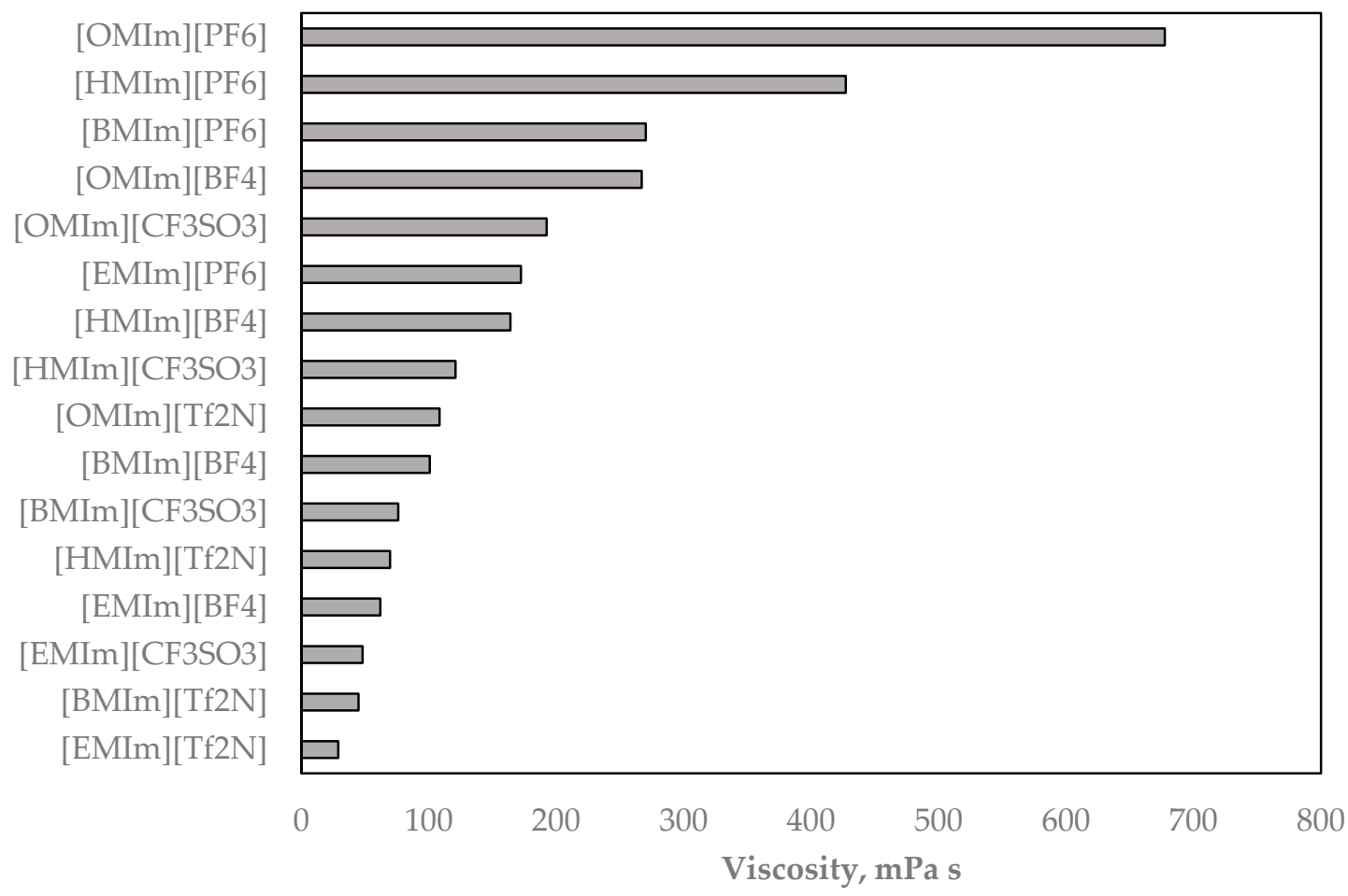

Figure 4. Figure showing the comparison of viscosity of air and water-stable ILs as a function of chain length at $298 \mathrm{~K}$. Anions: $\left[\mathrm{Tf}_{2} \mathrm{~N}\right]^{-} ;\left[\mathrm{BF}_{4}\right]^{-} ;\left[\mathrm{PF}_{6}\right]^{-} ;\left[\mathrm{CF}_{3} \mathrm{SO}_{3}\right]$. Cations: $[\mathrm{EMIm}]^{+} ;[\mathrm{BMIm}]^{+} ;[\mathrm{HMIm}]^{+} ;[\mathrm{OMIm}]^{+}$. Plotted based on the data from $[41,65]$<smiles>O=S(=O)(NS(=O)(=O)C(F)(F)F)C(F)(F)F</smiles>

bis(trifluoromethylsulfonyl)amide<smiles>F[Te](F)(F)(F)(F)F</smiles>

hexafluorophosphate<smiles>O=S(=O)([O-])C(F)(F)F</smiles>

trifluoromethyl sulfonate<smiles>F[B-](F)(F)F</smiles>

tetrafluoroborate<smiles>O=S(=O)([O-])C(F)(F)F</smiles>

trifluoromethane sulfonate<smiles>O=C([O-])C(F)(F)F</smiles>

trifluoroacetate

Figure 5. Schematic showing the structure of commonly used anions for preparing the ILs that are employed for the deposition of Al.

ILs with highly symmetric or spherical anions such as $\left[\mathrm{BF}_{4}\right]^{-},\left[\mathrm{PF}_{6}\right]^{-}$, have significantly high viscosities as can be from Figure 4, and as a result. they resist the ionic mobility and affect the deposition behavior. For instance, comparison of the viscosities of [BMIm]based ILs with different anions: $\left[\mathrm{BF}_{4}\right]^{-},\left[\mathrm{PF}_{6}\right]^{-},\left[\mathrm{CF}_{3} \mathrm{SO}_{3}\right]^{-},\left[\mathrm{Tf}_{2} \mathrm{~N}\right]^{-}$from Figure 4 follow the order: $\left[\mathrm{PF}_{6}\right]^{-}>\left[\mathrm{BF}_{4}\right]^{-}>\left[\mathrm{CF}_{3} \mathrm{SO}_{3}\right]^{-}>\left[\mathrm{Tf}_{2} \mathrm{~N}\right]^{-}$suggesting that the overall contribution to the viscosity of ionic liquids prepared with different cationic chain lengths is least for the $\left[\mathrm{Tf}_{2} \mathrm{~N}\right]^{-}$. Also, their least co-ordinating ability combined with greater flexibility makes 
$\left[\mathrm{Tf}_{2} \mathrm{~N}\right]^{-}$ions the most preferred choice of anions for the ILs that are used for $\mathrm{Al}$ deposition. Yang et al. [66] studied the deposition conditions of Al films on a Ni substrate by electrodeposition from chloroaluminate ILs: [EMIm] $[\mathrm{Cl}]-\mathrm{AlCl}_{3}$-based IL with varying $\mathrm{AlCl}_{3}$ concentrations. The results indicated that the concentration of the IL-based electrolyte had a crucial effect on the structure and morphology of the $\mathrm{Al}$ films obtained on the Ni substrate. The surface morphologies obtained with different aluminum concentrations were observed to be distinct, signifying an incremental change in particle size with increasing metal concentration suggesting the influence of metal precursor concentration on the morphological features of the deposited $\mathrm{Al}$ film. Besides, deposition potential, temperature, and time were reported to have a significant influence on the morphological structure, and nucleation characteristics of the $\mathrm{Al}$ deposit. In recent times, attempts were made in developing a chloroaluminate IL system, which has one type of halide in IL, while the metal salt has a different halide. For instance, Zhang et al. [67] conducted an electrochemical study on $\mathrm{Al}$ deposition in 1:2 [EMIm] $\mathrm{Br}]-\mathrm{AlCl}_{3}$ at room temperature. Electrochemical results from cyclic voltammetry, chronoamperometry, and electrochemical impedance spectroscopy confirmed the deposition of Al from a combination of 2 halides: bromide (from IL), chloride (from metal precursor) was a quasi-reversible process, followed an instantaneous nucleation mechanism and the growth of $\mathrm{Al}$ occurred via diffusion-controlled mechanism. However, kinetic complications were reported to be observed during the reaction. Since then, several studies have been performed on dialkyl-imidizolium- $\mathrm{AlCl}_{3}$-based RTILs with different anions such as $\mathrm{Cl}^{-},\left[\mathrm{Tf}_{2} \mathrm{~N}\right]^{-}$and the obtained highly corrosion-resistant $\mathrm{Al}$ deposits. Wang et al. [32] proposed the possibility of depositing Al from 1-[EMIm][F]$\mathrm{AlCl}_{3}$-based IL using copper as the substrate. The $\mathrm{AlCl}_{3}-[\mathrm{EMIm}][\mathrm{F}] \mathrm{ILs}$ were prepared via slow addition of $\mathrm{AlCl}_{3}$ to [EMIm][F] in a quartz crucible with continuous stirring in an inert glove box environment (filled with Ar). The results demonstrated that the dominant species is $\left[\left(\mathrm{Al}_{2} \mathrm{Cl}_{7}\right)\right]^{-}$similar to $[\mathrm{EMIm}] /[\mathrm{BMIm}][\mathrm{Cl}]$ and electrochemical results confirmed that the reduction of $\left[\left(\mathrm{Al}_{2} \mathrm{Cl}_{7}\right)\right]^{-}$to metallic aluminum in $\mathrm{AlCl}_{3}-[\mathrm{EMIm}][\mathrm{F}]$ (molar ratio 2.7:1) is an irreversible diffusion-controlled process and it proceeded via a one-step three-electron transfer process similar to dialkyl imidazolium chloride-based ILs: [EMIm][Cl]/[BMIm] $[\mathrm{Cl}]-\mathrm{AlCl}_{3}$ reported by Yang et al. [66], Karthika et al. [30]. Most of the studies on $\mathrm{Al}$ deposition were performed with $\left[\mathrm{Tf}_{2} \mathrm{~N}\right]^{-}$anion owing to their thermal stability indicative of higher decomposition temperatures in the range of $500-650^{\circ} \mathrm{C}$. However, most of the anions that are used for the preparation of air and water-stable ILs employed for the deposition of $\mathrm{Al}$ are hydrophilic and cannot perfectly overcome the problem of resistance against air and moisture. Though the problem is partly overcome by introducing hydrophobic materials such as undecane as a blanketing film, which can resist air and moisture, it still remains a primary challenge.

\subsection{Anodic Effect}

Anodes in electrodeposition shall not influence the electrochemical process but also controls the physical characteristics of the Al cathodic deposit such as surface morphology, crystal orientation and the anodic reactions occurring in ILs are significantly different owing to their increased ohmic resistance. Anodes can be either inert or soluble and are dependent on the metal to be deposited, electrolyte media. Anodic reactions during deposition from aqueous electrolyte media generally involve either electrolyte break down or anodic dissolution, and anodic oxidation process occurs at a relatively faster rate than the cathodic reduction process. On the contrary, the anodic reactions and the anode material play a significant role during metal deposition in ILs, especially when similar electrode areas and geometries are employed. Under such circumstances, the mass transportation of oxidizable species controls the anodic dissolution, which, in turn, governs the overall deposition process. Employing inert anodes during Al deposition from different ILs pose certain challenges such as (i) understanding of the nature of the anodic breakdown products, (ii) its influence on the deposition process, deposit characteristics, (iii) cost $[68,69]$. In such cases, soluble anodes are preferred and considered to beneficial owing to the fact 
that they decrease the overpotential and minimize the breakdown of the ILs. However, anodic dissolution in ILs takes place with the use of soluble metals, which limits the passivation of many metals during the deposition. Al slabs/rods are generally employed as a potential soluble anode material during the Al deposition in ILs and maintain the reducible cationic $\mathrm{Al}$ species constantly, favoring a good deposition. Abbott et al. [70] systematically investigated the anodic dissolution of a soluble $\mathrm{Al}$ anode during the $\mathrm{Al}$ deposition with similar electrode geometry from $[\mathrm{BMIm}][\mathrm{Cl}]-\mathrm{AlCl}_{3}$ containing lithium chloride $\left(\mathrm{LiCl}_{3}\right)$ and toluene, studied the effect of the anodic process in relation to the morphology of $\mathrm{Al}$ deposit. It was shown that anodic process influenced the morphological features of $\mathrm{Al}$ deposited at cathode. Pitting was observed on the Al anode and was attributed to the uneven dissolution rates at the bottom of the surface indicative of incomplete removal of the surface oxide layer. Further, in a different study conducted by the same group [71], it was demonstrated that the electrolytic oxidation of anodes in an IL environment is complicated and majorly dependent on (i) metal speciation, (ii) transport properties and, (iii) metal solubility. Incomplete removal of an oxide layer blocks the electrode surface and leads to a decrease in anodic current and affects the even dissolution of metal. Studies on the anodic dissolution in ionic media would provide an in-depth analysis of the anodic and cathodic process and the mechanism of Al growth (and metal speciation). While new strategies to develop the use of soluble anodes for the Al deposition in ILs are still in the research phase; studies on employing inert electrode materials and knowledge about the anodic processes that occur in ionic liquids need further investigation.

\section{Aluminum Alloy Deposition in Ionic Liquids}

Alloying with elements like titanium (Ti), manganese (Mn) is reported to have excellent chemical, electrical properties, and also such coatings exhibit excellent corrosion resistance with better hardness than the $\mathrm{Al}$ deposit while allowing their use as corrosionresistant metallic protection layer for automotive applications [7,36]. Al-Ti alloy deposits possess excellent resistance against pitting corrosion, oxidation resistance at high temperatures and attracted particular technological interest [72]. Despite certain advantages, electrodeposition of Al-Ti alloys poses certain thermodynamic challenges when electrodeposition was performed from aqueous electrolyte media due to the liberation of hydrogen gas at the cathode prior to either of the metal' deposition. First-generation chloroaluminatebased ILs are considered to be the potential electrolytes for electrodepositing Al-Ti alloys on different substrates when compared to the conventional high-temperature molten salts owing to non-flammable properties, relatively low temperature deposition of the former. As a result, Al-Ti alloy coatings obtained via electrodeposition were extensively studied from dialkyl imidazolium-based chloroaluminate IL systems [36,72-74]. Carlin et al. [74] studied on the Al-Ti alloys from dialkyl imidazolium chloroaluminate IL: [EMIm][Cl]$\mathrm{AlCl}_{3}$, performed a detailed investigation on the electrochemistry of titanium tetrachloride $\left(\mathrm{TiCl}_{4}\right)$ in the IL, demonstrated that the electroreduction of tetravalent $\mathrm{Ti}[\mathrm{Ti}(\mathrm{IV})]$ to divalent Ti [Ti(II)] occurred via a two-step process with trivalent titanium chloride $\left[\mathrm{TiCl}_{3}\right]$ as the intermediate precipitate, which appeared as a purple deposit on the cathode surface. Attempts were made to control the formation of the intermediate $\left[\mathrm{TiCl}_{3}\right]$ by reducing the $\mathrm{TiCl}_{4}$ concentration. Tsuda et al. [73] deposited Al-Ti alloys with varying Ti at.\% from the same IL but with different Ti metal source: titanium (II) chloride [ $\left.\mathrm{TiCl}_{2}\right]$ and successfully obtained Al-Ti deposit with $~ 19 \%$ atomic fraction (a/o) Ti at low current densities on copper-based substrates. The results showed a decrease in Ti content when the deposition was performed at high current densities. Aravinda et al. [36] electrodeposited Al-Ti alloys from $[\mathrm{MBIm}][\mathrm{Cl}]-\mathrm{AlCl}_{3}$-based acidic IL with $\mathrm{TiCl}_{4}$ as the metal source on gold ( $\mathrm{Au}$ ) substrate. Results from the study confirmed that the deposition followed a 2-D nucleation and $\mathrm{Al}-\mathrm{Ti}$ clusters were reported to be formed on the Au substrate at a potential of $0.5 \mathrm{~V}$ (vs. $\mathrm{Al} / \mathrm{Al}(\mathrm{III}))$.

Pradhan et al. [74] studied the potentiostatic deposition of Al-Ti alloys from $\{\mathrm{BMIm}][\mathrm{Cl}]-\mathrm{AlCl}_{3}$-based IL at different temperatures ranging from 70 to $125{ }^{\circ} \mathrm{C}$ with 
$\mathrm{TiCl}_{4}$ as the $\mathrm{Ti}$ metal precursor. The molar ratio of the IL electrolyte mixture was maintained at 1:2:0.019 and deposition was performed at constant potential in the range 1.5-3 V (vs. Al/Al(III)). The optimum condition to obtain a Al-Ti deposit with fine particle size and high Ti content was reported to be at potentials $1.5-2 \mathrm{~V}$ with deposition temperatures between $70-100{ }^{\circ} \mathrm{C}$. Though the study identified the optimium conditions and discussed the dependencies of alloy composition, surface morphology on applied potential, temperature, studies relating to co-deposition behavior, influence of Ti(IV) concentration were not performed. Most of the reported works on Al-Ti deposition from ILs were mostly conducted with substrates: platinum, gold, copper. Though there are certain advantages on obtaining Al-Ti deposits from such substrates such as (i) simple pretreatment, (ii) noble character, (iii) electrochemical stability, it will be very more beneficial to deposit corrosion-resistant Al-Ti coatings on industrially used substrates, especially mild steel owing to their numerous applications in different industry segments. Xu et al. [75] studied the electrodeposited Al-Ti alloy in a Lewis acidic [BMIm][Cl]- $\mathrm{AlCl}_{3}$-based IL with different $\mathrm{Ti}(\mathrm{IV})$ ion concentrations, investigated the co-deposition behavior detail under galvanostatic conditions with different applied current densities at a deposition temperature of $70{ }^{\circ} \mathrm{C}$. Dense and adherent Al-Ti deposits were reported to be obtained on mild steel substrates with varying Ti content from 5.3 to 11.4 at.\%. They also investigated the current density effects, influence of $\mathrm{TiCl}_{4}$ concentration and studied its relation to the Al-Ti alloy composition and surface morphology of the obtained deposits. Galvanostatic deposition results reported that the Ti content increased when the current density is varied from $1 \mathrm{~mA} \mathrm{~cm}^{-2}$ to $5 \mathrm{~mA} \mathrm{~cm}{ }^{-2}$. On increasing the current density beyond $5 \mathrm{~mA} \mathrm{~cm}^{-2}$, the partial current that is utilized for the reduction of Ti cations reached a limiting value while the current for the reduction of $\left[\mathrm{Al}_{2} \mathrm{Cl}_{7}\right]^{-}$increased and resulted in the decreased $\mathrm{Ti}$ content. Cyclic voltammetric results demonstrated that the electroreduction of tetravalent $\mathrm{Ti}$ [Ti(IV)] to metallic Ti proceeded via the three-step reaction. Ispas et al. [7] performed the deposition of $\mathrm{Al}-\mathrm{Mn}$ alloys using [EMIm] $[\mathrm{Cl}]-\mathrm{AlCl}_{3}$ ionic liquid on low carbon steel substrates focusing on the morphology, structure. and corrosion properties of these layers. Al-Mn [80-20 at.\%] alloys deposited in the current density range between $0.5 \mathrm{~mA} \mathrm{~cm}^{-2}$ and $8 \mathrm{~mA} \mathrm{~cm}-{ }^{2}$ displayed a smooth layer with nodular morphology in contrast to the plate-like morphology obtained in the case of Al deposits. Also, the roughness of Al-Mn layers is relatively very low compared to the pure Al deposits. Corrosion currents obtained from Tafel plots for the Al-Mn coatings in neutral $3.5 \mathrm{wt} \%$ sodium chloride $(\mathrm{NaCl})$ solution showed that the Al-Mn alloy deposit exhibited better corrosion protection properties than the $\mathrm{Al}$ deposit. Also, Tafel plots indicated that the corrosion potentials $\left(E_{\mathrm{Corr}}\right)$ are shifted anodically by $100 \mathrm{mV}$ for Al-Mn compared to the Al deposit indicating the Al-Mn alloys' dominating corrosion-resistant behavior. Also, the corrosion potential results showed that addition of $\mathrm{Mn}$ to the $\mathrm{Al}$ coatings shall enable the coating to behave like a better sacrificial anode than the Al coatings when deposited on the low carbon steel.

\section{Other Al-X Alloys}

Tsuda and Hussey group [76-78] studied the electrodeposition of Al-based alloys such as $\mathrm{Al}-\mathrm{W}$ [76], $\mathrm{Al}-\mathrm{Hf}$ [77] employing [EMIm][Cl] $-\mathrm{AlCl}_{3}$-based ILs and $\mathrm{K}_{3}\left[\mathrm{~W}_{2} \mathrm{Cl}_{9}\right.$ ], Hf as the source for W, Hf. Al-W deposits with Low W-content (3 at.\%) resulted in a dense and compact film on one hand, while deposits above 30 at. $\% \mathrm{~W}$ resulted in the formation of a powdery and brittle deposit. There are few reports published by the same group on the deposition of $\mathrm{Al}$ alloys such as $\mathrm{Al}-\mathrm{Zr}$ [78], Al-Mo [45] employing the [EMIm][Cl]- $\mathrm{AlCl}_{3}$ based ILs. Also, a detailed review of the Al-X alloys from chloroaluminate ILs has been published by the same group [79]. Table 7 shows the list of Al alloys studied on different substrates employing various ILs. 
Table 7. Table showing the list of Al-X alloys studied employing different ionic liquid systems.

\begin{tabular}{ccccc}
\hline Ionic Liquid & $\mathrm{Al}-\mathbf{X}$ & Alloy Source $(\mathbf{X})$ & Substrate & Ref. \\
\hline [BMIm][Cl] & $\mathrm{Al}-\mathrm{Ti}$ & $\mathrm{TiCl}_{4}$ & Mild Steel & {$[75]$} \\
\hline & $\mathrm{Al}-\mathrm{Hf}$ & $\mathrm{HfCl}_{4}$ & Copper & {$[77]$} \\
\cline { 2 - 5 } & $\mathrm{Al}-\mathrm{Mg}$ & $\mathrm{MgCl}_{2}$ & Copper & {$[80]$} \\
\cline { 2 - 5 } & $\mathrm{Al}-\mathrm{Mn}$ & $\mathrm{MnCl}_{2}$ & Low carbon steel & {$[7]$} \\
\cline { 2 - 5 } & $\mathrm{Al}-\mathrm{Mo}$ & $\left(\mathrm{Mo}_{6} \mathrm{Cl}_{8}\right) \mathrm{Cl}_{4}$ & Glassy carbon/platinum & {$[45]$} \\
\cline { 2 - 5 }$[\mathrm{EMIm}][\mathrm{Cl}]$ & $\mathrm{Al}-\mathrm{Ti}$ & $\mathrm{TiCl}_{2}$ & Copper & {$[72]$} \\
\cline { 2 - 5 } & $\mathrm{Al}-\mathrm{Zn}$ & $\mathrm{ZnCl}_{2}$ & AZ91D Mg alloy & {$[81]$} \\
\cline { 2 - 5 } & $\mathrm{Al}-\mathrm{Zr}$ & $\mathrm{ZrCl}_{4}$ & Copper & {$[78]$} \\
\cline { 2 - 5 } & $\mathrm{Al}-\mathrm{W}$ & $\mathrm{K}_{3}\left[\mathrm{~W}_{2} \mathrm{Cl}_{9}\right]$ & Copper & {$[76]$} \\
\hline$[\mathrm{MBIm}][\mathrm{Cl}]$ & $\mathrm{Al}-\mathrm{Ti}$ & $\mathrm{TiCl}_{4}$ & Gold & {$[36]$} \\
\hline$[\mathrm{EMIm}][\mathrm{Br}]$ & $\mathrm{Al}-\mathrm{Ni}$ & $\mathrm{NiCl}_{2}$ & Copper & {$[31]$} \\
\hline
\end{tabular}

\section{Pretreatment and Interface Effects}

In the critical step of precleaning/treatment, ionic liquids have the potential to provide an environment able to remove the insulating oxide/hydroxide layer. Among the numerous methods studied thus far, the best adhesion of the aluminum coating to the substrate when tested by performing a simple peeling test using sticky tape, has resulted from grinding with $\mathrm{SiC}$ paper followed by a mechanical polish and treat them with $10 \%-$ $50 \%$ phosphoric acid before deposition [54]. It should be noted that in using this scheme anodic electrochemical etch potentials and cycle time are dependent on the substrate and the electrolyte. Additionally, metal substrates such as $\mathrm{Mg}$ and its alloys have considerably large negative electrode potentials and require larger anodic pulses over a longer period to remove the oxide [82]. The surfaces pretreated using ionic liquids differ from aqueous pretreatments in that they must be dry before exposure to the plating solution, which may pose a problem for reactive, rapidly oxidizing metals. Another pretreatment option lies in the replacement of the oxide/hydroxide layer either as a companion for, or substitute to, further deposition. Few examples include the surface pretreatment of substrates such as copper [83], where which were conducted outside the glove box while an electrochemical etching pretreatment via anodic polarization of certain substrates such as stainless steel (Grade: 316L) substrates was performed inside the glove box, prior to aluminum deposition [84]. The literature largely covers substrates such as glassy carbon [70,85], platinum [31], which are often used at lab scale and can be pretreated by simple and easy procedures.

Removal of oxide layers on highly reactive industrial substrates such as stainless steel, $\mathrm{Mg}$ alloys is often a critical challenge as they readily form a new oxide layer due to their extreme affinity for atmospheric oxygen and moisture. Huang et al. [86] investigated the breakdown of passivated oxide layers on stainless steel substrates (Grade: $316 \mathrm{~L}$ ) from [EMIm] $[\mathrm{Cl}]-\mathrm{AlCl}_{3}$-based IL, analyzed the mechanism of breakdown pattern. It was shown that the $\mathrm{Cl}^{-}$ion played a critical role in breaking the oxide layer prior to deposition and the break down followed a combined pattern of general oxide breakdown and planar dissolution. On one hand, general oxide allows the generated $\mathrm{Cl}^{-}$to penetrate the oxide surface utilizing the electric field via pulse, chronoamperometric methods. On the other hand, chloride metal salt generation followed by microcrack formation facilitated the IL to reach the oxide surface, separated the oxide layer and the base metal. On subsequent stirring, the oxide layer, metal salts were shown to be completely removed. Such a pretreatment on stainless steel substrates are expected to produce an adherent $\mathrm{Al}$ deposit as they guarantee the complete removal of oxide layers. Liu et al. [87] focused on the electrodeposition of $\mathrm{Al}$ on mild steel, which is the most preferred choice of base material for many industrial applications and obtained adherent, dense Al layers employing [EMIm] $[\mathrm{Cl}]-\mathrm{AlCl}_{3}$, which can 
offer corrosion protection to the mild steel substrates. [EMIm][Cl]- $\mathrm{AlCl}_{3}$ systems which are known to be the first-generation ionic liquids, possess certain excellent features such as low viscosity and wide electrochemical window. In this context, it is important to understand the electrochemical stability of the ILs as they form a basis for the selection of ILs besides other physical properties. The electrochemical stability of an IL system is often characterized by the measuring the electrochemical potential window. Figure 6 compares the potential windows of various ILs, which represent the electrochemical stability at different electrode materials based on the data obtained from the literature $[37,38,42-44,60,88-90]$. The data from Figure 6 signify that they are adequate to perform electrodeposition of not only $\mathrm{Al}, \mathrm{Al}$ alloys but also can be extended to rare earth metals. As can be seen in the figure, the stability windows are reported to be in the wide range from 2 to $5.7 \sim 6 \mathrm{~V}$. Certain DES systems such as choline chloride-based exhibit a better electrochemical potential window justify its competitiveness as a promising potential electrolyte media for plating applications. However, it is important to note that the comparison of the data presented in the figure is either based on $\mathrm{Ag}^{+}$vs. $\mathrm{Ag}$ (or) $\mathrm{Fc}^{+} / \mathrm{Fc}$ reference electrodes and glassy carbon/platinum working electrodes at a current density of $1 \mathrm{~mA} \mathrm{~cm}^{-2}$. Also, these ILs have mostly been reported to be employed for the deposition of $\mathrm{Al}$ and its alloys on different substrates owing to their simple preparation combined with the easy handling under inert (or) dry gas conditions. Some of the key benefits in employing these ILs as electrolytes over the other non-aqueous systems such as organic solvents is (i) the non-flammable and non-volatile nature of these ILs, (ii) $\mathrm{Al}$ with different geometries can be used as a sacrificial anode. Though the $\mathrm{Al}$ deposits obtained on pretreated mild steel yielded a high-quality deposit, the optical microscopy results displayed a poor adhesion to the substrate. The $\mathrm{Al}$ deposits obtained on the mild steel substrates pretreated using the IL by electrochemical etching was reported to be well-adherent and resistant to mechanical scratching. Anodic electrochemical pretreatment of the mild steel substrates in [EMIm] $[\mathrm{Cl}]-\mathrm{AlCl}_{3}$ (prior to $\mathrm{Al}$ deposition), will remove the surface oxides that are formed as rust on the mild steel surface responsible for preventing the adhesion of $\mathrm{Al}$ to the substrates. Also, electrochemical etching of the substrate reduced the iron $\left(\mathrm{Fe}^{2+} / \mathrm{Fe}^{3+}\right)$ ions close to the surface and resulted in the formation of an $\mathrm{Al}-\mathrm{Fe}$ deposit. This allowed strong adhesion between the substrate and the deposit. Also, the immersion test results in aqueous $\mathrm{NaCl}$ solution for the $\mathrm{Al}$ coating deposited on the electrochemically etched substrate showed that the Al-coated deposit is unaffected while the mild steel substrate was reported to be corroded.

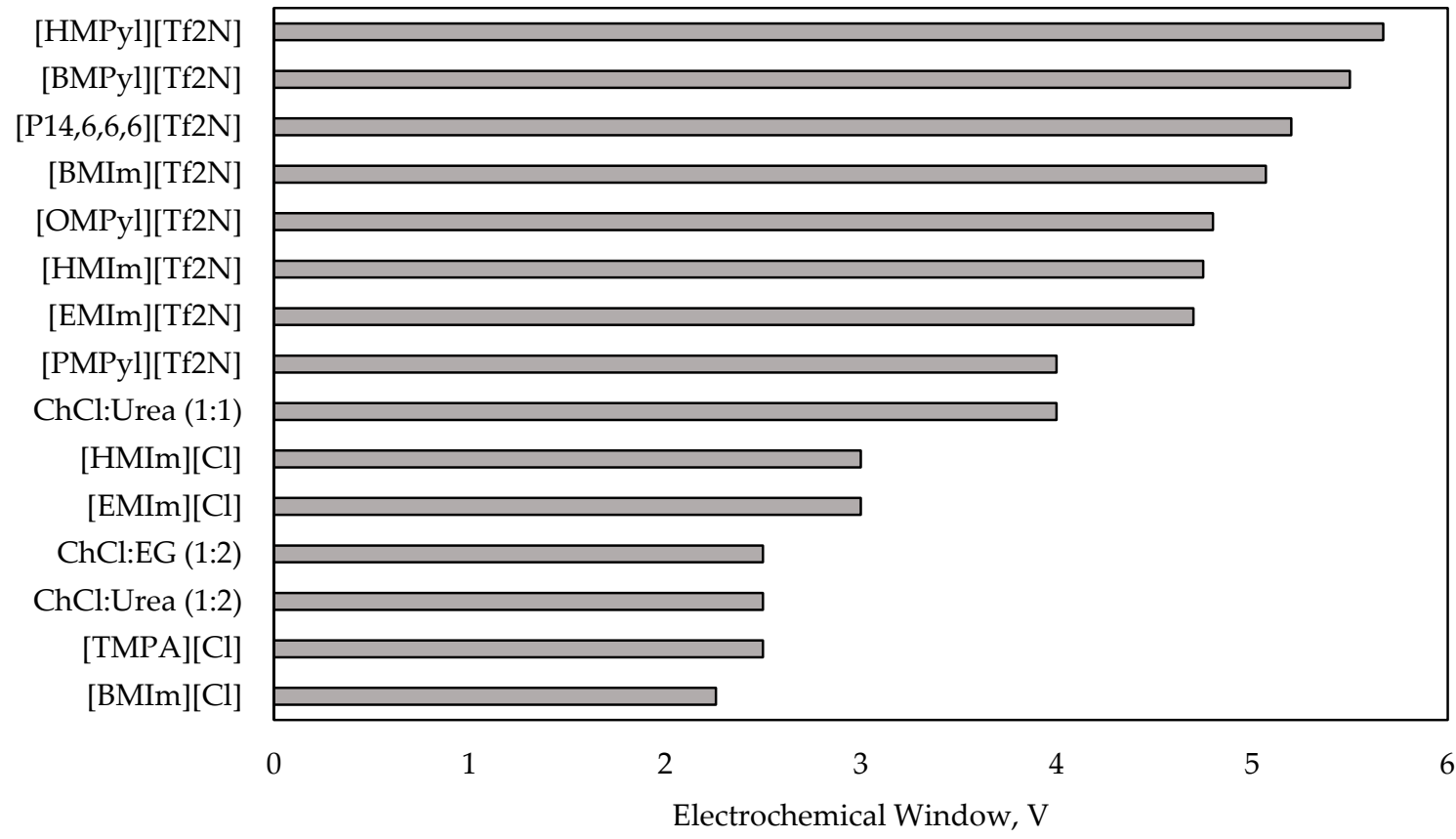

Figure 6. Plot showing the electrochemical windows of various ILs that are employed for the deposition of Al. 
Tang et al. [91] introduced an additional zincating pretreatment prior to copper ionassisted surface activation of the AZ91D Mg alloy substrate and obtained a well-adherent $\mathrm{Al}$ deposit on the pretreated substrate. Pre-deposition of fine $\mathrm{Cu}$ particles during surface activation aids the $\mathrm{Zn}$ deposition (during zincating process) by acting as seeds on both $\alpha$ (an $\mathrm{Mg}$ solid solution phase) and $\beta$-phase (an intermetallic phase $\mathrm{Mg}_{x} \mathrm{Al}_{y}$ ) areas of AZ91D substrate and facilitated better adhesion of the final $\mathrm{Al}$ deposit. Presence of $\mathrm{Cu}^{2+}$ ions in surface activation prior to zincating, contributed to obtaining a uniform Zn layer on AZ91D Mg alloy substrate during the zincating pretreatment. The formation of highly dense fine $\mathrm{Cu}$ layer prior to zincating acted as active nucleation sites which favored $\mathrm{Zn}$ deposition on the surface. Employing the zincating pretreatment followed by Al deposition with an increase in current density beyond $8 \mathrm{~mA} \mathrm{~cm}^{-2}$ increased the Al nucleation density during the initial galvanostatic electrodeposition. During the electrodeposition, the entire replacement of $\mathrm{Zn}$ by $\mathrm{Al}$ took place, and as a result, the substrate gets covered completely with Al deposit of nominal thickness. Such deposits are referred to as dense coatings. The density and morphological characteristics of such Al deposits are significantly influenced by the polarization method and deposition conditions. For instance, increasing the current density from $8 \mathrm{~mA} \mathrm{~cm}^{-2}$ to $15 \mathrm{~mA} \mathrm{~cm}^{-2}$ via the galvanostatic mode resulted in $\mathrm{Al}$ coatings with good density and adhesion(adhesion strength: 8-9 MPa). The adhesive strength of $\mathrm{Al}$ coatings was reported to be improved to $>11 \mathrm{MPa}$ via the bipolar current pulse (BCP) mode deposition when the cathode polarization current was increased up to $25 \mathrm{~mA} \mathrm{~cm}^{-2}$ while keeping the anodic polarization current at lowest value $\left(0.5 \mathrm{~mA} \mathrm{~cm}^{-2}\right)$. Increasing the cathodic current density increased the nucleation density of the initial Al deposit when deposited on zincated $\mathrm{Mg}$ alloy by galvanostatic mode. Increasing the cathodic polarization current in the BCP mode while keeping the anodic polarization current decreased the duty cycle ratio $\left(r_{C}\right)$ helps to maintain the sufficient $\mathrm{Al}(\mathrm{III})$ ion concentration surrounding the cathodic surface, favoring a uniform, smooth and denser deposit with good coverage. Figure 7 shows the representative schematic, which shows the pretreatment procedure that has been developed for the surface preparation of $\mathrm{Mg}$-based alloys prior to Al deposition in ILs, which resulted in a well adherent deposit. Also, the work by [92,93] demonstrated the effect of zincate pretreatment on adherence of the $\mathrm{Al}$ deposit to the $\mathrm{Mg}$ alloy substrate and the mode of deposition improved the uniformity of Al deposits. The Al deposit obtained on non-zincated $\mathrm{Mg}$ alloys was reported to be porous which resulted in a poor corrosion resistance, demonstrating the importance of zincate pretreatment.

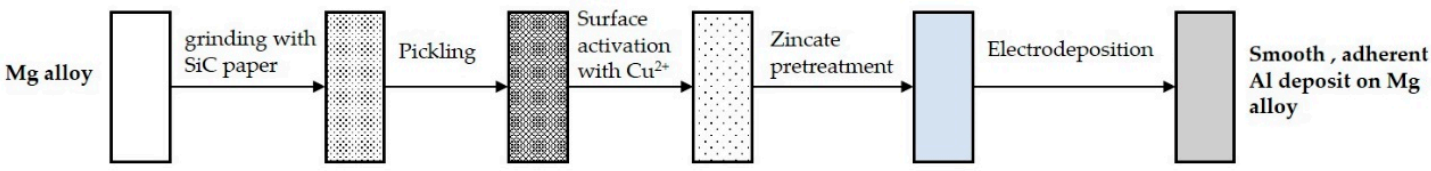

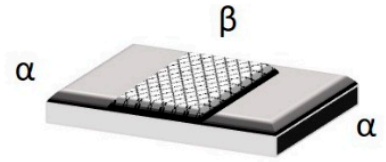

AZ91D Mg alloy substrate

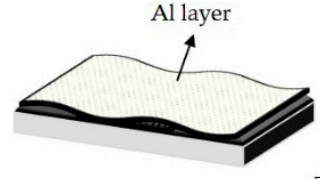

Non-zincated, galvanostatic $\mathrm{Al}$ deposit

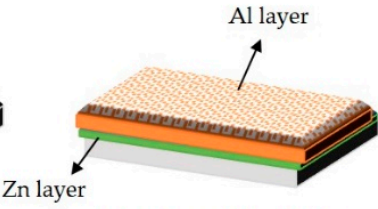

Zincated, galvanostatic Al deposit

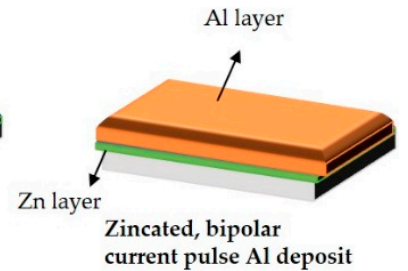

current pulse Al deposit

Figure 7. Schematic showing the effect of zincating pretreatment of AZ91D Mg alloys prior to Al deposition and the mode of deposition on the $\mathrm{Al}$ deposit [92]. Green layer indicates the $\mathrm{Mg}$ alloy substrate after zincate pretreatment. Orange layer indicates the $\mathrm{Al}$ deposited on the zincated substrate.

Xu et al. [82] simplified the complexity of the process associated the pretreatment and electrodeposition of $\mathrm{Al}$ on $\mathrm{AZ91D} \mathrm{Mg}$ alloy substrate in $[\mathrm{EMIm}] \mathrm{Cl}-\mathrm{AlCl}_{3}$ by electrochemically etching the substrate in the same IL used for deposition. It was demonstrated that galvanostatic electrochemical etching at current densities in the range of $5-25 \mathrm{~mA} \mathrm{~cm}^{-2}$ in the IL followed by deposition at $10 \mathrm{~mA} \mathrm{~cm}^{-2}$ resulted in a dense coating with an adhesive 
strength of $4 \mathrm{MPa}$. Electrochemical etching in ILs at a higher current density of $25 \mathrm{~mA} \mathrm{~cm}-2$ resulted in the formation of a viscous layer on the substrate while favoring the complete removal of surface oxides, uniform dissolution of the phases $(\alpha, \beta)$. On the contrary, electrochemical etching at a low current density of $5 \mathrm{~mA} \mathrm{~cm}^{-2}$ did not produce a complete viscous layer on the substrate and adherent deposit. The formation of viscous layer on the AZ91D substrate at a higher current density was shown to be playing a critical role in producing an adherent deposit. Electrodeposition of Al from ILs is strongly dependent on the interaction strength of cationic species in ILs with the substrate surface. Moustafa et al. [57] reported the electrodeposition of $\mathrm{Al}$ on gold $\mathrm{(Au}$ ) substrate employing the upper phase of bi-phasic [EMIm] $\left[\mathrm{Tf}_{2} \mathrm{~N}\right]-\mathrm{AlCl}_{3}$, [BMPyl][Tf $\left.f_{2} \mathrm{~N}\right]-\mathrm{AlCl}_{3}$ IL mixtures as electrolyte for depositing $\mathrm{Al}$ and evidenced the absence of underpotential deposition (UPD) process in the later. This behavior was attributed to the role of cationic species in [BMPyl][Tf $2 \mathrm{~N}]-\mathrm{AlCl}_{3} \mathrm{ILs}$, which played an important role in controlling the UPD process, their adsorption to the electrode surface. McFarlane et al. [94] studied the surface interaction effects of [EMIm] $\left[\mathrm{Tf}_{2} \mathrm{~N}\right]$ and $[\mathrm{BMPyl}]\left[\mathrm{Tf}_{2} \mathrm{~N}\right]$ using atomic force microscopy $(\mathrm{AFM})$, demonstrated that [BMPyl][Tf $\left.\mathrm{B}_{2} \mathrm{~N}\right]$ exhibited strong cation interaction with the substrate than [EMIm] $\left[\mathrm{Tf}_{2} \mathrm{~N}\right]$. The results indicated that the force exerted by AFM tip to break the innermost layer was highest for [BMPyl][Tf $\left.f_{2} \mathrm{~N}\right]$. Al deposition on steel substrates depends majorly on the adhesion to the substrate and developing an adherent $\mathrm{Al}$ coating for corrosion protection will be beneficial to practical real time world. Amongst the steel substrates, spring steel is mostly used material for manufacture of complex shaped parts and consist of silicon, chrome which affects the coating adhesion due to the formation of an oxide layer with iron, carbon.

$\mathrm{Al}$ deposition on such substrates with good adhesive strength shall enable its use in various corrosive environments. Fomin et al. [37] performed the $\mathrm{Al}$ deposition on spring steel substrates using the IL mixture $[\mathrm{EMIm}]\left[\mathrm{Tf}_{2} \mathrm{~N}\right]-\mathrm{AlCl}_{3} ;[\mathrm{EMIm}][\mathrm{Cl}]-\mathrm{AlCl}_{3}$. The results showed that the deposit was adherent with excellent mechanical scratch resistance, bending resistance, highlighting the importance of electrochemical pretreatment of the substrates such as (i) electro-etching, (ii) anodic polarization prior to electrodeposition. It was demonstrated that it is possible to deposit $\mathrm{Al}$ on spring steel utilizing the upper phase of $[\mathrm{EMIm}]\left[\mathrm{Tf}_{2} \mathrm{~N}\right]-\mathrm{AlCl}_{3}$ bi-phasic IL and from monophasic [EMIm] $[\mathrm{Cl}]-\mathrm{AlCl}_{3}$. Though the results demonstrate the complete removal of oxide layer via electrochemical anodic etching prior to deposition, the authors observed the formation of black particles in the final deposit, confirmed iron incorporation in the $\mathrm{Al}$ deposit, and attributed this to the re-deposition of iron on the $\mathrm{Al}$ surface which affected the final appearance of the coating, adherence. Comparison of iron contents, quality of Al deposit, deposition from [EMIm] [Cl] yielded the least iron content and better quality $\mathrm{Al}$ coating than the [EMIm] $\left[\mathrm{Tf}_{2} \mathrm{~N}\right]$-based IL. Attempts were made to remove the iron particles via electrolyte replacement and successfully obtained the high quality deposits. As an alternative to electrochemical anodic etching, plasma etching can be considered as an efficient approach to remove the surface oxide layer before $\mathrm{Al}$ deposition and favor a well adherent $\mathrm{Al}$ deposit [95]. Though $\mathrm{Al}$ deposition from different substrates from ILs have proven to be successful, there are certain challenges associated with $\mathrm{Al}$ electroplating. Firstly, the extreme reactive nature of $\mathrm{Al}$ requires a lot of care to minimize the interference from formation of loose immersion layers via surface displacement. Such a layer shall not only influence the electrochemical reduction process, but also affect the final $\mathrm{Al}$ adhesion $[96,97]$. Another challenge lies in achieving an adherent quality metal coating on $\mathrm{Mg}$ alloy substrates such as AZ91D Mg alloy, as the substrates tend to form intermetallic species, such as $\mathrm{Mg}_{x} \mathrm{Al}_{y}$, at the grain boundaries, interfere with the deposition and influence the deposit's adherence to the substrate [93].

\section{Recent Developments}

\subsection{General Remarks}

To overcome the disadvantages associated with the chloroaluminate-based ILs such as hygroscopic nature of the ILs, susceptible decomposition, the research focus has been 
shifted to air- and water-stable ILs, which, unfortunately, have not yet been extensively used for $\mathrm{Al}$ electrodeposition [98]. There were few reports on the development of thirdgeneration ILs, deep eutectic solvents (DES) considering their applicability to the deposition of light-weight metals such as Al. For instance, Abbott et al. $[17,99,100]$ and other groups [101-103] studied on the $\mathrm{Al}$ electrodeposition from various deep eutectic solvents mixtures of Lewis acidic metal halide $\mathrm{AlCl}_{3}$ and hydrogen bond donors: urea, acetamide or N, N di-methylurea on different substrates such as copper, mild steel and demonstrated that it can overcome the problem of low resistance against moisture and air (as observed in the case of air- and water-stable ionic liquids). In recent times, IL-like systems have been gaining significant attention as electrolytes for the deposition of $\mathrm{Al}$ and $\mathrm{Al}$ alloy coatings, as they exhibit similar physiochemical properties similar to those of the conventional ILs. Li et al. [1,8,104] systematically investigated the electrodeposition of $\mathrm{Al}$ in IL-like systems, which include an organic amide (acetamide, propionamide, butyramide) and $\mathrm{AlCl}_{3}$. Coleman and Hogg $[105,106]$ described a range of liquid coordination complexes prepared by mixing donor molecules with metal chlorides in varying proportions, achieving $\mathrm{Al}$ electrodeposition on a gold substrate from a dimethylacetamide- $\mathrm{AlCl}_{3}$ system. Fang et al. $[107,108]$ extended it further and reported on the Al electrodeposition on platinum electrodes from mixtures of $\mathrm{AlCl}_{3}$ and 4-propylpyridne (or) dipropyl sulfide prepared via complexation with $\mathrm{AlCl}_{3}$. Other ILs such as dimethylsulfone, ethylene carbonate have been added as neutral ligands to $\mathrm{AlCl}_{3}$, for the deposition of $\mathrm{Al}$ on different substrates such as $\mathrm{Mg}$ alloys and are reported in $[109,110]$. Deposition of Al from such IL mixtures provide a unique advantage over the deposition from conventional ILs in terms of simple reduction, good deposition efficiency, good coverage. However, multinuclear nuclear magnetic resonance (NMR) spectroscopy analysis results from [106] for few of the neutral ligand IL mixtures prepared with donor molecules such as urea, acetamide, demonstrated that most of these mixtures comprise charge-neutral complexes rather than ionic ones and are often described as pseudo-ILs. In addition, the electrochemical stability and the solubility issues associated with IL-like systems remains challenging. Also, most of the literature focused on the $\mathrm{Al}$ and $\mathrm{Al}$ alloy deposition from first-generation chloroaluminate-based ILs, which are hygroscopic and corrosive. Development of halide-free and non-haloaluminate ionic liquids as electrolytes for the development of $\mathrm{Al}$ and $\mathrm{Al}$ alloy deposits shall overcome the technical challenges associated with the current IL electrolytes.

\subsection{Influence of Additives}

$\mathrm{Al}$ deposits obtained from different generation ILs are reported to be non-uniform and rendered a rough surface. In particular, when the thickness and/or the current density is increased, rough and dendritic $\mathrm{Al}$ deposits are obtained, which are not well adhered and could be easily peeled off. One of the possible approaches is the introduction of additives into these systems. Additives can be inorganic or organic and are often added in small quantities to the electrolyte to improve additional functional properties of the Al deposit. While inorganic additives have the potential to alter the speciation of aluminum, organic molecules (generally small size) favor uniform and dense aluminum coatings with sufficient smoothness, good coverage. A key advantage with organic/inorganic additives is the possibility and flexibility in achieving high purity Al coating as they don't tend co-deposit with Al [111-114]. For instance, the addition of ethylene glycol effectively reduced the formation of cavities and favored the flatness in $\mathrm{Al}$ deposit, with concentrations at $0.1 \mathrm{M}$ displaying a mirror-like surface and a dense Al layer when deposited from [EMIm][Cl]$\mathrm{AlCl}_{3}$-based IL [111,115]. Zhang et al. [112] investigated the effect of nicotinamide on the electrodeposition of $\mathrm{Al}$ from [BMIm] [Cl]- $\mathrm{AlCl}_{3}$ IL system and observed that addition of nicotinamide improved the uniform deposition of Al. The authors attributed this feature to the adsorption of nicotinamide on the electrode surface, which allowed it to play the role of a levelling agent. Few reports on the addition of organic additives such as nicotinic acid, methyl nicotinic acid, and 3-methyl pyridine have demonstrated good results on surfaces with areas $10 \mathrm{~mm} \times 10 \mathrm{~mm}$ and flat geometry and shown that these served as 
brighteners $[113,114]$. Similarly, Al deposits obtained from IL mixture with the addition of 1,10- phenantroline as an additive were tested on car wheel bolts [116]. Also, reports from [115] demonstrated that the addition of nicotinic acid to the [EMIm] $[\mathrm{Cl}]-\mathrm{AlCl}_{3}$ ionic liquid reduces the $\mathrm{Al}$ crystal size from $>100 \mathrm{~nm}$ to $\sim 10 \mathrm{~nm}$. Al deposition has been successfully carried out from chloroaluminate-based ILs: imidazolium, pyridinium chloride- $\mathrm{AlCl}_{3}$ on different substrates. However, the Al deposits are reported to be non-homogeneous and exhibited either dendritic type morphology or matt surface or burnt areas on the cathode surface $[28,29,84,117]$. While the process is still not optimized, these deposits displayed poor throwing power and tend to peel off on increasing the current density or coating thickness when applied in real-time industrial applications, indicating the poor performance of the electrolyte. Guinea et al. [118] studied the effect of light aromatic naphtha additive on the morphology, texture of the $\mathrm{Al}$ coatings deposited on 3D- copper shaped parts from chloroaluminate-based IL: $[\mathrm{BMIm}][\mathrm{Cl}]-\mathrm{AlCl}_{3}$. It was demonstrated that the addition of light aromatic naphtha influenced the morphology and in obtaining a homogeneous $\mathrm{Al}$ deposit. Varying the additive concentration changed the brightness of the Al deposit, which can be ascribed to the change in crystallographic orientation from full random arrangement type to a moderate textured orientation with (111) as the predominant facet. In addition, the results demonstrated that the Al deposits obtained were very homogeneous, adherent, and compact with the addition of light aromatic naphtha additive to the chloroaluminate-based IL with an enhancement in throwing power. In recent times, attempts were also made to improve the quality of the deposit in terms of morphology, smoothness, brightness using inorganic rare earth metal chlorides such as lanthanum chloride $\left(\mathrm{LaCl}_{3}\right)$. Liu et al. [119] demonstrated that smoothness, compactness, particle size, and structure of the $\mathrm{Al}$ deposit can be varied by employing rare earth metal chlorides such as $\mathrm{LaCl}_{3}$, neodymium chloride $\left(\mathrm{NdCl}_{3}\right)$, and cerium chloride $\left(\mathrm{CeCl}_{3}\right)$. It was shown that these additives influenced the nucleation characteristics, the morphology of the $\mathrm{Al}$ deposit by altering the metal speciation. Table 8 shows the list of additives employed for the deposition of $\mathrm{Al}$ in various ILs.

Table 8. Table showing the list of additives employed for the deposition of $\mathrm{Al}$ and $\mathrm{Al}$ alloys in various ILs.

\begin{tabular}{|c|c|c|c|c|}
\hline System & Additive & Substrate & Function & Ref. \\
\hline \multirow{6}{*}[\mathrm{BMIm}]{$[\mathrm{Cl}]-\mathrm{AlCl}_{3}$} & 1, 10-phenanthroline & Carbon Steel & Brightener & [116] \\
\hline & Rare earth chlorides $\left(\mathrm{LaCl}_{3}, \mathrm{CeCl}_{3}, \mathrm{NdCl}_{3}\right)$ & Copper & Grain refiner & [119] \\
\hline & Nicotinamide & Copper & Leveler & [112] \\
\hline & Nicotinic acid & Copper & Brightener & [113] \\
\hline & Methyl nicotinate & Copper & Brightener & [113] \\
\hline & 3-methyl pyridine & Copper & Brightener & [113] \\
\hline \multirow{4}{*}[\mathrm{EMIm}]{$[\mathrm{Cl}]-\mathrm{AlCl}_{3}$} & Ethylene glycol & AZ121 Mg Alloy & Leveler & [111] \\
\hline & Nicotinic acid & Glassy carbon & Brightener & [115] \\
\hline & 2-chloronicotinyl chloride & Low carbon steel & Brightener & [120] \\
\hline & Niacinamide & Platinum plate & Grain refiner & [121] \\
\hline
\end{tabular}

\section{Industrial Applications and Future Challenges \\ 6.1. Cost and Scability}

With the increasing developments in ILs for its use in industrial applications such as electroplating, it becomes vital to produce ILs at a relatively larger scale. While cost reduction can be achieved through bulk scale production of ILs, availability of raw materials and their supply to prepare the ILs are seen as the important factors that hinder their development on an industrial scale [122]. As a consequence, ILs are regarded as uneconomical relative to other electrochemical deposition media such as organic solvents, high 
temperature molten salts, owing to their high cost, and maintenance, which contributed to their hinderance for large scale applications. Considering the physicochemical, transport properties, ILs are highly viscous in nature with low ion mobility, combined with their low diffusion coefficient influence the mass transport properties, alter the metal speciation and deposition behavior. Also, the conductivity of IL is largely influenced by the low viscosity. Increasing the concentration of ions might incur additional production costs and may not result in high conductivities as increased concentrations shall lead to either ion-pair formation or ion aggregation or a combination of both and result in reduced conductivity. Furthermore, the large size of ions in ionic liquids reduces the ion mobility and the number of charge carriers, which in turn affect the quality of the Al deposit on an industrial scale. Furthermore, Al deposition at lower temperatures yields dendritic type morphology with increased roughness, while deposition at temperatures beyond $60{ }^{\circ} \mathrm{C}$ shall yield a smoother deposit. In such cases, additives are added to the ILs to achieve a bright, smooth, and uniform deposit which may incur additional costs. ILs tend to degrade when employed in the plating bath at temperatures beyond $60{ }^{\circ} \mathrm{C}$. To understand the issues that are hindering commercialization, it is worth analyzing the cost trends associated with $\mathrm{Al}, \mathrm{Al}$ alloys deposition from commonly used ILs and understand the limitations. Figures 8 and 9 compare the cost required to prepare a $100 \mathrm{~L}$ plating solution using ILs that are employed for the deposition of $\mathrm{Al}$ and its alloys.

The cost required for the makeup is calculated and presented considering the volume of individual constituents that are required to be added to prepare $100 \mathrm{~L}$ fresh IL solution by considering the IL systems from the references [7,30,31,35-37,57,72,76,77,81] and the value of each constituent is calculated based on the known market price. From the figure, it is interesting to note from Figure 8 that make up cost for $\mathrm{ChCl}$ :urea-based IL is the least among the other ILs, followed by imidazolium-based ILs evidencing the economic competitiveness of choline-based ILs besides technical. To justify the economic feasibility of IL systems at a practical scale, cost for $\mathrm{AlCl}_{3}-\mathrm{NaCl}-\mathrm{KCl}$ inorganic molten salt [123] system is calculated and represented in Figure 8. It is pretty clear that certain imidazaolium-based ILs such as $[\mathrm{EMIm}][\mathrm{Cl}] /[\mathrm{BMIm}][\mathrm{Cl}]$ are in line with the molten salt electrolyte media, evidencing the techno-commercial viability of the ILs. Though the cost calculated for other ILs seems uneconomical, increasing the bulk scale production combined with their judicious selection it is possible to achieve the average IL cost in the order of few US dollars [124], shall enable them to compete economically with conventional solvent electrolyte media. Reusing the major fraction of previous-batch plating solution followed by the optimum addition of fresh chemicals, metal precursors/salts can also reduce the recycling costs. However, deposition of $\mathrm{Al}$ and $\mathrm{Al}$ alloys in ILs requires a set up that includes materials that can withstand the highly corrosive reduction process, inert atmosphere, and harsh operating conditions. For instance, the tank material, agitator made with mild steel gets corroded easily and might have to be replaced with poly (vinyl chloride)/polypropylene tanks and polymeric materials for agitators (for electrolyte recirculation) with good thickness, incurring additional overheads, and frequent maintenance. Fortunately, the majority of the plating plants constructed so far for the deposition of $\mathrm{Al}$ in ionic liquids employed polymers such as polyethylene, polypropylene, polyvinylchloride, and so on. Also, pumping an IL solution may be a limiting factor in the industrial application of ILs owing to their highly viscous nature and might incur additional pumping and labor costs $[2,3,125]$. Performing Al deposition in such an environment might incur problems such as high energy consumption, environmental pollution, and lower energy efficiency. With the increasing demand and interest in ionic liquids, few companies like Iolitec, BASF etc. can deliver ILs on the bulk scale with competitive pricing. Also, developing solutions for Al electroplating for the corrosion protection of mild steel and other commercially used substrates such as $\mathrm{Mg}$ alloys would be highly interesting for the aerospace sector owing to their self-passivating oxide layer formation in contrast to zinc layers offering better corrosion resistance. 


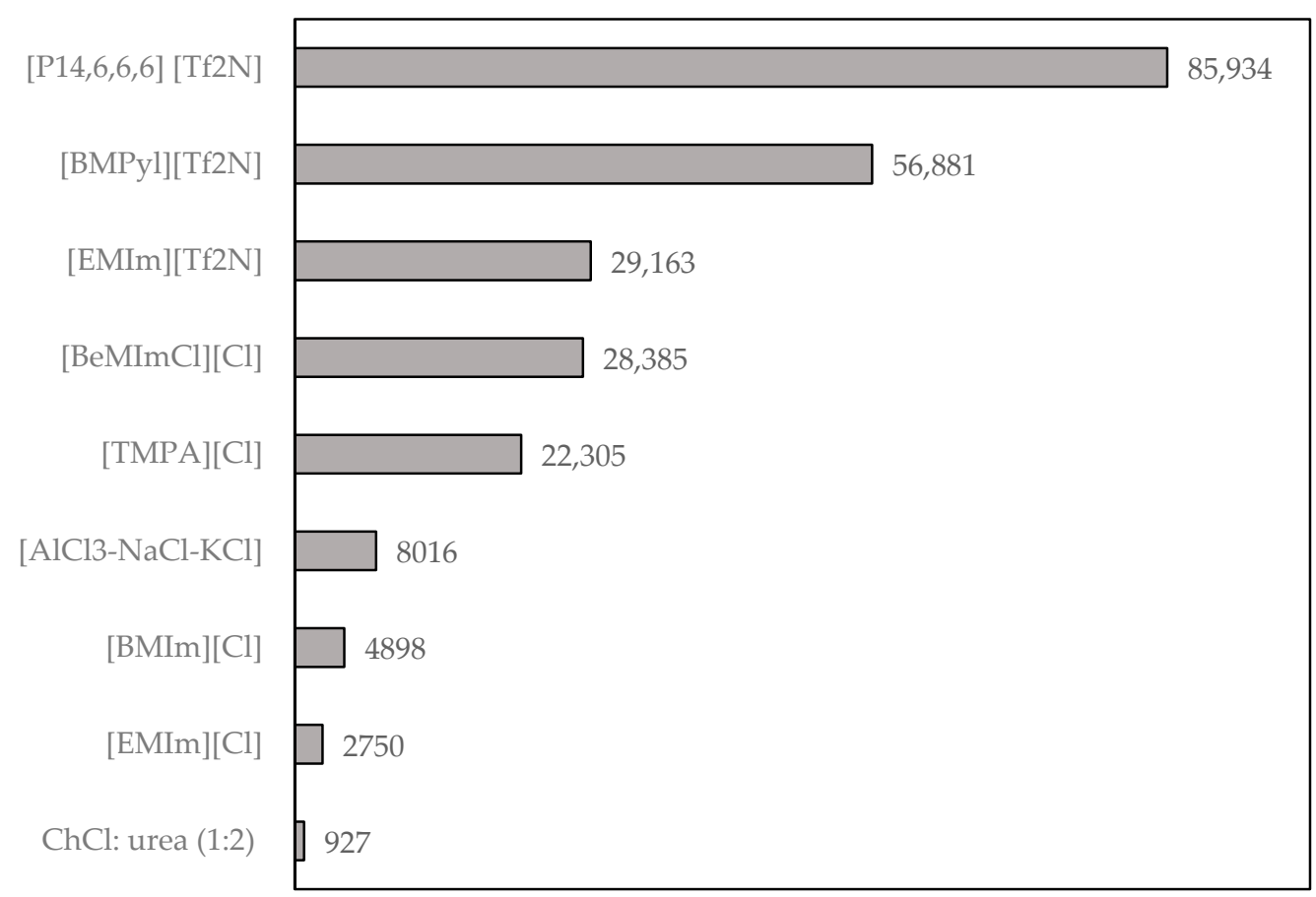

Figure 8. Plot showing the cost comparison of the ionic liquid-based systems and an inorganic molten temperature salt system for the deposition of $\mathrm{Al}$ considering the initial make up of $100 \mathrm{~L}$ solution.

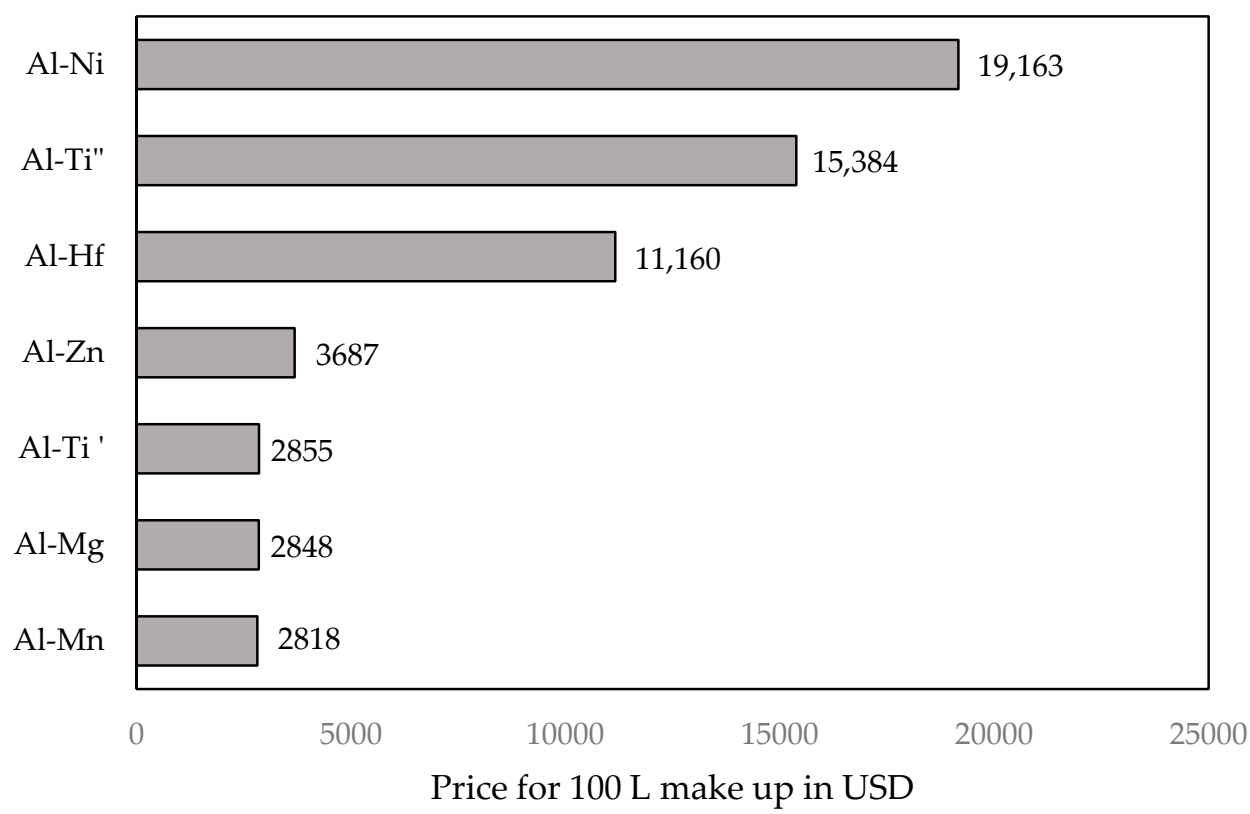

Figure 9. Plot showing the cost comparison of the ionic liquid-based systems for the deposition of Al-X alloys considering the initial make up of $100 \mathrm{~L}$ solution. Al-Ti' represents the deposition of $\mathrm{Al}-\mathrm{Ti}$ alloy from solution containing $\mathrm{TiCl}_{2}$ and $\mathrm{Al}-\mathrm{Ti}^{\prime \prime}$ represents the deposition of $\mathrm{Al}-\mathrm{Ti}$ alloy from solution containing $\mathrm{TiCl}_{4}$.

While ILs differ from aqueous solutions, there are certain challenges associated with the scaling up of the process such as (i) materials compatibility, (ii) pretreatment protocols, (iii) post-treatment, (iv) recycling, (v) synthesis, supply, and availability at bulk scale (in metric tons) $[21,126]$. Considering the corrosive nature of chloroaluminate ILs, it is important to choose the right material for the construction of plating plants especially the plating tanks, which is stable, durable, and withstand corrosion, temperature [2,3]. Also, the development of pretreatment, post-treatment, and recycling protocols at a larger scale 
will be challenging depending on the substrate, IL employed. For instance, pretreatments of $\mathrm{Mg}$ alloys and mild steel differ, and the material needs to be dried before employing for the deposition of $\mathrm{Al}$ in ILs. The key issue that one can expect is associated with the removal of metallic impurities from ionic liquids, as they often require a suitable method to be developed before recycling. Though many competitors are readily available to supply the chemicals that are required to perform the aqueous plating, few companies produce selective ionic liquids and supply for the intended use of plating. Development of IL-based electrolytes for the plating processes on a larger scale with good material compatibility and optimization of the deposition, operative conditions shall motivate the industries to produce bulk quantity of ILs and enable the plating technologies quickly enter the market, contribute towards commercialization.

\subsection{Industrial Applications}

Electrodeposition of $\mathrm{Al}$ onto commercial substrates is practically important for corrosion protection. Caporali [125] studied the $\mathrm{Al}$ deposition from [BMIm] $\left[\mathrm{Al}_{2} \mathrm{Cl}_{7}\right]$-based IL a carbon steel (UNI Fe360B) sheets with 2 different geometries: flat sheets, round cylinders and obtained $\mathrm{Al}$ deposits with the thickness ranging from 10 to $40 \mu \mathrm{m}$ at different deposition times: $1 \mathrm{~h}, 2 \mathrm{~h}$, and $4 \mathrm{~h}$. Scanning electron micrograph results showed that the average crystal size of the $\mathrm{Al}$ deposits grew with longer deposition time, deposit thickness and increased the roughness, indicative of crystals' preferential orientation. Open-circuit potential $(\mathrm{OCP})$ of the commercial $\mathrm{Al}, \mathrm{Al}$ deposits obtained on carbon steel at three different deposition times and carbon steel substrate, demonstrated that the potentials of the $\mathrm{Al}$ deposits were more negative than the bare carbon steel. Furthermore, electrochemical impedance spectra and potentiodynamic polarization results implied a decrease in the corrosion rate of the $\mathrm{Al}$ deposits relative to the substrate, indicative of better corrosion resistance. Also, neutral salt spray results displayed that the thicker Al deposits had the least corrosion rate indicative of excellent corrosion resistance. Though the results demonstrated the possibility of utilizing ILs as potential electrolytes for the deposition of $\mathrm{Al}$ on an industrial scale, the $\mathrm{Al}$ deposits failed through a pitting mechanism owing to the $\mathrm{Al}$ metal film/layer breakdown and the initiation of pitting corrosion.

Fomin et al. [37] successfully performed the Al deposition from different air- and water-

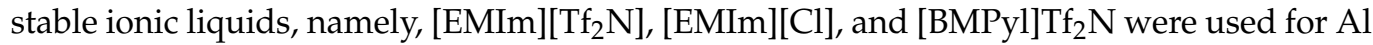
electroplating of the spring steel substrates used in automotive. $\mathrm{Al}$ and $\mathrm{Al}$ alloy deposition utilizing alkyl-imidazolium-halide- $\mathrm{AlCl}_{3}$ - (Halide: $\mathrm{Cl}^{-}, \mathrm{Br}^{-}, \mathrm{F}^{-}$)-based ILs as electrolytes have proven to be superior in producing $\mathrm{Al}$ deposits with good corrosion resistance to other electrolytes. Al deposition studies were also extended from single common halide to a combination of halides in ILs such as [EMIm] [Br)]- $\mathrm{AlCl}_{3}$-based [67], which showed a deposition behavior consistent with single halide systems: [EMIm][Cl]/[BMIm] $[\mathrm{Cl}]-\mathrm{AlCl}_{3}$ based RTILs [30]. In addition, the morphological characteristics of the $\mathrm{Al}$ deposits obtained were also reported to be consistent in the imidazolium-based ILs. Chloroaluminate ILs have been demonstrated to achieve smooth and thick $\mathrm{Al}$ deposits at lab scale on industrial materials such as carbon steel $[115,116,127]$, magnesium alloys $[54,92,93,128]$. Table 9 lists some of the commonly used industrial substrates on which the $\mathrm{Al}$ deposition was performed. To achieve industry-quality Al-coatings, studies on the effect of deposition parameters: (i) current density, (ii) deposition potential, (iii) mode of deposition, process conditions: (i) temperature, (ii) mixing, on the rate of deposition rate, deposit characteristics (crystalline structure, morphology), and roughness remain significant. Such a study shall not only provide a better insight into optimizing the processes on an industrial scale but also gives an understanding between the deposit quality and the durability life of the electroplating bath, often termed as bath life, shall pave the way towards the industrial commercialization of Al-plating process using chloroaluminate ILs such as alkyl imidazolium halide- $\mathrm{AlCl}_{3}$. 
Table 9. Table showing the deposition of $\mathrm{Al}$ and $\mathrm{Al}$ alloys on most commonly used industrial-based substrates along with the ILs employed.

\begin{tabular}{|c|c|c|c|c|}
\hline System & Substrate & Al/Al-X & $\begin{array}{l}\text { Nature of } \\
\text { Deposit }\end{array}$ & Ref. \\
\hline \multirow{3}{*}[\mathrm{BMIm}]{$\mathrm{Cl}-\mathrm{AlCl}_{3}$} & Mild steel & $\mathrm{Al}-\mathrm{Ti}$ & Microcrystalline & [75] \\
\hline & AZ91D Mg alloy & $\mathrm{Al}$ & Nanocrystalline & [53] \\
\hline & Stainless steel & $\mathrm{Al}$ & Microcrystalline & [127] \\
\hline \multirow{7}{*}[\mathrm{EMIm}]{$\mathrm{Cl}-\mathrm{AlCl}_{3}$} & Mild steel & $\mathrm{Al}$ & Nanocrystalline & [63] \\
\hline & AZ91D Mg alloy & $\mathrm{Al}-\mathrm{Zn}$ & Microcrystalline & [81] \\
\hline & Spring steel & $\mathrm{Al}$ & $\begin{array}{l}\text { Microcrystalline } \\
\text { Nanocrystalline }\end{array}$ & [37] \\
\hline & AZ91D Mg alloy & $\mathrm{Al}$ & Microcrystalline & [91] \\
\hline & $\mathrm{TiB}_{2} / \mathrm{A} 356 \mathrm{C}$ & $\mathrm{Al}$ & Microcrystalline & [129] \\
\hline & Fe9Cr1Mo & $\mathrm{Al}$ & Microcrystalline & [130] \\
\hline & Low carbon steel & $\mathrm{Al} / \mathrm{Al}-\mathrm{Mn}$ & Microcrystalline & [7] \\
\hline \multirow{3}{*}[\mathrm{TMPA}]{$\mathrm{Cl}-\mathrm{AlCl}_{3}$} & AZ31 Mg alloy & $\mathrm{Al}$ & Microcrystalline & {$[92,131]$} \\
\hline & Carbon steel & $\mathrm{Al}$ & Microcrystalline & [35] \\
\hline & Spring steel & $\mathrm{Al}$ & Microcrystalline & [37] \\
\hline \multirow{2}{*}[\mathrm{EMIm}]{$\mathrm{Tf}_{2} \mathrm{~N}-\mathrm{AlCl}_{3}$} & Spring steel & $\mathrm{Al}$ & Nanocrystalline & [37] \\
\hline & Mild steel & $\mathrm{Al}$ & Nanocrystalline & {$[57,63]$} \\
\hline$[\mathrm{BMPyl}] \mathrm{Tf}_{2} \mathrm{~N}-\mathrm{AlCl}_{3}$ & Spring steel & $\mathrm{Al}$ & Nanocrystalline & [37] \\
\hline
\end{tabular}

Berretti et al. [132] aimed at improving the quality of the $\mathrm{Al}$ deposit and investigated the individual as well as combined effects of deposition temperature, mixing conditions on the electrodeposition of $\mathrm{Al}$ on brass substrates with different substrate sizes; smaller one for investigating the individual effect on the $\mathrm{Al}$ deposition and larger one for studying the combined effects. It is well-known that stirring (or) mechanical agitation of the solution during electrodeposition shall facilitate the reduction of diffusion layer thickness, favor a good deposition rate and result in a uniform deposit. The authors addressed this problem with an aim of determining the ideal operative conditions for carrying out the electroplating of $\mathrm{Al}$ process, at an industrial level by investigating the effect of sonication, the roughness of the deposit besides solution stirring, and temperature. SEM and roughness results demonstrated that increasing the temperature enhanced the deposition yield (ratio of the weight of actual deposit to theoretical deposit) and the smoothness of the deposit. Similarly, sonication was shown to improve the ion mobility with better mass transport in the IL, but increased the roughness slightly. Higher temperatures with stronger mixing conditions were demonstrated to promote the Al deposition and achieve a smooth, thicker deposit.

\subsection{Future Challenges}

$\mathrm{Al}$ deposition on commercial substrates from ILs has received significant attention from industries such as the automotive, aerospace, renewable energy (such as solar), and so on. In order to move towards the industrial commercialization of the process and enhance the durable life of the IL, it was observed that the operating temperature for performing deposition should be in the range of $60^{\circ} \mathrm{C}$ and below. The $\mathrm{Al}$ deposition experiments performed by various researchers, industry, and academia with various conditions demonstrated that $\mathrm{Al}$ deposition in ILs at temperatures above $60^{\circ} \mathrm{C}$, stirring the solution by mechanical agitation shall favor the reduction in the roughness of the deposits. In addition, mild sonication was demonstrated to be superior in producing industrial-quality $\mathrm{Al}$ coatings to the mechanical stirring. Increasing the temperature combined with strong sonication increased the electrolyte temperature as sonication generates heat, raise the local 
temperature, and result in IL degradation. Below $40{ }^{\circ} \mathrm{C}$, it was shown that temperature influenced the morphology of $\mathrm{Al}$ deposits more effectively and tends towards forming a dendritic $\mathrm{Al}$ deposit with increased roughness. Apart from the handling difficulties associated with chloroaluminate ILs, their aggressive reaction with atmospheric moisture, their high metal content in the final deposit, low viscosity, and excellent electrochemical stability makes the chloroaluminate ILs predominant for Al deposition, as they promote a high deposition rate at around $10 \mu \mathrm{m} \mathrm{h}^{-1}$. Moreover, these ILs work for a long time, indicating their strong durability, and the system does not require frequent replenishing of fresh chemicals. However, the synthesis of these ILs is complex, and the resulting products require multi-step purification and separation, which significantly increases their production cost and reduces their green character. This motivated to develop air and waterstable ILs, which could overcome some of the challenges associated with first-generation ILs [26,54]. Also, the sensitivity of the species to impurities and corrosivity to the equipment pose industrial challenges and increase the mechanical and maintenance costs. An issue associated with the development of biphasic IL system is the separation of the lower phase from the upper phase and performing the Al deposition in an inert atmosphere at an industrial scale. The formation of bi-phasic mixtures with few commonly used air- and water-stable ILs such as [BMPyl] $\mathrm{Tf}_{2} \mathrm{~N},[\mathrm{EMIm}] \mathrm{Tf}_{2} \mathrm{~N}$ shall require the deposition of $\mathrm{Al}$ to be performed from the upper phase of the mixture. In such a case, the phases formed might need to be separated before deposition which will increase the additional separation equipment, labor costs, and project overheads. Also, the viscosity of the upper phases is reported to be much higher than the actual ILs $[6,7,37]$ and as a result, the overall quality of the deposit in terms of thickness, coverage, and uniformity might be significantly affected by the slow mass transportation of the reducible cationic species to the electrode surface. As the number of ILs with different process conditions are developed over the decade, it is important to understand the heat capacity of the newly developed ILs. For instance, it is well-known that Al deposition from ILs under different mixing conditions such as solution stirring, sonication shall yield a good deposit with improved thickness, uniformity, better coverage, and so on. However, such conditions shall lead to ohmic heating with an increase in bath temperature, which will subsequently reduce the durable bath life of ILs and undergo decomposition in a short span of time, affect the deposit characteristics.

To overcome these challenges, efforts should be made to design and prepare ILs, which can form a homogeneous solution and favor $\mathrm{Al} / \mathrm{Al}$ alloy deposition with good alloy formation, in an open environment condition at lab scale. By careful selection of the right cation-anion combination, it is possible to tailor the properties and, achieve the desired physicochemical, transport properties, make them interesting for diverse range of applications. Also, various attempts have been made on the development of alkyl imidazolium-based ILs for the deposition of $\mathrm{Al}$ and its alloys on a wide range of commercial substrates from carbon steel to $\mathrm{Mg}$ alloys. However, the studies were limited to lab-scale and reports on the developments on an industrial scale are scarce. Replacing the harsh environmentally unfriendly chemicals within deposition baths with the recyclable ionic electrolytes, which often carry superior current efficiencies can be considered as a beneficial approach for the deposition of $\mathrm{Al}$ and its alloys on an industrial scale. Such systems would not only reduce the environmental impact, but also save maintenance and recycling costs. In addition, corresponding measures should be taken in exploring the deposition mechanism, choosing the right material of construction for equipment, and reducing the overall cost of the electroplating process. Such systems are expected to provide an effective, environmentally friendly solution to several technical challenges that are currently faced with the $\mathrm{Al}$ deposition process. One of the biggest challenges in introducing ILs for electroplating is their necessity to comply with certain legislation bodies such as Registration, Evaluation, Authorization, and Restriction of Chemical substances (REACH), which are attempting effortlessly to restrict the use of hazardous chemicals.

Though a complete characterization of the behavior of aluminum in chloroaluminate ILs has been demonstrated, understanding and optimization of the electrolyte nature and its 
conditions, deposition conditions are of particular importance for further development of air- and water-stable ionic liquids, new deep eutectic solvent systems for the deposition of $\mathrm{Al}$ and its alloys. Development of another type of bi-phasic systems such as the mixture of Urea: $\mathrm{AlCl}_{3}$ by introducing a protective insulating layer with the addition of hydrocarbons such as decane, undecane, shall allow the $\mathrm{Al}$ deposition to be carried out in an environment with ambient moisture eliminating the need for a glove box. Such a technology is expected to be the research focus over the forthcoming decade, but the safety concerns with the hydrocarbon layer on a long run need to be addressed. Similarly, process solution is lost when third-generation ILs such as DESs are employed for the electroplating of $\mathrm{Al}$ and $\mathrm{Al}$ alloys through the cavities or gaps present in the barrel or rack equipment or parts that are being plated [133]. Process solution lost in this way shall increase the production and recycling costs as they consume a significant proportion of the electrolyte, and call for frequent chemical replenishing. Though the reports by Haerens et al. [134] demonstrate that the solution drag out is three times higher compared to other ILs, it is expected to be several orders for [HMPyl], [OMPyl]-based ILs as they possess significantly higher viscosity. Also, they increase the contaminations in the rinse water in the form of impurities, which will not only reduce the process performance of the IL-based electrolyte but also the electrolyte lifetime. Employing a system of rinsing the IL drag with a miscible liquid will allow the separation of the IL and circumvents the effort in processing rinse water of significantly huge volume. The selection of appropriate rinsing liquid that is miscible, will depend on the nature of the ionic liquid, their phase behavior, conditions and remains to be a future challenge. Also, the development of post-treatment protocols, regeneration, and recycling of ILs needs further understanding and detailed study [21].

\section{Conclusions and Future Outlook}

Electrodeposition of $\mathrm{Al}, \mathrm{Al}$ alloys in ionic liquids have gained significant attention in recent years. The progress in the development of deposition techniques, ionic liquids as electrolytes, different $\mathrm{Al}$-containing precursors, and applications are covered in detail in this review. Electrodeposition of $\mathrm{Al}$ and its alloys have provided many advantages and can be considered as a potential alternative to conventional nickel-chrome, $\mathrm{Zn}-\mathrm{Ni}$, and other coatings in many applications. $\mathrm{Al}$ and $\mathrm{Al}$ alloy coatings deposited from imidazolium-based cations such as 1-ethyl-3-methylimidazolium, pyrrolidinium cations such as 1-butyl1-methyl pyrrolidinium, and bis(trifulormethylsulfonate) amide anion-based ILs were found to produce a uniform dense coating with good coverage and thickness. While increasing the alkyl chain length of cations favors a wide electrochemical window of the ILs, their influence on the mass transportation of the reducible species is significant and affect the quality of the final deposit owing to their increased viscosity and require a high concentration of $\mathrm{AlCl}_{3}$ for the electroreduction of $\mathrm{Al}(\mathrm{III})$ species on the substrate. Also, these ILs form a biphasic mixture that requires the $\mathrm{Al}$ deposition to be performed from the upper highly viscous phase of the mixture. The few works that reported on utilizing a combination of different halides in the chloroluminate IL system to deposit Al were also covered in this review. Pretreatment of the substrates such as mild steel and Mg alloys play an important role in producing denser $\mathrm{Al}$ coatings with good adherence. There are a few published reports on the deposition of $\mathrm{Al}$ alloys such as $\mathrm{Al}-\mathrm{Ti}, \mathrm{Al}-\mathrm{Mn}$ that showed a better corrosion resistance than pure Al. Employing additives not only alters the metal speciation but also improves the brightness and smoothness of the Al deposits. Also, employing inorganic rare earth metal chlorides as additives has the potential to influence the nucleation and tailor the morphology of $\mathrm{Al}$ deposit from microcrystalline to nanocrystalline. Though there are published works on the Al deposition from ILs containing additives, studies on the mechanism of $\mathrm{Al}$ growth in the presence of additives remain scarce. Although deposition of $\mathrm{Al}$ and its alloys on different substrates in a variety of ILs have proven their applicability at the lab scale, certain aspects require urgent investigations for their better application and commercialization. A significant number of reported works on the Al deposition on industrially used substrates such as mild steel $\mathrm{Mg}$ alloys have been covered 
in the review, starting from Al deposition from ILs, influence of cations, anions, Al alloy deposition, pretreatment effects, with recent developments, cost, and future industrial challenges. The problems associated with the recently developed ILs were addressed to a significant extent. Most of the reported study concluded that that lower alkyl halide imidazolium ILs: [EMIm][Cl], [BMIm][Cl] are the most promising electrolytes for the deposition of $\mathrm{Al}$ on a practical bulk scale application.

Also, certain factors must be considered in real-time conditions that lack significant study. For instance, the stability of the ILs, their impact on the real-time test parts, and the materials of construction of the plating tanks were rarely discussed. Performing a study considering these aspects would be beneficial when the feasibility of the whole process technology has to be defined along with ILs' continuous manageability safely and reliably. Also, periodic data monitoring of materials that are involved in the $\mathrm{Al}, \mathrm{Al}$ alloy deposition process and their stability on real contact with the environment that are rich in halides such as bromide, chloride, and fluoride, combined with their corrosion parameters when exposed to a halide-rich environment, needs a detailed study. Such a study would provide an insight into the development of the technology on an industrial scale. In addition to the inherent properties of ILs such as viscosity, conductivity, etc., the optimization of deposition conditions and operating conditions remains challenging. To utilize the anti-corrosion ability of the Al-coatings, the formation of high-quality coatings with good homogeneity and a crack-free surface is very critical. While there is a lack of systematic and in-depth research on the regulating effects of other parameters such as electrolyte composition, deposition current, electrolyte temperature, mixing conditions, sonication, and water content on electrodeposition process in ILs, the long-term stability and the durability of the developed electrolytes for long-term production require further investigation. Also, the industrial commercialization of the Al electroplating process utilizing additive-free chloroaluminate ionic liquids requires further optimization of the process operating conditions, especially when they are operated in an inert environment as they pose certain challenges in process handling difficulties. The development of nonhaloaluminate ILs is one interesting area that can solve the problems associated with the chloroaluminate-based ILs. Besides, the design and development of a pretreatment process for the commercial substrates before deposition would simplify the process operation and reduce the overall cost of the process.

Author Contributions: K.K.M. wrote the draft paper and S.P. reviewed the draft and provided supervision. Both authors have read and agreed to the published version of the manuscript.

Funding: This research has received funding from the European Union's Horizon 2020 research and innovation programme under the Marie Sklodowska-Curie grant agreement No. 885793.

Data Availability Statement: Not applicable.

Conflicts of Interest: The authors declare no conflict of interest.

\section{References}

1. Li, M.; Gao, B.; Liu, C.; Chen, W.; Shi, Z.; Hu, X.; Wang, Z. Electrodeposition of aluminium from $\mathrm{AlCl}_{3} /$ acetamide eutectic solvent. Electrochim. Acta 2015, 180, 811-814. [CrossRef]

2. Peter, I. Effect of ionic liquid environment on the corrosion resistance of al-based alloy. Key Eng. Mater. 2017, 750 KEM, 97-102. [CrossRef]

3. Peter, I.; Rosso, M.; Gobber, F.S. Study of protective coatings for aluminum die casting molds. Appl. Surf. Sci. 2015, 358, 563-571. [CrossRef]

4. Alumi Plate. Available online: https://www.alumiplate.com/ (accessed on 24 December 2020).

5. Al Farisi, M.S.; Hertel, S.; Wiemer, M.; Otto, T. Aluminum patterned electroplating from $\mathrm{AlCl}_{3}$-[EMIm]Cl ionic liquid towards microsystems application. Micromachines 2018, 9, 598. [CrossRef] [PubMed]

6. Zhao, Y.; VanderNoot, T.J. Electrodeposition of aluminium from nonaqueous organic electrolytic systems and room temperature molten salts. Electrochim. Acta 1997, 42, 3-13. [CrossRef]

7. Ispas, A.; Vlaic, C.A.; Camargo, M.K.; Bund, A. Electrochemical Deposition of Aluminum and Aluminum-Manganese Alloys in Ionic Liquids. ECS Trans. 2016, 75, 657-665. [CrossRef] 
8. Li, M.; Gao, B.; Liu, C.; Chen, W.; Wang, Z.; Shi, Z.; Hu, X. $\mathrm{AlCl}_{3}$ /amide ionic liquids for electrodeposition of aluminium. J. Solid State Electrochem. 2017, 21, 469-476. [CrossRef]

9. Fransaer, J.; Leunis, E.; Hirato, T.; Celis, J.-P. Aluminium composite coatings containing micrometre and nanometre-sized particles electroplated from a non-aqueous electrolyte. J. Appl. Electrochem. 2002, 32, 123-128. [CrossRef]

10. Eftekhari, A.; Liu, Y.; Chen, P. Different roles of ionic liquids in lithium batteries. J. Power Sources 2016, 334, 221-239. [CrossRef]

11. Bakkar, A.; Neubert, V. Electrodeposition and corrosion characterisation of micro- and nano-crystalline aluminium from $\mathrm{AlCl}_{3} / 1-$ ethyl-3-methylimidazolium chloride ionic liquid. Electrochim. Acta 2013, 103, 211-218. [CrossRef]

12. Endres, F.; Zein El Abedin, S. Air and water stable ionic liquids in physical chemistry. ChemPhysChem 2006, 8, 2101. [CrossRef] [PubMed]

13. Rogers, R.D.; Seddon, K.R. Ionic Liquids-Solvents of the Future? Science 2003, 302, 792-793. [CrossRef] [PubMed]

14. Endres, F. Ionic liquids: Solvents for the electrodeposition of metals and semiconductors. ChemPhysChem 2002, 3, 144-154. [CrossRef]

15. Schubert, T.J.S. Current and future ionic liquid markets. ACS Symp. Ser. 2017, 1250, 35-65. [CrossRef]

16. Böttcher, R.; Valitova, A.; Ispas, A.; Bund, A. Electrodeposition of aluminium from ionic liquids on high strength steel. Trans. Inst. Met. Finish. 2019, 97, 82-88. [CrossRef]

17. Smith, E.L.; Abbott, A.P.; Ryder, K.S. Deep Eutectic Solvents (DESs) and Their Applications. Chem. Rev. 2014, 114, 11060-11082. [CrossRef]

18. Marcus, Y. Application of Deep Eutectic Solvents. In Deep Eutectic Solvents; Springer Nature: Cham, Switzerland, 2019 ; pp. 111-151. [CrossRef]

19. Bernasconi, R.; Panzeri, G.; Accogli, A.; Liberale, F.; Nobili, L.; Magagnin, L. Electrodeposition from Deep Eutectic Solvents. In Progress and Developments in Ionic Liquids; Intechopen: Rijeka, Croatia, 2017.

20. Tomé, L.I.N.; Baião, V.; da Silva, W.; Brett, C.M.A. Deep eutectic solvents for the production and application of new materials. Appl. Mater. Today 2018, 10, 30-50. [CrossRef]

21. Endres, F.; Doughlas, R.M.; Abbott, A. Electrodeposition from Ionic Liquids; Wiley-VCH: Weinheim, Germany, 2008 ; pp. 83-92.

22. Abbott, A.P.; Dalrymple, I.; Endres, F.; Macfarlane, D.R. Why use Ionic Liquids for Electrodeposition? In Electrodeposition from Ionic Liquids; Wiley-VCH Verlag GmbH \& Co. KGaA: Weinheim, Germany, 2008; pp. 1-13.

23. Welton, T. Ionic liquids: A brief history. Biophys. Rev. 2018, 10, 691-706. [CrossRef]

24. Lei, Z.; Chen, B.; Koo, Y.M.; Macfarlane, D.R. Introduction: Ionic Liquids. Chem. Rev. 2017, 117, 6633-6635. [CrossRef]

25. Abbott, A.P.; Frisch, G.; Ryder, K.S. Electroplating Using Ionic Liquids. Annu. Rev. Mater. Res. 2013, 43, 335-358. [CrossRef]

26. Zhang, Q.; Wang, Q.; Zhang, S.; Lu, X.; Zhang, X. Electrodeposition in Ionic Liquids. ChemPhysChem 2016, 17, 335-351. [CrossRef] [PubMed]

27. Liu, F.; Deng, Y.; Han, X.; Hu, W.; Zhong, C. Electrodeposition of metals and alloys from ionic liquids. J. Alloys Compd. 2016, 654, 163-170. [CrossRef]

28. Zazybin, A.G.; Rafikova, K.; Yu, V.; Zolotareva, D.; Dembitsky, V.M.; Sasaki, T. Metal-containing ionic liquids: Current paradigm and applications. Russ. Chem. Rev. 2017, 86, 1254-1270. [CrossRef]

29. Kujime, T.; Ando, F.; Gunji, T.; Matsumoto, F. Review of the electrochemical deposition of an aluminum layer using aprotic solvents, old and new solvents, additives, and new technologies. Curr. Top. Electrochem. 2019, 21, 1-20.

30. Karthika, B.; Mohan, S.; Bera, A.; Rajasekaran, N. Structure, microstructure and electrodeposition behaviours of aluminium from $\mathrm{AlCl}_{3}$-EMIC and $\mathrm{AlCl}_{3}$-BMIC ionic liquid electrolytes-A comparative study. Surf. Eng. 2020, 36, 1012-1021. [CrossRef]

31. Zhang, L.; Yu, X.; Ge, Z.; Dong, Y.; Li, D. Co-deposition of Al-Ni alloy in NiCl 2- $\mathrm{AlCl}_{3}$-1-ethyl-3-methylimidazolium bromide ([EMIM]Br) ionic liquid. Appl. Mech. Mater. 2012, 121-126, 65-69. [CrossRef]

32. Wang, D. Electrodeposition of Aluminum from $\mathrm{AlCl}_{3}-1$-Ethyl-3- Methylimidazolium Fluoride. Int. J. Electrochem. Sci. 2019, 14, 9482-9489. [CrossRef]

33. Giridhar, P.; Zein El Abedin, S.; Endres, F. Electrodeposition of aluminium from 1-butyl-1-methylpyrrolidinium chloride/ $\mathrm{AlCl}_{3}$ and mixtures with 1-ethyl-3-methylimidazolium chloride/ $\mathrm{AlCl}_{3}$. Electrochim. Acta 2012, 70, 210-214. [CrossRef]

34. Ismail, A.S. Nano-sized aluminum coatings from aryl-substituted imidazolium cation based ionic liquid. Egypt. J. Pet. 2016, 25, 525-530. [CrossRef]

35. Vivegnis, S.; Devillers, S.; Delhalle, J.; Mekhalif, Z. Electrodeposition of Crystalline Aluminium on Carbon Steel in Aluminium Chloride-Trimethylphenyl Ammonium Chloride Ionic Liquid. Prot. Met. Phys. Chem. Surfaces 2018, 54, 652-661. [CrossRef]

36. Aravinda, C.L.; Mukhopadhyay, I.; Freyland, W. Electrochemical in situ STM study of Al and Ti-Al alloy electrodeposition on $\mathrm{Au}(111)$ from a room temperature molten salt electrolyte. ChemPhysChem 2004, 6, 5225-5231. [CrossRef]

37. Fomin, A. Studies on the Electrodeposition of Aluminium from Different Air and Water Stable Ionic Liquids. Ph.D. Thesis, Clausthal University of Technology, Clausthal-Zellerfeld, Germany, 2010. Available online: https://d-nb.info/1008342475/34 (accessed on 28 September 2020).

38. Xue, Z.; Qin, L.; Jiang, J.; Mu, T.; Gao, G. Thermal, electrochemical and radiolytic stabilities of ionic liquids. Phys. Chem. Chem. Phys. 2018, 20, 8382-8402. [CrossRef] [PubMed]

39. Wang, Q.; Zhang, Q.; Lu, X.; Zhang, S. Electrodeposition of Al from chloroaluminate ionic liquids with different cations. Ionics 2017, 23, 5. [CrossRef] 
40. Crosthwaite, J.M.; Muldoon, M.J.; Dixon, J.K.; Anderson, J.L.; Brennecke, J.F. Phase transition and decomposition temperatures, heat capacities and viscosities of pyridinium ionic liquids. J. Chem. Thermodyn. 2005, 37, 559-568. [CrossRef]

41. Rooney, D.; Jacquemin, J.; Gardas, R. Thermophysical Properties of Ionic Liquids. In Ionic Liquids: Topics in Current Chemistry; Kirchner, B., Ed.; Springer: Berlin/Heidelberg, Germany, 2009; Volume 290, pp. 185-212. [CrossRef]

42. Prabu, S.; Wang, H.-W. Factors Affecting the Electrodeposition of Aluminum Metal in an Aluminum Chloride-Urea Electrolyte Solution. J. Chin. Chem. Soc. 2017, 64, 1467-1477. [CrossRef]

43. Abood, H.M.A.; Dawood, N.L. Morphology of electrodeposited aluminium metal from aluminium chloride-urea room temperature ionic liquid (RTIL) at variable parameters. Int. J. Sci. Res. 2015, 4, 753-760.

44. Zhang, Q.; Hua, Y.; Xu, C.; Li, Y.; Li, J.; Dong, P. Non-haloaluminate ionic liquids for low-temperature electrodeposition of rare-earth metals-A review. J. Rare Earths 2015, 33, 1017-1025. [CrossRef]

45. Tsuda, T.; Hussey, C.L.; Stafford, G.R. Electrodeposition of Al-Mo Alloys from the Lewis Acidic Aluminum Chloride-1-ethyl-3methylimidazolium Chloride Molten Salt. J. Electrochem. Soc. 2004, 151, C379. [CrossRef]

46. Alesary, H.F.; Cihangir, S.; Ballantyne, A.D.; Harris, R.C.; Weston, D.P.; Abbott, A.P.; Ryder, K.S. Influence of additives on the electrodeposition of zinc from a deep eutectic solvent. Electrochim. Acta 2019, 304, 118-130. [CrossRef]

47. Jiang, T.; Chollier Brym, M.J.; Dubé, G.; Lasia, A.; Brisard, G.M. Electrodeposition of aluminium from ionic liquids: Part I-electrodeposition and surface morphology of aluminium from aluminium chloride $\left(\mathrm{AlCl}_{3}\right)$-1-ethyl-3-methylimidazolium chloride ([EMIm]Cl) ionic liquids. Surf. Coat. Technol. 2006, 201, 1-9. [CrossRef]

48. Jiang, T.; Chollier Brym, M.J.; Dubé, G.; Lasia, A.; Brisard, G.M. Electrodeposition of aluminium from ionic liquids: Part IIStudies on the electrodeposition of aluminum from aluminum chloride $\left(\mathrm{AICl}_{3}\right)$-Trimethylphenylammonium chloride (TMPAC) ionic liquids. Surf. Coat. Technol. 2006, 201, 10-18. [CrossRef]

49. Pradhan, D.; Reddy, R.G. Dendrite-Free Aluminum Electrodeposition from $\mathrm{AlCl}_{3}$-1-Ethyl-3- Methyl-Imidazolium Chloride Ionic Liquid Electrolytes. Metall. Mater. Trans. B Process Metall. Mater. Process. Sci. 2012, 43, 519-531. [CrossRef]

50. Robinson, J.; Osteryoung, R.A. The Electrochemical Behavior of Aluminum in the Low Temperature Molten Salt System n Butyl Pyridinium Chloride: Aluminum Chloride and Mixtures of This Molten Salt with Benzene. J. Electrochem. Soc. 1980, 127, 122-128. [CrossRef]

51. Zheng, Y.; Dong, K.; Wang, Q.; Zhang, J.; Lu, X. Density, Viscosity, and Conductivity of Lewis Acidic 1-Butyl- and 1-Hydrogen-3methylimidazolium Chloroaluminate Ionic Liquids. J. Chem. Eng. Data 2013, 58, 32-42. [CrossRef]

52. Bakkar, A.; Neubert, V. A new method for practical electrodeposition of aluminium from ionic liquids. Electrochem. Commun. 2015, 51, 113-116. [CrossRef]

53. Zhang, D.; Mu, Y.; Li, H.; Yang, Z.; Yang, Y. A new method for electrodeposition of Al coatings from ionic liquids on AZ91D Mg alloy in air. RSC Adv. 2018, 8, 39170-39176. [CrossRef]

54. Chang, J.K.; Chen, S.Y.; Tsai, W.T.; Deng, M.J.; Sun, I.W. Electrodeposition of aluminum on magnesium alloy in aluminum chloride $\left(\mathrm{AlCl}_{3}\right.$ )-1-ethyl-3-methylimidazolium chloride (EMIC) ionic liquid and its corrosion behavior. Electrochem. Commun. 2007, 9, 1602-1606. [CrossRef]

55. ASM International. Available online: https://www.asminternational.org/ (accessed on 23 December 2020).

56. He, M.; Liu, L.; Wu, Y.; Tang, Z.; Hu, W. Improvement of the properties of AZ91D magnesium alloy by treatment with a molten $\mathrm{AlCl}_{3}-\mathrm{NaCl}$ salt to form an $\mathrm{Mg}-\mathrm{Al}$ intermetallic surface layer. J. Coat. Technol. Res. 2009, 6, 407-411. [CrossRef]

57. Moustafa, E.M. Electrodeposition of Aluminium in Different Air and Water Stable Ionic Liquids. Master's Thesis, Clausthal University of Technology, Clausthal-Zellerfeld, Germany, 2007. Available online: https:/ /dokumente.ub.tuclausthal.de/servlets/ MCRFileNodeServlet/import_derivate_00000412/db108669.pdf (accessed on 29 September 2020).

58. Zein El Abedin, S.; Moustafa, E.M.; Hempelmann, R.; Natter, H.; Endres, F. Electrodeposition of Nano- and Microcrystalline Aluminium in Three Different Air and Water Stable Ionic Liquids. ChemPhysChem 2006, 7, 1535-1543. [CrossRef]

59. Pulletikurthi, G.; Bödecker, B.; Borodin, A.; Weidenfeller, B.; Endres, F. Electrodeposition of Al from a 1-butylpyrrolidine-AlCl 3 ionic liquid. Prog. Nat. Sci. Mater. Int. 2015, 25, 603-611. [CrossRef]

60. El Abedin, S.Z.; Moustafa, E.M.; Hempelmann, R.; Natter, H.; Endres, F. Additive free electrodeposition of nanocrystalline aluminium in a water and air stable ionic liquid. Electrochem. Commun. 2005, 7, 1111-1116. [CrossRef]

61. Zhang, X.; Huo, F.; Liu, X.; Dong, K.; He, H.; Yao, X.; Zhang, S. Influence of Microstructure and Interaction on Viscosity of Ionic Liquids. Ind. Eng. Chem. Res. 2015, 54, 3505-3514. [CrossRef]

62. Eiden, P.; Liu, Q.; Zein El Abedin, S.; Endres, F.; Krossing, I. An Experimental and Theoretical Study of the Aluminium Species Present in Mixtures of $\mathrm{AlCl}_{3}$ with the Ionic Liquids [BMP]Tf ${ }_{2} \mathrm{~N}$ and [EMIm]Tf ${ }_{2}$ N. Chem. A Eur. J. 2009, 15, 3426-3434. [CrossRef] [PubMed]

63. Liu, Q.X.; Zein El Abedin, S.; Endres, F. Electrodeposition of Nanocrystalline Aluminum: Breakdown of Imidazolium Cations Modifies the Crystal Size. J. Electrochem. Soc. 2008, 155, D357. [CrossRef]

64. Zein El Abedin, S.; Endres, F. Ionic Liquids: The Link to High-Temperature Molten Salts? Acc. Chem. Res. 2007, 40, 1106-1113. [CrossRef] [PubMed]

65. Zhao, N. Evaluation of Physical Properties of Ionic Liquids. Ph.D. Thesis, Queen's University, Belfast, Ireland, 2017. Available online: https://pure.qub.ac.uk/en/studentTheses/evaluation-of-physical-properties-of-ionic-liquids (accessed on 15 November 2020). 
66. Yang, Y.; Liu, S.; Chi, C.; Hao, J.; Zhao, J.; Xu, Y.; Li, Y. Electrodeposition of a continuous, dendrite-free aluminum film from an ionic liquid and its electrochemical properties. J. Mater. Sci. Mater. Electron. 2020, 31, 9937-9945. [CrossRef]

67. Zhang, L.P.; Ge, Z.W.; Yu, X.J.; Zhao, Z.D.; Dong, Y.H. Al electrodeposition from chloroaluminate ionic liquid. Can. Metall. Q. 2013, 52, 398-404. [CrossRef]

68. Jiang, Y.; Luo, L.; Mei, J.; Wang, X. The anodic behavior of cerium in $\mathrm{AlCl}_{3}$-1-ethyl-3-methyl-imidazolium chloride ionic liquid. J. Rare Earths 2018, 36, 1221-1225. [CrossRef]

69. Böttcher, R.; Mai, S.; Ispas, A.; Bund, A. Aluminum Deposition and Dissolution in [EMIm]Cl-Based Ionic Liquids-Kinetics of Charge-Transfer and the Rate-Determining Step. J. Electrochem. Soc. 2020, 167, 102516. [CrossRef]

70. Abbott, A.P.; Qiu, F.; Abood, A.M.; Ali, M.R.; Ryder, K. Double layer, diluent and anode effects upon the electrodeposition of aluminium from chloroaluminate based ionic liquids. ChemPhysChem 2010, 12, 1648. [CrossRef]

71. Abbott, A.P.; Frisch, G.; Hartley, J.; Karim, W.O.; Ryder, K.S. Anodic dissolution of metals in ionic liquids. Prog. Nat. Sci. Mater. Int. 2015, 25, 595-602. [CrossRef]

72. Tsuda, T.; Hussey, C.L.; Stafford, G.R.; Bonevich, J.E. Electrochemistry of titanium and the electrodeposition of Al-Ti alloys in the lewis acidic aluminium chloride-1-ethyl-3-methylimidazolium chloride melt. J. Electrochem. Soc. 2003, 150, C234-C243. [CrossRef]

73. Pradhan, D.; Reddy, R.G. Electrochemical production of Ti-Al alloys using $\mathrm{TiCl}_{4}-\mathrm{AlCl}_{3}-1$-butyl-3-methyl imidazolium chloride (BmimCl) electrolytes. Electrochim. Acta 2009, 54, 1874-1880. [CrossRef]

74. Carlin, R.T.; Osteryoung, R.A.; Wilkes, J.S.; Rovang, J. Studies of titanium(IV) chloride in a strongly Lewis acidic molten salt: Electrochemistry and titanium NMR and electronic spectroscopy. Inorg. Chem. 1990, 29, 3003-3009. [CrossRef]

75. Xu, C.; Hua, Y.; Zhang, Q.; Li, J.; Lei, Z.; Lu, D. Electrodeposition of Al-Ti alloy on mild steel from $\mathrm{AlCl}_{3}-\mathrm{BMIC}$ ionic liquid. J. Solid State Electrochem. 2017, 21, 1349-1356. [CrossRef]

76. Tsuda, T.; Ikeda, Y.; Arimura, T.; Hirogaki, M.; Imanishi, A.; Kuwabata, S.; Stafford, G.R.; Hussey, C.L. Electrodeposition of Al-W Alloys in the Lewis Acidic Aluminum Chloride-1-Ethyl-3-Methylimidazolium Chloride Ionic Liquid. J. Electrochem. Soc. 2014, 161, D405-D412. [CrossRef]

77. Tsuda, T.; Kuwabata, S.; Stafford, G.R.; Hussey, C.L. Electrodeposition of aluminum-hafnium alloy from the Lewis acidic aluminum chloride-1-ethyl-3-methylimidazolium chloride molten salt. J. Solid State Electrochem. 2013, 17, 409-417. [CrossRef]

78. Tsuda, T.; Hussey, C.L.; Stafford, G.R.; Kongstein, O. Electrodeposition of Al-Zr Alloys from Lewis Acidic Aluminum Chloride-1Ethyl-3-methylimidazolium Chloride Melt. J. Electrochem. Soc. 2004, 151, C447. [CrossRef]

79. Tsuda, T.; Stafford, G.R.; Hussey, C.L. Review-Electrochemical Surface Finishing and Energy Storage Technology with RoomTemperature Haloaluminate Ionic Liquids and Mixtures. J. Electrochem. Soc. 2017, 164, H5007-H5017. [CrossRef]

80. Rostom Ali, M.; Andrew, P.; Abott, K.S.R. Electrodeposition of Al-Mg alloys at room temeperature from ionic liquid. J. Electrochem. 2015, 3, 2-10. [CrossRef]

81. Pan, S.J.; Tsai, W.T.; Sun, I.W. Electrodeposition of Al-Zn on Magnesium alloy from $\mathrm{ZnCl}_{2}$-containing ionic liquids. Electrochem. Solid-State Lett. 2010, 13, 69-71. [CrossRef]

82. Xu, B.; Zhang, M.; Ling, G. Electrolytic etching of AZ91D Mg alloy in $\mathrm{AlCl}_{3}$-EMIC ionic liquid for the electrodeposition of adhesive Al coating. Surf. Coat. Technol. 2014, 239, 1-6. [CrossRef]

83. Uehara, K.; Gunji, T.; Tanabe, T.; Kaneko, S.; Matsumoto, F. The Effect of Brighteners on the Fabrication of Electroplated Bright Aluminum Films Using an $\mathrm{AlCl}_{3}$-EMIC-Toluene Bath. ECS Trans. 2015, 69, 7-13. [CrossRef]

84. Xue, D.; Chen, Y.; Ling, G.; Liu, K.; Chen, C.; Zhang, G. Preparation of aluminide coatings on the inner surface of tubes by heat treatment of Al coatings electrodeposited from an ionic liquid. Fusion Eng. Des. 2015, 101, 128-133. [CrossRef]

85. Rodríguez-Clemente, E.; Manh, T.L.; Guinto-Pano, C.E.; Romero-Romo, M.; Mejía-Caballero, I.; Morales-Gil, P.; Palacios-González, E.; Ramírez-Silva, M.T.; Palomar-Pardavé, M. Aluminum Electrochemical Nucleation and Growth onto a Glassy Carbon Electrode from a Deep Eutectic Solvent. J. Electrochem. Soc. 2019, 166, D3035-D3041. [CrossRef]

86. Huang, J.; Pan, Z.; Jiang, L.; Ling, G. The breakdown of a 316L stainless steel oxide film in an $\mathrm{AlCl}_{3}$-EMIC ionic liquid. Int. J. Electrochem. Sci. 2019, 14, 6431-6443. [CrossRef]

87. Liu, Q.X.; El Abedin, S.Z.; Endres, F. Electroplating of mild steel by aluminium in a first generation ionic liquid: A green alternative to commercial Al-plating in organic solvents. Surf. Coat. Technol. 2006, 201, 1352-1356. [CrossRef]

88. Kandil, M.E.; Marsh, K.N.; Goodwin, A.R.H. Measurement of the viscosity, density, and electrical conductivity of 1-hexyl-3methylimidazolium bis(trifluorosulfonyl)imide at temperatures between (288 and 433) K and pressures below $50 \mathrm{MPa}$. J. Chem. Eng. Data 2007, 52, 2382-2387. [CrossRef]

89. Kazemiabnavi, S.; Zhang, Z.; Thornton, K.; Banerjee, S. Electrochemical Stability Window of Imidazolium-Based Ionic Liquids as Electrolytes for Lithium Batteries. J. Phys. Chem. B 2016, 120, 5691-5702. [CrossRef]

90. Hayyan, M.; Mjalli, F.S.; Hashim, M.A.; AlNashef, I.M.; Mei, T.X. Investigating the electrochemical windows of ionic liquids. J. Ind. Eng. Chem. 2013, 19, 106-112. [CrossRef]

91. Tang, J.; Azumi, K. Improvement of Al coating adhesive strength on the AZ91D magnesium alloy electrodeposited from ionic liquid. Surf. Coat. Technol. 2012, 208, 1-6. [CrossRef]

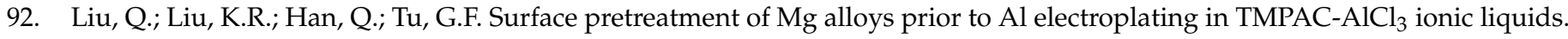
Trans. Nonferrous Met. Soc. China 2011, 21, 2111-2116. [CrossRef]

93. Chen, L.; Wang, G.; He, Y.; Wang, Y.; Zhang, M. The influence of overpotential on electrodeposited aluminum coating onto zincated ZM5 magnesium alloy in ionic liquid. Mater. Lett. 2020, 258, 126814. [CrossRef] 
94. McFarlane, D.; Sun, J.; Golding, J.; Meakin, P.; Forsyth, M. High conductivity molten salts based on the imide ion. Electrochim. Acta 2000, 45, 1271-1278. [CrossRef]

95. Martínez, C.; Kyrsta, S.; Cremer, R.; Neuschütz, D. Application of argon r.f. plasma etching for the removal of oxidic scales on ULC steels. Surf. Interface Anal. 2002, 34, 396-399. [CrossRef]

96. Gray, J.E.; Luan, B. Protective coatings on magnesium and its alloys-A critical review. J. Alloys Compd. 2002, 336, 88-113. [CrossRef]

97. Zhang, M.; Kamavarum, V.; Reddy, R.G. New electrolytes for aluminum production: Ionic liquids. JOM 2003, 55, 54-57. [CrossRef]

98. Abood, H.M.A.; Abbott, A.P.; Ballantyne, A.D.; Ryder, K.S. Do all ionic liquids need organic cations? Characterisation of [AlCl2·nAmide]+ AlCl4- and comparison with imidazolium based systems. Chem. Commun. 2011, 47, 3523. [CrossRef]

99. Abbott, A.P.; Ahmed, E.I.; Harris, R.C.; Ryder, K.S. Evaluating water miscible deep eutectic solvents (DESs) and ionic liquids as potential lubricants. Green Chem. 2014, 16, 4156-4161. [CrossRef]

100. Huynh, T.C.; Dao, Q.P.D.; Truong, T.-N.; Doan, N.-G.; Ho, S.-L. Electrodeposition of Aluminum on Cathodes in Ionic Liquid Based Choline Chloride/Urea/ALCL3. Environ. Pollut. 2014, 3. [CrossRef]

101. Cvetkovic, V.S.; Vukicevic, N.M.; Jovicevic, N.; Stevanovic, J.S.; Jovicevic, J.N. Aluminium electrodeposition under novel conditions from $\mathrm{AlCl}_{3}$-urea deep eutectic solvent at room temperature. Trans. Nonferrous Met. Soc. China 2020, 30, 823-834. [CrossRef]

102. Li, Q.; Jiang, J.; Li, G.; Zhao, W.; Zhao, X.; Mu, T. The electrochemical stability of ionic liquids and deep eutectic solvents. Sci. China Chem. 2016, 59, 571-577. [CrossRef]

103. Li, M. Aluminum Electrodeposition using $\mathrm{AlCl}_{3} /$ urea Ionic Liquid. Int. J. Electrochem. Sci. 2020, 8498-8505. [CrossRef]

104. Li, M.; Gao, B.; Chen, W.; Liu, C.; Wang, Z.; Shi, Z.; Hu, X. Electrodeposition behavior of aluminum from urea-acetamide-lithium halide low-temperature molten salts. Electrochim. Acta 2015, 185, 148-155. [CrossRef]

105. Coleman, F.; Srinivasan, G.; Swadźba-Kwaśny, M. Liquid Coordination Complexes Formed by the Heterolytic Cleavage of Metal Halides. Angew. Chem. Int. Ed. 2013, 52, 12582-12586. [CrossRef] [PubMed]

106. Hogg, J.M.; Brown, L.C.; Matuszek, K.; Latos, P.; Chrobok, A.; Swadźba-Kwaśny, M. Liquid coordination complexes of Lewis acidic metal chlorides: Lewis acidity and insights into speciation. Dalt. Trans. 2017, 46, 11561-11574. [CrossRef]

107. Fang, Y.; Yoshii, K.; Jiang, X.; Sun, X.-G.; Tsuda, T.; Mehio, N.; Dai, S. An $\mathrm{AlCl}_{3}$ based ionic liquid with a neutral substituted pyridine ligand for electrochemical deposition of aluminum. Electrochim. Acta 2015, 160, 82-88. [CrossRef]

108. Fang, Y.; Jiang, X.; Sun, X.-G.; Dai, S. New ionic liquids based on the complexation of dipropyl sulfide and $\mathrm{AlCl}_{3}$ for electrodeposition of aluminum. Chem. Commun. 2015, 51, 13286-13289. [CrossRef]

109. Miyake, M.; Fujii, H.; Hirato, T. Electroplating of $\mathrm{Al}$ on $\mathrm{Mg}$ alloy in a dimethyl sulfone-aluminum chloride bath. Surf. Coat. Technol. 2015, 277, 160-164. [CrossRef]

110. Zhang, B.; Shi, Z.; Shen, L.; Liu, A.; Xu, J.; Hu, X. Electrodeposition of Al, Al-Li Alloy, and Li from an Al-Containing Solvate Ionic Liquid under Ambient Conditions. J. Electrochem. Soc. 2018, 165, D321-D327. [CrossRef]

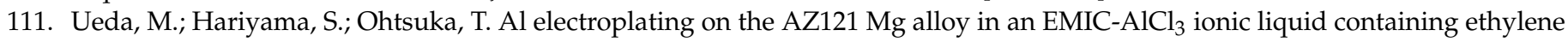
glycol. J. Solid State Electrochem. 2012, 16, 3423-3427. [CrossRef]

112. Zhang, Q.; Wang, Q.; Zhang, S.; Lu, X. Effect of nicotinamide on electrodeposition of Al from aluminium chloride (AlCl 3$)-1$-butyl3-methylimidazolium chloride ([Bmim]Cl) ionic liquids. J. Solid State Electrochem. 2014, 18, 257-267. [CrossRef]

113. Wang, Q.; Zhang, Q.; Chen, B.; Lu, X.; Zhang, S. Electrodeposition of Bright Al Coatings from 1-Butyl-3-Methylimidazolium Chloroaluminate Ionic Liquids with Specific Additives. J. Electrochem. Soc. 2015, 162, D320-D324. [CrossRef]

114. Wang, Q.; Chen, B.; Zhang, Q.; Lu, X.; Zhang, S. Aluminum Deposition from Lewis Acidic 1-Butyl-3-Methylimidazolium Chloroaluminate Ionic Liquid ([Bmim]Cl/ $\left.\mathrm{AlCl}_{3}\right)$ Modified with Methyl Nicotinate. Chem. Electro. Chem. 2015, 2, 1794-1798. [CrossRef]

115. Endres, F.; Bukowski, M.; Hempelmann, R.; Natter, H. Electrodeposition of nanocrystalline metals and alloys from ionic liquids. Angew. Chem. Int. Ed. 2003, 42, 3428-3430. [CrossRef] [PubMed]

116. Barchi, L.; Bardi, U.; Caporali, S.; Fantini, M.; Scrivani, A.; Scrivani, A. Electroplated bright aluminium coatings for anticorrosion and decorative purposes. Prog. Org. Coat. 2010, 67, 146-151. [CrossRef]

117. Zheng, Y.; Zhang, S.; Lu, X.; Wang, Q.; Zuo, Y.; Liu, L. Low-temperature Electrodeposition of Aluminium from Lewis Acidic 1-Allyl-3-methylimidazolium Chloroaluminate Ionic Liquids. Chin. J. Chem. Eng. 2012, 20, 130-139. [CrossRef]

118. Guinea, E.; Salicio-Paz, A.; Iriarte, A.; Grande, H.; Medina, E.; García-Lecina, E. Robust Aluminum Electrodeposition from Ionic Liquid Electrolytes Containing Light Aromatic Naphta as Additive. ChemistryOpen 2019, 8, 1094-1099. [CrossRef]

119. Liu, L.; Lu, X.; Cai, Y.; Zheng, Y.; Zhang, S. Influence of additives on the speciation, morphology, and nanocrystallinity of aluminium electrodeposition. Aust. J. Chem. 2012, 65, 1523-1528. [CrossRef]

120. Sheng, P.-F.; Chen, B.; Shao, H.-B.; Wang, J.-M.; Zhang, J.-Q.; Cao, C.-N. Electrodeposition and corrosion behavior of nanocrystalline aluminum from a chloroaluminate ionic liquid. Mater. Corros. 2015, 66, 1338-1343. [CrossRef]

121. Zheng, Y.; Zheng, Y.; Wang, Q.; Wang, Z.; Peng, C. Electrodeposition of nanocrystalline aluminium from 1-ethyl-3methylimidazolium chloroaluminate with niacinamide as an efficient additive. Int. J. Electrochem. Sci. 2018, 13, 10948-10960. [CrossRef]

122. Prado, R.; Weber, C.C. Applications of Ionic Liquids. In Application, Purification, and Recovery of Ionic Liquids; Kuzmina, O., Hallett, J.P., Eds.; Elsevier BV: Amsterdam, The Netherlands, 2016; pp. 1-58. [CrossRef] 
123. Chen, L.; Sharifzadeh, M.; Mac Dowell, N.; Welton, T.; Shah, N.; Hallett, J.P. Inexpensive ionic liquids:[HSO 4 - Based solvent production at bulk scale. Green Chem. 2014, 16, 3098-3106. [CrossRef]

124. Hang, Y.; Murakoshi, H.; Ueda, M.; Azumi, K. Protection of an AZ91D substrate by an intermediate Zn layer for Al plating from an $\mathrm{AlCl}_{3}-\mathrm{NaCl}-\mathrm{KCl}$ molten salt bath. Surf. Coat. Technol. 2015, 270, 164-169. [CrossRef]

125. Caporali, S.; Fossati, A.; Lavacchi, A.; Perissi, I.; Tolstogouzov, A.; Bardi, U. Aluminium electroplated from ionic liquids as protective coating against steel corrosion. Corros. Sci. 2008, 50, 534-539. [CrossRef]

126. Shamsuri, A.A. Ionic Liquids: Preparations and Limitations. MAKARA Sci. Ser. 2011, 14, 101-106. [CrossRef]

127. Yue, G.; Zhang, S.; Zhu, Y.; Lu, X.; Li, S.; Li, Z. A promising method for electrodeposition of aluminium on stainless steel in ionic liquid. AIChE J. 2009, 55, 783-796. [CrossRef]

128. Uehara, K.; Yamazaki, K.; Gunji, T.; Kaneko, S.; Tanabe, T.; Ohsaka, T.; Matsumoto, F. Evaluation of Key Factors for Preparing High Brightness Surfaces of Aluminum Films Electrodeposited from $\mathrm{AlCl}_{3}$-1-Ethyl-3-Methylimidazolium Chloride-Organic Additive Baths. Electrochim. Acta 2016, 215, 556-565. [CrossRef]

129. Huang, W.; Wang, M.; Wang, H.; Ma, N.; Li, X. The electrodeposition of aluminum on TiB2/A356 composite from ionic liquid as protective coating. Surf. Coat. Technol. 2012, 213, 264-270. [CrossRef]

130. Choudhary, R.K.; Kain, V.; Hubli, R.C. Stirring effects on aluminium coatings electrodeposited in ionic liquids. Surf. Eng. 2014, 30, 562-567. [CrossRef]

131. Liu, K.R.; Liu, Q.; Han, Q.; Tu, G.F. Electrodeposition of $\mathrm{Al}$ on AZ31 magnesium alloy in TMPAC-AlCl 3 ionic liquids. Trans. Nonferrous Met. Soc. China 2011, 21, 2104-2110. [CrossRef]

132. Berretti, E.; Giaccherini, A.; Martinuzzi, S.M.; Innocenti, M.; Schubert, T.J.S.; Stiemke, F.M.; Caporali, S. Aluminium electrodeposition from ionic liquid: Effect of deposition temperature and sonication. Materials 2016, 9, 719. [CrossRef] [PubMed]

133. Chung, P.P.; Wang, J.; Durandet, Y. Deposition processes and properties of coatings on steel fasteners-A review. Friction 2019, 7, 389-416. [CrossRef]

134. Haerens, K.; Van Deuren, S.; Matthijs, E.; Van der Bruggen, B. Challenges for recycling ionic liquids by using pressure driven membrane processes. Green Chem. 2010, 12, 2182. [CrossRef] 